\title{
Air Pollution Analysis in Kuwait Using a Statistical Technique (CUSUM)
}

\author{
A. Al-Rashed1 , N. Al-Mutairi'2, M. Al Attar' \\ ${ }^{1}$ Science Department, Public Authority of Applied Education and Training, Safat, Kuwait \\ ${ }^{2}$ Department of Civil Engineering, Kuwait University, Safat, Kuwait \\ Email: ahmedbufarsan@gmail.com
}

How to cite this paper: Al-Rashed, A. Al-Mutairi, N. and Al Attar, M. (2019) Air Pollution Analysis in Kuwait Using a Statistical Technique (CUSUM). International Journal of Geosciences, 10, 254-294. https://doi.org/10.4236/ijg.2019.103016

Received: December 10, 2018

Accepted: March 18, 2019

Published: March 21, 2019

Copyright (c) 2019 by author(s) and Scientific Research Publishing Inc. This work is licensed under the Creative Commons Attribution International License (CC BY 4.0).

http://creativecommons.org/licenses/by/4.0/

(c) (i) Open Access

\begin{abstract}
Investigating the changes in the air pollutants trends of an area is important as it helps in making further action plans for further implementation of control strategies. Time series analysis provides indication to analyze any effect of uncontrolled changes in pollutants. In this study, exponentially weighted moving average (EWMA) and cumulative sum (CUSUM) analyzing methods are applied for detecting the trends and change in air pollutant concentrations in Kuwait. CUSUM method is effective in detecting shifts from average mean obtained by EWMA technique. The study aimed to investigate trends in major pollutants in three selective areas in Kuwait during the past five years. The data obtained from three monitoring stations in the study areas Ali Subah Al-Salem, Al-Mutla, and Al-Mansouriya for carbon monoxide (CO), nitrogen dioxide $\left(\mathrm{NO}_{2}\right)$, sulfur dioxide $\left(\mathrm{SO}_{2}\right)$, particulate matter-less than 10 micrometers (PM10), hydrogen sulphide $\left(\mathrm{H}_{2} \mathrm{~S}\right)$, and non-methane hydrocarbon (NMHC). Increase in $\mathrm{CO}$ and $\mathrm{NMHC}$ concentrations in the three areas and decrease in $\mathrm{PM} 10, \mathrm{SO}_{2}$, and $\mathrm{NO}_{2}$ concentration levels in non-industrial areas Al-Mutla and Al-Mansouriya are observed using CUSUM method.
\end{abstract}

\section{Keywords}

Air Pollution, CUSM, Kuwait, EWMA

\section{Literature Review}

\subsection{General}

The effect of air pollution on the quality of environment is considered as major and continues public concern since it affects human life and public health. Air pollution is considered as a risk that threatens people's lives. Historically, examples of air pollution episodes happened in Belgium where 63 died in 1930, in 
Donora, Pennsylvania where 20 were killed in 1948, and in New York City where 200 people were killed in 1953, in the Manse Valley, [1]. In the last decade, the huge and significant development in the urban life especially in transportation system and the motorized road vehicle fleet encourage the mobility for the increasing population. As a result of the vehicle growth and the need for mobility, the fuel consumption has also increased. Motor vehicles are a critical source of urban air pollution (PM10, $\mathrm{CO}, \mathrm{CO}_{2}, \mathrm{NOx}, \mathrm{O}_{3}, \mathrm{SO}_{2}$ and VOC's) [2] [3] [4].

The burning of fossil fuels and the decline of the world's forest areas have both directly affected a steady rise in $\mathrm{CO}_{2}$ concentrations in the last half century. On the other hand, still there is no clear and uncertain impact on the long-term [5]. Britain's Meteorological Office and the USA's NASA Goddard Center for Space Research both confirm recent rises in global temperatures, but it is unclear whether these are due to levels of greenhouse gases or natural variations in global climate [6].

Kuwait's development policy plan aims at diversifying sources of income by encouraging the expansion of the economy and reducing the country dependency on oil exports. As a result of that plan, the industrial sector receives special support and encouragement from the government. As an example, the Shuaiba Industrial Area is a governmental authority located $50 \mathrm{~km}$ south of $\mathrm{Ku}$ wait city between Ahmadi south pier and Mina Abdulla along the costline, with an independent budget and attached to the Minister of Commerce and Industry. Shuaiba Industrial plants locate near the expanding residential projects such as Ali Subah Al-Salem area, Subah Al-Ahmad area, Jaber Al-Ahmed etc. Emissions from the various industries have increased continuously in Shuaiba over the last three decades [5]. The resulting impact on both the performance of the industries and the environment around Shuaiba is a cause for increasing concern to the State Authorities of Kuwait, the Shuaiba Area Authority and even local industry. This has led to a recognition of the need for the scientific community to develop a sound approach for assessing the wide range of health and environmental effects that result from exposure to toxic chemicals [7].

[8] proved the effectiveness of both techniques Cumulative Sum Control Charting and Exponentially Weighted Moving Average Control Charting. The study investigated that Cumulative Sum Charting provided slightly earlier alarms, and Exponentially Weighted Moving Averages are easier to use. In addition, the study noted that use of these techniques could allow detection of changes in time to mitigate the negative effects of the change and could be applied to a very wide range of processes. The purpose of this study is to investigate the ability of the Cumulative sum (CUSUM) technique to identify a step change in pollution levels in three areas in Kuwait. If appropriate, the technique could then be developed further for application in more parameters and areas in Kuwait. The exponentially weighted moving average (EWMA) and cumulative sum (CUSUM) techniques are applied to air quality data at three areas in Kuwait Ali Subah Al-Salem, Al-Mutla, and Al-Mansouriya. The site is characterized as monitoring stations in each area with daily concentration measurements. In Ali 
Subah Al-Salem, industrial plants are located nearby the area, while Al-Mansouriya area are surrounded by heavy traffic because of main rings and roads in Kuwait City. However, Al-Mutla is plain area with no major external exposure. The continuous monitoring is carried out by Kuwait Environment Public Authority, Kuwait. The 24 hourly data observed during 2013-2017 (study time) for CO, $\mathrm{NO}_{2}, \mathrm{SO}_{2}, \mathrm{PM} 10, \mathrm{H}_{2} \mathrm{~S}$, and NMHC is considered to analyse for any changes in the behavior of these pollutants. Environmental studies are essential before any plans especially the residential ones. This research investigates the trends of pollutants in three areas in Kuwait using CUSUM technique, which can be easily applied in several Environmental projects for several purposes especially in the design of new residential areas like Al-Mutla or other future development plans in Kuwait. In addition, the study investigates the uncontrol pollutants levels in order to apply some control program to decrease the bad effect of rising pollutants in some study areas.

\subsection{Background of Kuwait}

Kuwait is located on the north-western coast of Arabian Gulf. It borders Iraq, Saudi Arabia and Arabian Gulf (Figure 1). The total area of Kuwait is about $17,818 \mathrm{~km}^{2}$. The Total area is mainly arid land while urban development is on the coastline of the gulf. The climate is mostly dry consisting of intensely hot summer and short, cool winter. The mean elevation is $108 \mathrm{~m}$ where the lowest point is the Arabian Gulf which is $0 \mathrm{~m}$ and the highest point is $3.6 \mathrm{~km}$ West of Al-Salmi Border Post $300 \mathrm{~m}$. Kuwait is modern well developed and planned emerging economic country having $6608 \mathrm{~km}$ of total road network according to the statistical data for year 2010 (Figure 1).

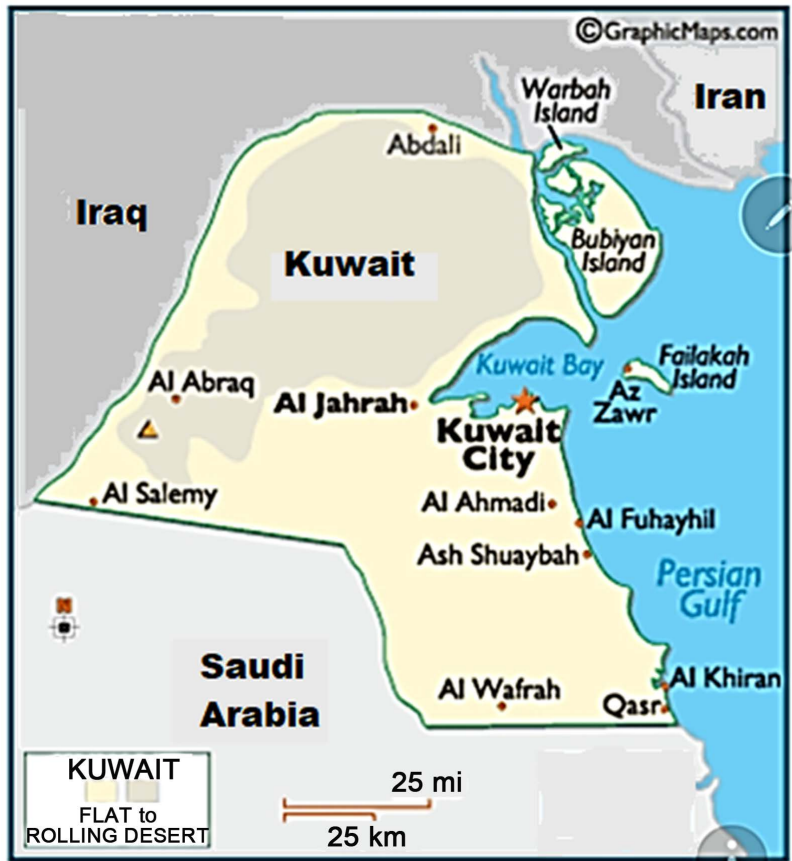

Figure 1. Location map of Kuwait. 
Despite the dependency of the Kuwait economy in crude oil only as the main energy source and the major generating commodity, Kuwait has a geographically small, but wealthy, relatively open economy with crude oil reserves of about 102 billion barrels more than $6 \%$ of world reserves. Kuwaiti officials plan to increase production to 4 million barrels of oil equivalent per day by 2020. Petroleum accounts for over half of Gross Domestic Product (GDP), 92\% of export revenues, and $90 \%$ of government income. In 2015, Kuwait, for the first time in 15 years, realized a budget deficit after decades of high oil prices; in 2016, the deficit grew to $16.5 \%$ of GDP. The GDP per capita (PPP) in Kuwait was around $\$ 71,900$ in year 2016 which is considered high to many countries.

Kuwait has a well-developed road system, although there are no trains, and public transport is limited to buses and taxis. Plans are on to build a railway system in future, but, buses, cars or taxis are the only means of common public transport available in Kuwait at present. Using any kind of transportation whether private car or public is necessary because of the extreme weather conditions especially in summer. Summer season extends over seven months, from April to October and the temperatures reaches $50 \mathrm{C}$ and above especially in July and August. The hot and dry nature of Kuwait weather increases the demand toward transportation in general.

\section{Methodology}

The CUSUM technique was developed initially for statistical quality control [9] [10] [11] applied CUSUM to change point detection of gaseous and particulate pollution at road side location at Marylebone. Also, Barratt et al. (2007) applied the approach to vehicle count and CO concentration data at Marylebone for the purpose of detection change in air pollutant concentrations. Due to the easy computations of the CUSUM technique, the applications of the approach is now become in large scale. CUSUM works better in detecting the small shifts in the process than other techniques such as Shewhart chart and exponential weighted moving average chart, however both techniques CUSUM and EWMA are used in this study [12]. CUSUM methods apply to observations recorded over time (daily, weekly, monthly). The observations may be physical measurements, counts or rates and may be grouped (in production batches for example) or individual observations (e.g., as here, daily average concentrations of a pollutant at a monitoring station).

In order to apply the CUSUM approach to air pollutants in Kuwait areas, the procedure is described briefly. First, we will consider each concentration measured in a day as a point in the EMWA and CUSUM charts. This mean each arising point will refer to the day when this rising happened.

Let $x i, i=1-n$; ( $n$ being the number of data points) is an independent time series to be studied for the presence of any changes. The cumulative sum Si can be calculated as;

$$
\mathrm{Si}=\mathrm{Si}-1+\mathrm{zi} ; \mathrm{i}=1-\mathrm{n}
$$


where $S O=0, z i$ is the standard normal variate.

Thus, if there is a shift in the process mean away from the target then $z i$ will tend to be larger or smaller than the target average and the CUSUM will steadily increase or decrease. Depending upon the magnitude of the shift in the mean the CUSUM may not detect the change immediately, requiring a number of observations at the new level before it begins to pick up the change in mean.

$$
\mathrm{Zi}=
$$

where $x i$ is the observed value at time $i, X$ is the desired process mean and $s$ is an estimate of the standard deviation of the observed values. These are accumulated over time to compute the CUSUM, S, at each time point (i).

Moreover, the change in terms of increased or decreased process mean can be detected, respectively by computing the quantities as (10);

$$
\begin{aligned}
& \text { SHi }=\operatorname{MAX}[0,(z i-k)+\text { SHi-1 }] \\
& \text { SHi }=\operatorname{MIN}[0,(z i-k)+\text { SLi-1 }]
\end{aligned}
$$

where parameter $k$ is the reference value to be chosen appropriately. For the normally distributed variables with mean 0 and unit standard deviation, slackness factor $\mathrm{k}$ can be chosen as 0.5 to indicate the shift of $1 \sigma$ in process mean. The confidence limits specified for the CUSUM control charts are $\pm h \sigma x$, where $h=4$ or 5 and $\sigma x$ is the standard deviation, slackness factor $k$ can be chosen as 0.5 to indicate the shift of $1 \mathrm{r}$ in process mean. The confidence limits specified for the CUSUM control charts are $\pm h \sigma x$, where $h=4$ or 5 and $\sigma x$ is the standard deviation [13].

\section{Results}

The study will be based on data from three areas in Kuwait from different environment conditions and different Governorates. There will be brief description of each of area in the case study.

\section{Capital Governorate (Al-Mansouriya)}

Mansouriya is an area in the Capital Governorate and a suburb of Kuwait City as shown in (Figure 2), its Population reaches 8352 in 2008 [2]. The total area is $1,255,302.329 \mathrm{~m}^{2}$. The area selected faces severe air pollution problem mainly from transportation and daily traffic emissions from huge number of vehicles passing by its surrounding roads. The study will evaluate the pollutants levels in this area from Environment Public Authority last 5 years for urban air pollution (PM10, $\mathrm{CO}, \mathrm{H}_{2} \mathrm{~S}, \mathrm{NO}_{2}, \mathrm{SO}_{2}$, NMHC).

\section{Al-Jahra Government (Al-Mutla)}

Al-Mutla is a series of plateaus located north-east of Kuwait, Al-Mutla area is $40 \mathrm{~km}$ away from the Kuwait capital.

\section{About Future AL Mutla Housing Project:}

In order to meet the increasing demand for housing care for citizens, the Public Authority for Housing Welfare (PAHW) is undertaking a series of projects in the form of new large urban areas, outside the current Metropolitan Area is one such project. 


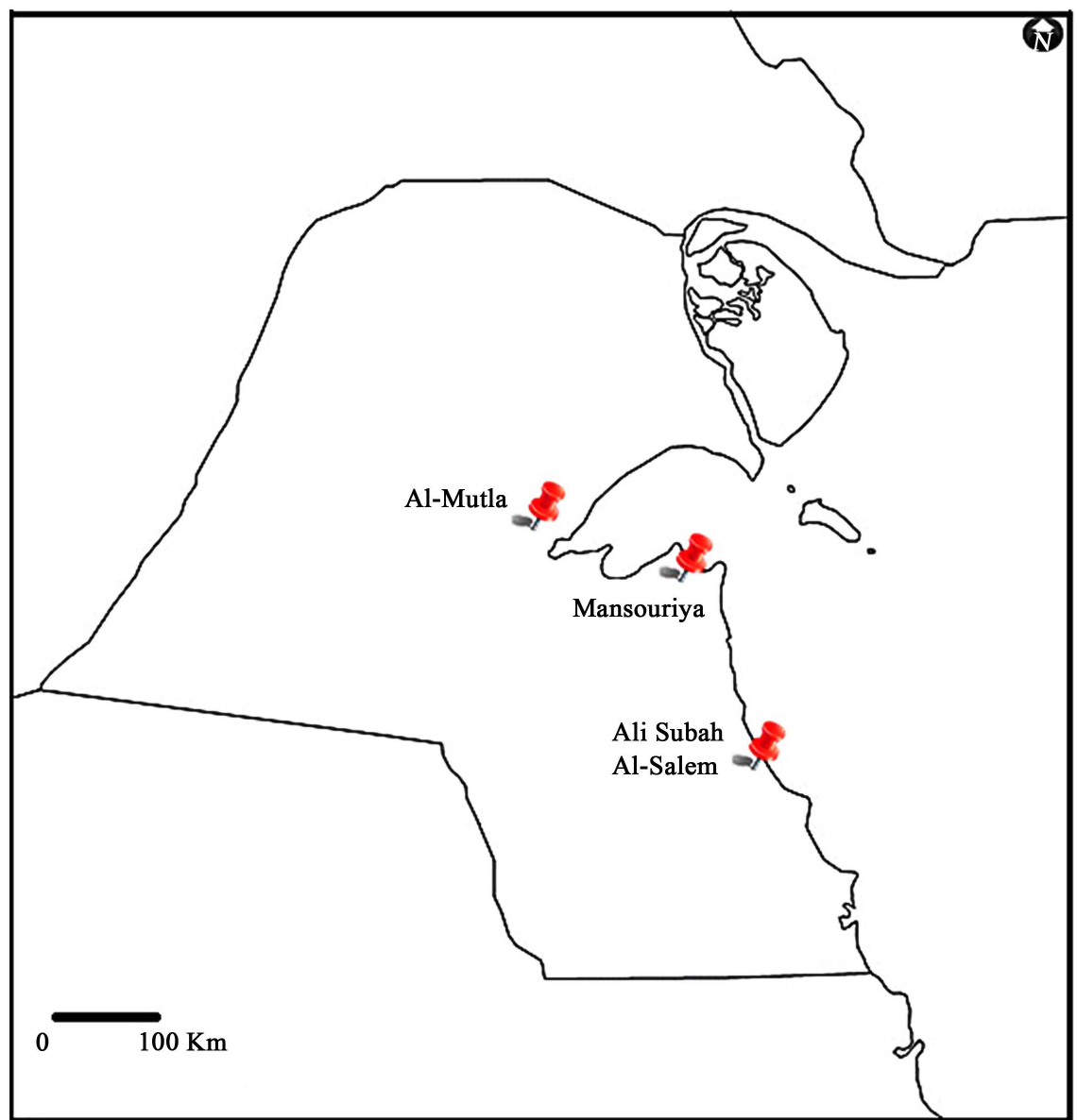

Figure 2. Location map of sampling area.

ALMutlaa City is proposed to be located to the north-west of Mtropolitan Area. PAHW commissioned a consortium led by Parsons Brinkkerhoff along with Malone Given Parsons (MGP), Deloitte and Kuwait Technical Consulting Bureau (KTCB) to develop AL Mutlaa Housing Project through the detailed planning and desigh stage. The expected date of completion September 2020.

Project Area: 9000 hectares

Components of the project:

It consists of 12 residential suburb (220,000 Kuwaiti residents in 30,500 units):

9769 housing units N1, N2, N3, N4.

18,519 housing units N5, N6, N7, N8, N9, N10, N11, N12

Total $=28,288$ housing units

The unit area of $400 \mathrm{~m}^{2}$

\section{Al-Ahmadi Government (Ali Subah Al-Salem)}

Ali Subah Al-Salem area is located the South Kuwait (Figure 2). The area is considered from the newest urban areas in the last years in that region. The area consists of 9 blocks with total population of 47,302.

A residential area of Umm al-Hayman (now known as Ali Sabah al-Salem) was planned, without taking into account the environmental and health effects associated with the site, which was chosen for the residence of hundreds of 
thousands of citizens, especially that the site is close to the industrial zones of the private and government sectors. Citizens complain of environmental diseases and problems they are constantly exposed to.

The environmental and health problem in Ali Subah Al-Salem is not a unique problem in Kuwait. Similarly, Qurain area faces problem with the waste disposal location, which was established next to the area. Although the problem was handled in a temporary and better way comparing to the Ali Subah Al-Salem.

Globally, in the United States, there was the problem of the residential area known as Love Canal, which was built next to a site for the disposal of industrial waste where diseases and cancer increased unexpectedly, causing population discontent and social and political problems with the local authorities. After a long period of the seriousness of the problem, authorities considered the area condition as a disaster and compensated the population for the environmental and health damage. However, still many countries in the world, including countries in Europe and the United States, have industrial zones close to residential areas.

\section{Results and Discussion}

The CUSUM and EWMA techniques are applied to air quality data at three areas in Kuwait Ali Subah Al-Salem, Al-Mutla, and Al-Mansouriya. The site is characterized as monitoring stations in each area with daily concentration measurements. In Ali Subah Al-Salem, industrial plants are located nearby the area, while Al-Mansouriya area are surrounded by heavy traffic because of main rings and roads in Kuwait City. However, Al-Mutla is plain area with no major external exposure. The continuous monitoring is carried out by Kuwait Environment Public Authority, Kuwait. The 24 hourly data observed during 2013-2017 (study time) for $\mathrm{CO}, \mathrm{NO}_{2}, \mathrm{SO}_{2}, \mathrm{PM}_{10}, \mathrm{H}_{2} \mathrm{~S}$, and $\mathrm{NMHC}$ is considered to analyze for any changes in the behaviour of these pollutants.

Data analysis and Discussion for output:

\section{Ali-Subah Al-Salem}

The data were collected from Ali Subah Al-Salem monitoring station from period 2013 to 2017, study time. In addition, the data that taken from Rya) are measured daily. Following graphs are analysed yearly and period from 2013-2017 for each pollutant $\mathrm{CO}, \mathrm{NO}_{2}, \mathrm{SO}_{2}, \mathrm{PM} 10, \mathrm{H}_{2} \mathrm{~S}$, and NMHC respectively.

From Figure 3 and Figure 4, it can be observed that EWMA showed alarms of exceed concentration level at the time period (9 to 89 points) from 9 Jan. to 30 March. Since each point refer to number of the day during the year(s), the alarm period refers to the first three months in 2013. CUSUM showed the same results but in accurate manner by which it specifies the uncontrolled increasing concentration of $\mathrm{CO}$ in 2013 from the point 9, means from the day of 9 Jan., until it reaches the maximum value in 2013 in 85 point, 26 March. Then it keep gradually decreasing but still above the average reference limit in 2013. 


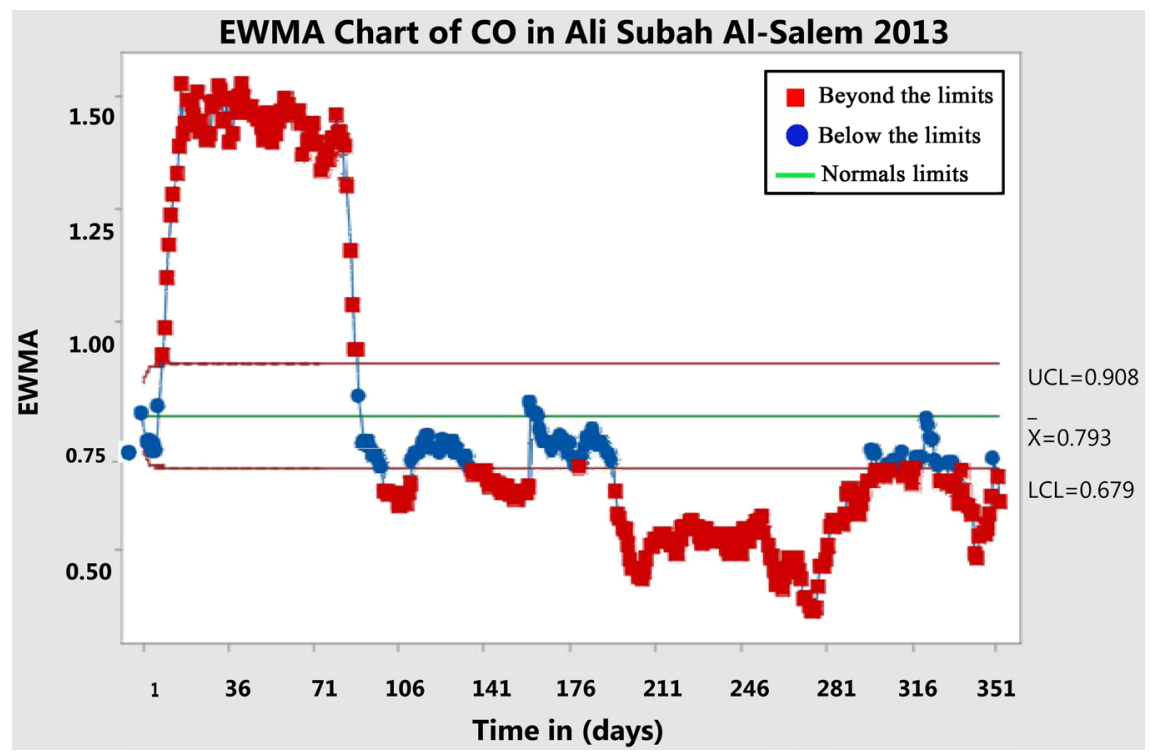

Figure 3. EWMA chart of CO in Ali Subah Al-Salem 2013.

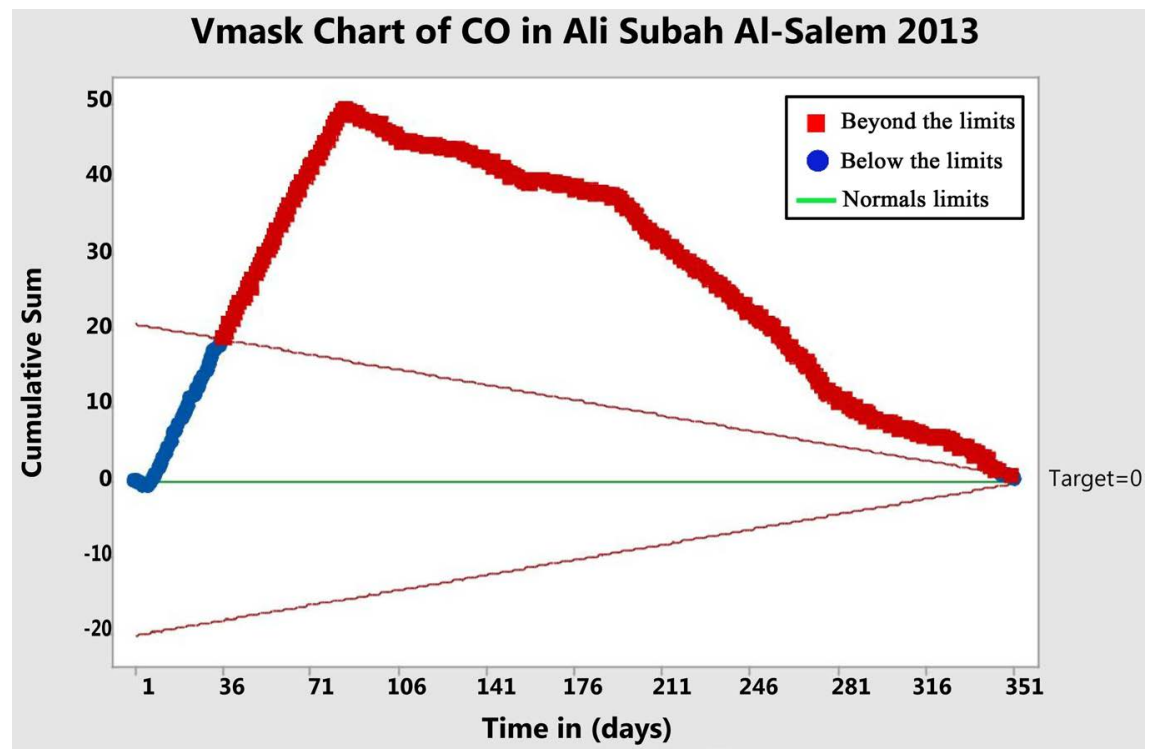

Figure 4. CUSUM chart of CO in Ali Subah Al-Salem 2013.

From Figure 5 and Figure 6, it can be concluded that EMWA displayed alarms at the time period from day 3 Sep. to the end of the year, means it almost keep increasing for 119 day. CUSUM displays no increasing distribution above the average of this year except the last two days in 2014 faced some increase in $\mathrm{CO}$ concentration.

From Figure 7 and Figure 8, it can be observed that the period from 18 Jan. to 2 Apr. (duration $=74$ days) showed increasing concentration upon the normal average (avg $=1.066$ ) but the CUSUM showed normal distribution within the year average at the same period. CUSUM starts the alarm period from point 1 Jan. to 2 Apr. then it decreases gradually from 2 Apr. to 10 Jun. after which it decreases normally under the average. 


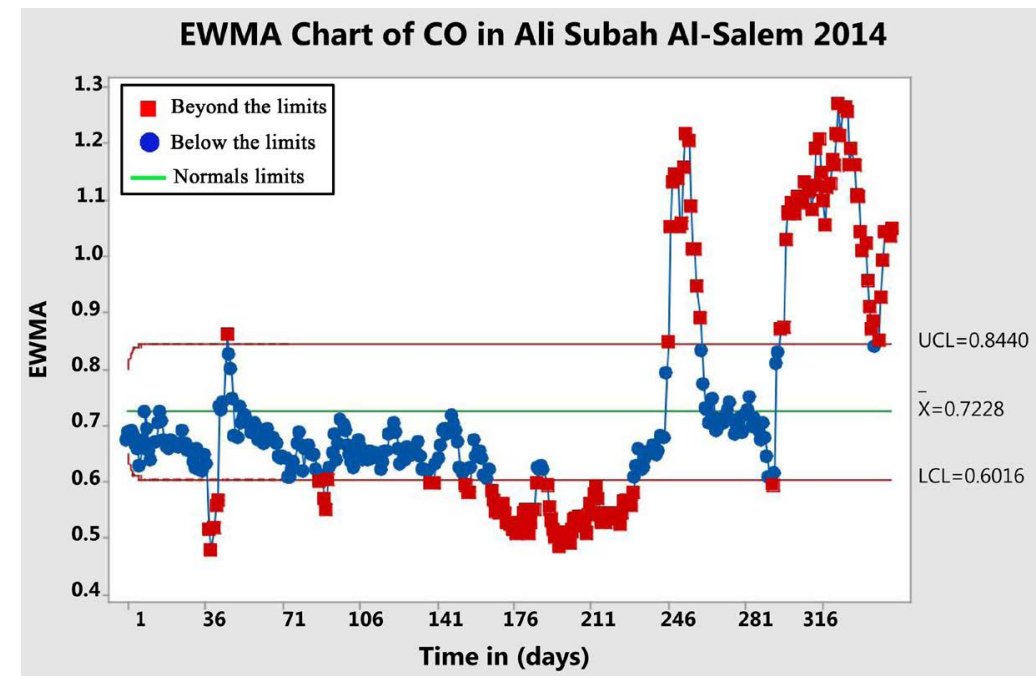

Figure 5. EWMA chart of CO in Ali Subah Al-Salem 2014.

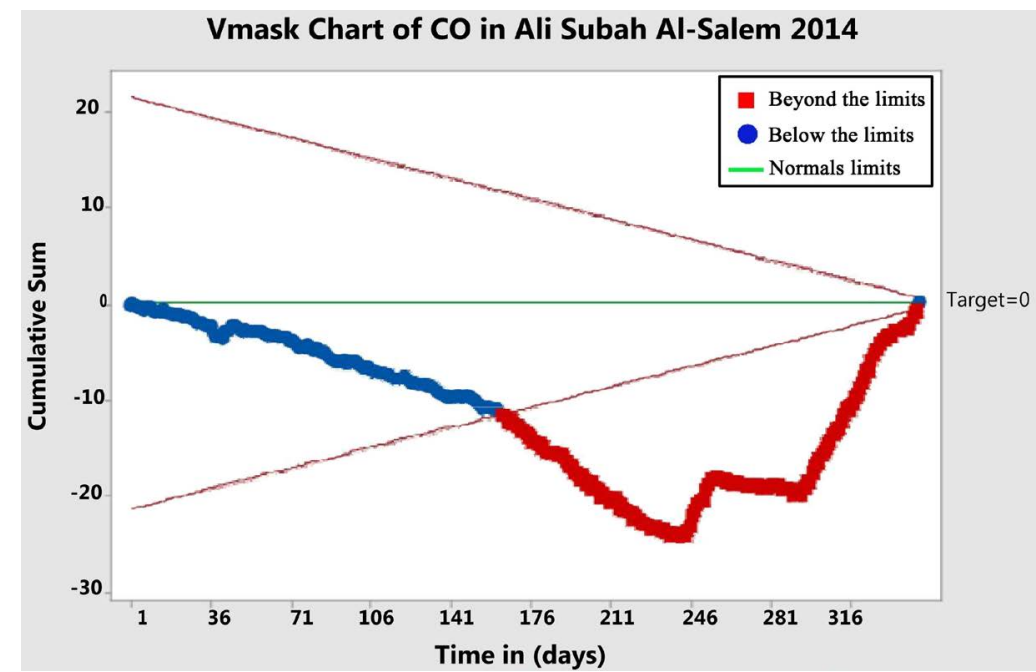

Figure 6. CUSUM chart of CO in Ali Subah Al-Salem 2014.

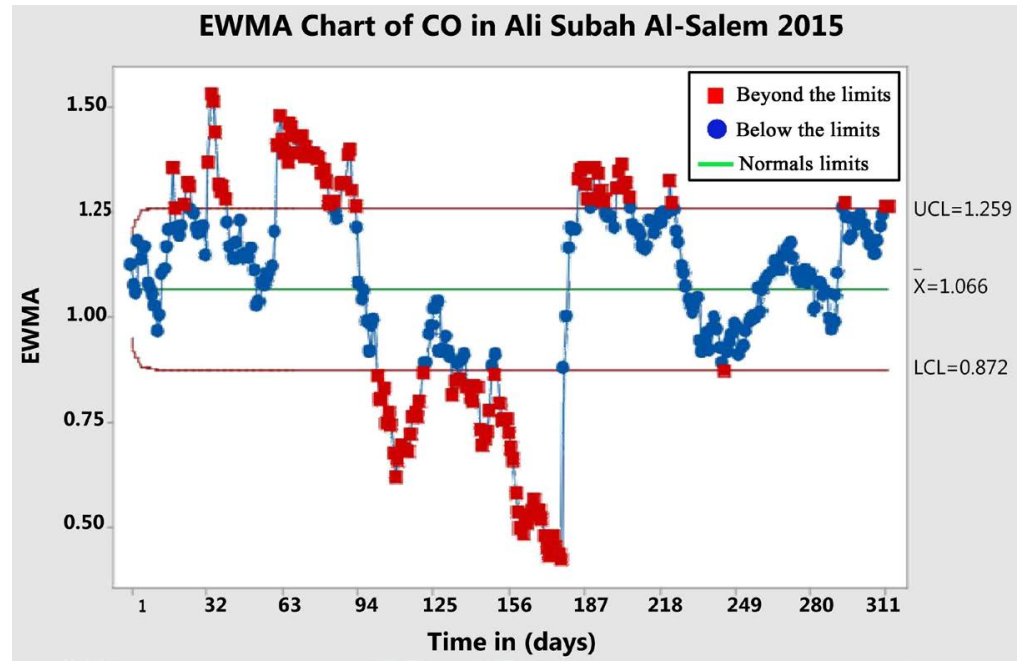

Figure 7. EWMA chart of CO in Ali Subah Al-Salem 2015. 


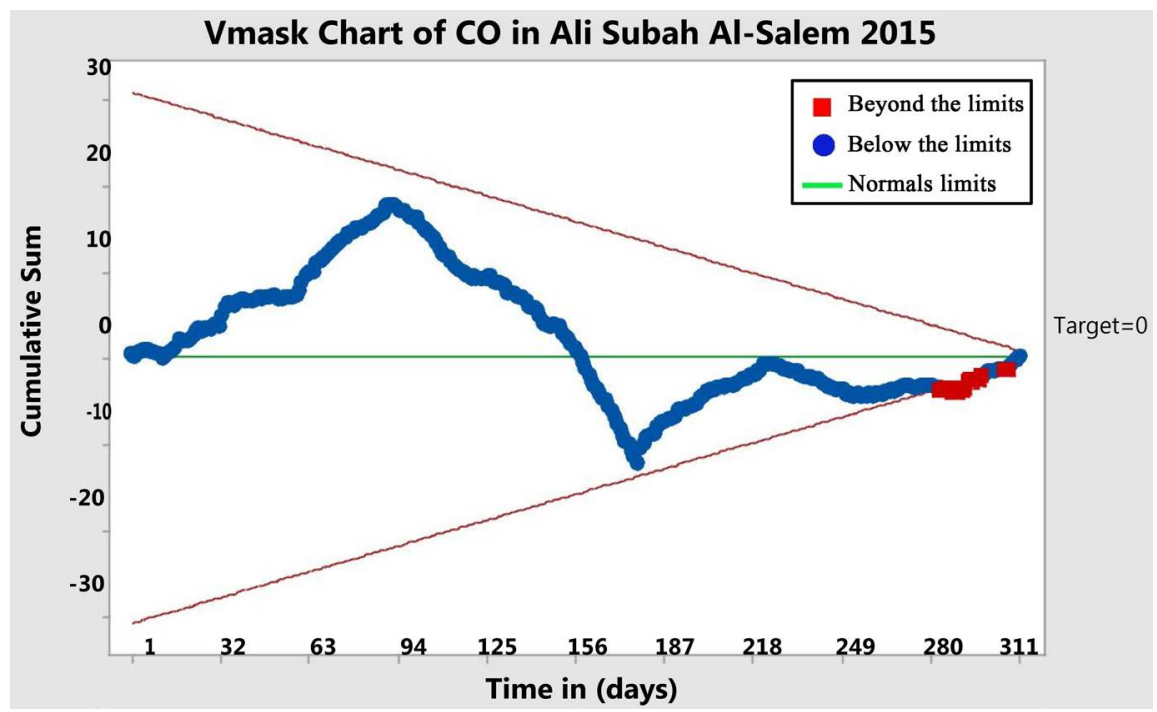

Figure 8. CUSUM chart of CO in Ali Subah Al-Salem 2015.

From Figure 9 and Figure 10, EMWA showed 3 alarming periods 15 Apr. to 14 May, 18 May to 14 Jun., and 24 Jun. to 10 Jul.. CUSUM showed the increasing distribution of CO concentration above the average level from point 9 Jun. to 12 Sep. then it go in normal distribution within the Vmask.

From Figure 11 and Figure 12, it can be observed that EMWA viewed the alarming periods 6 Jan. to 26 Jan., 8 Feb. to 14 Feb., 21 Feb. to 13 Apr., and 21 Apr. to 17 May. The CUSUM draw the out-of-control distribution from point 8 Feb. to 15 Aug.

From Figure 13 and Figure 14, EMWA showed many intervals that exceed the standard level of CO during the 5 years. These intervals are the points 11 Jan 2013 to 27 Mar. 2013 (duration = 75 days), 22 Aug. 2014 to 26 Aug. 2014 (duration $=4$ days), 13 Oct. 2014 to 22 Jan. 2015 (duration = 101 days), 2 Feb. 2015 to 6 Mar. 2015 (duration= 32 days), 22 May 2015 to 20 Jul. 2015 (duration=59 days), 22 July 2015 to 26 Dec. 2015 (duration = 157 days), 15 Jan. 2016 to 22 Apr. 2016 (duration $=98$ days), and 4 May 2016 to 30 Jun. 2016 (duration $=57$ days). CUSUM showed only one period of out-of-control distribution from points 25 Mar. 2016 to 26 Feb. 2017 (duration = 390 days).

From Figure 15 and Figure 16, it can be observed that EWMA showed alarms at the points from 1 Jan. 2013 to 10 Jan. 2013, 25 Jun. 2013, 12 Jul. 2013 to 23 Jul. 2013, 6 Aug. 2013 to 1 Sep. 2013, 7 Sep. 2013 to 26 Sep. 2013, 30 Sep. 2013 to 8 Oct. 2013, 16 Oct. 2013 to 24 Oct. 2013, 29 Dec. 2013. CUSUM showed only the upper limit period from points 21 Oct. 2013 to 10 Nov. 2013 while the other act within average distribution.

From Figure 17 and Figure 18, it obvious that EMWA displayed alarms at the time period from 24 Mar. 2014 to 25 Apr. 2014, 23 May 2014 to 1 Jun. 2014, 8 Jun. 2014 to 1 Jul. 2014, 11 Oct. 2014 to 14 Oct. 2014, and 27 Oct 2014 to 30 Oct 2014. EMWA gives clear view that the period from 8 Jun. 2014 to 1 Jul. 2014 had recognized a very high jump in gas concentration level specially in the day 12 


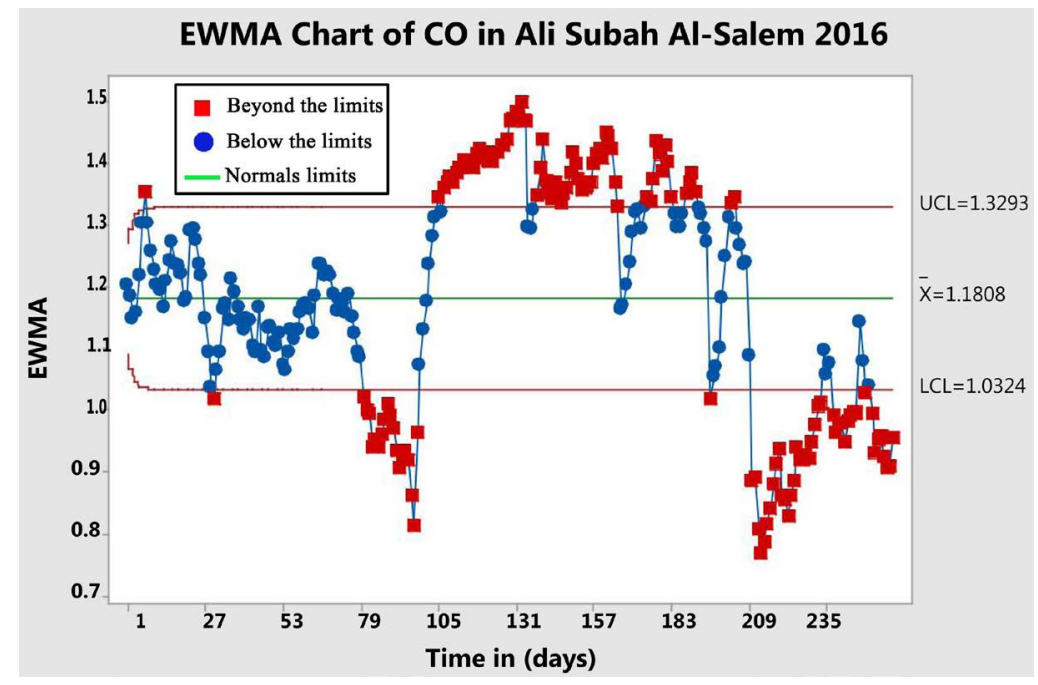

Figure 9. EWMA chart of CO in Ali Subah Al-Salem 2016.

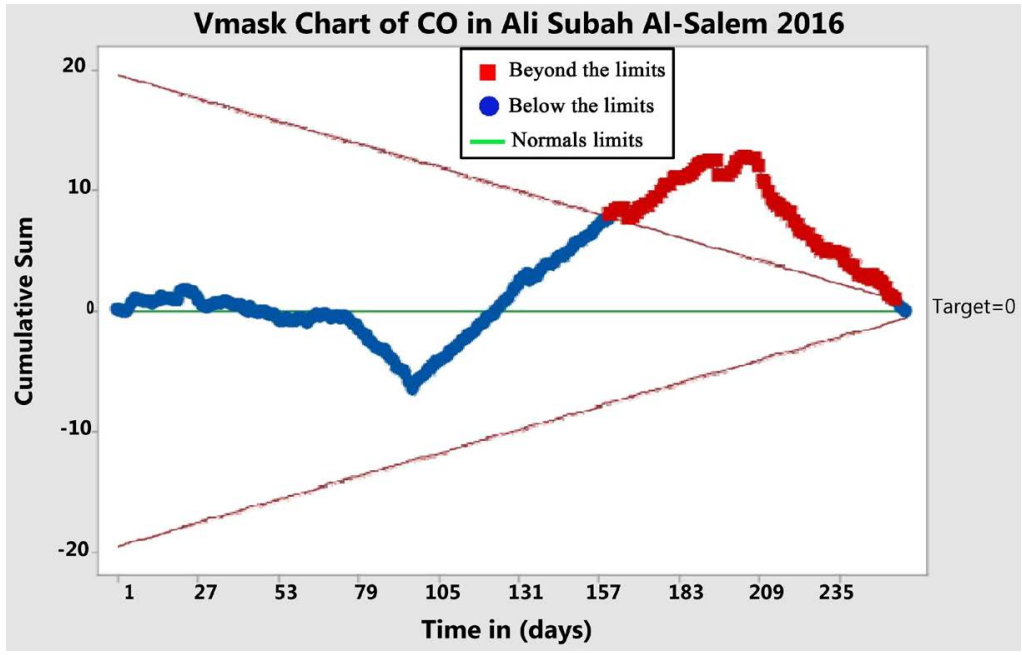

Figure 10. CUSUM chart of CO in Ali Subah Al-Salem 2016.

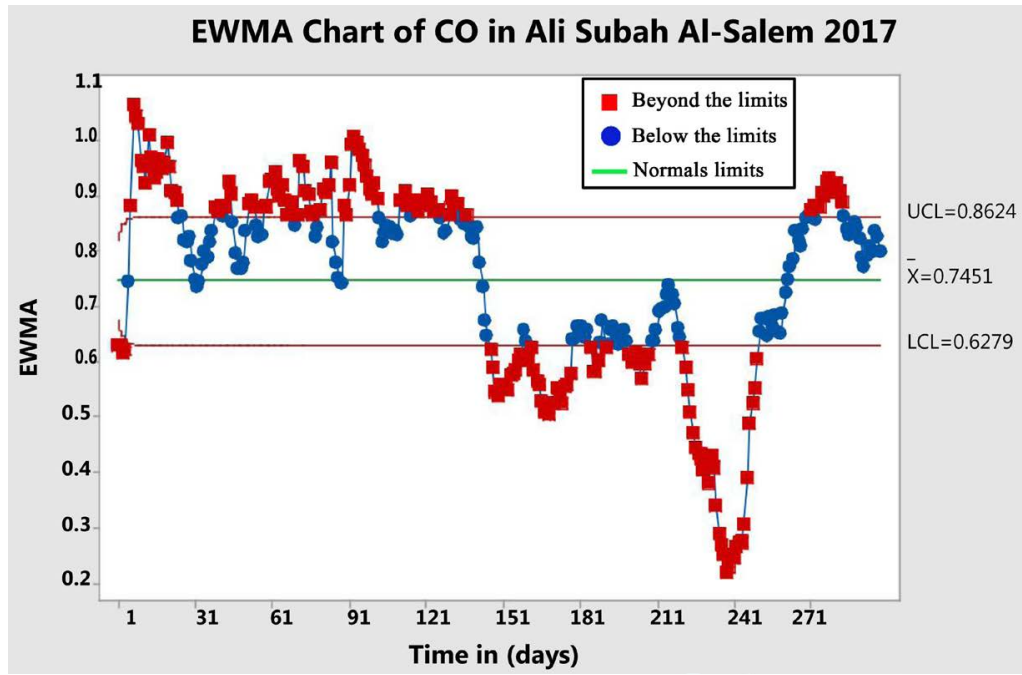

Figure 11. EWMA chart of CO in Ali Subah Al-Salem 2017. 


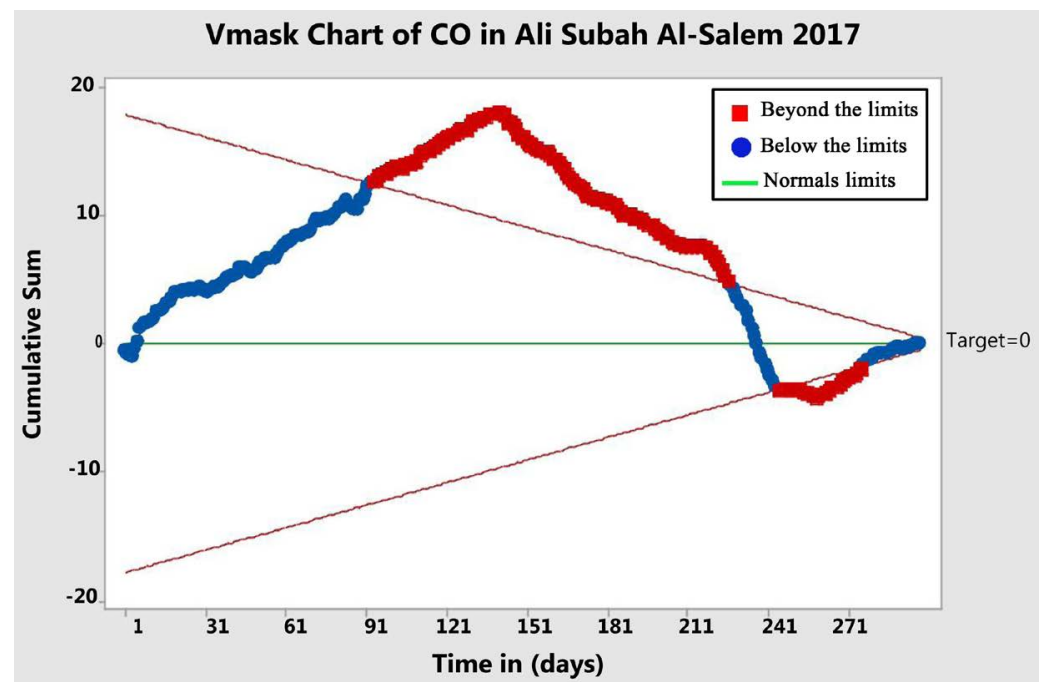

Figure 12. CUSUM chart of CO in Ali Subah Al-Salem 2017.

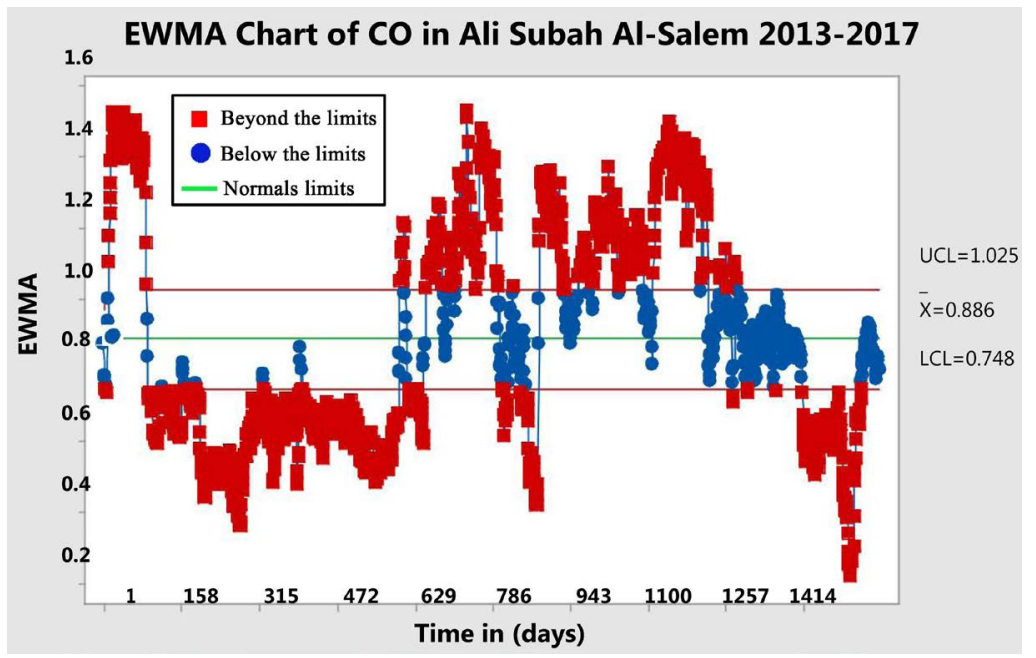

Figure 13. EWMA chart of CO in Ali Subah Al-Salem 2013-2017.

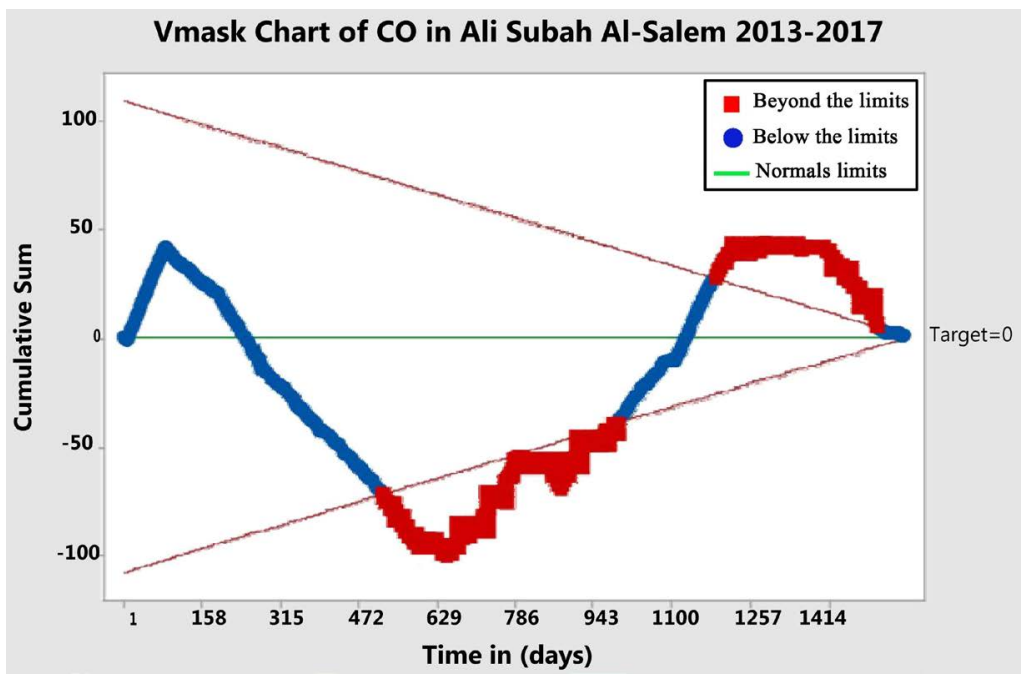

Figure 14. CUSUM chart of CO in Ali Subah Al-Salem 2013-2017. 


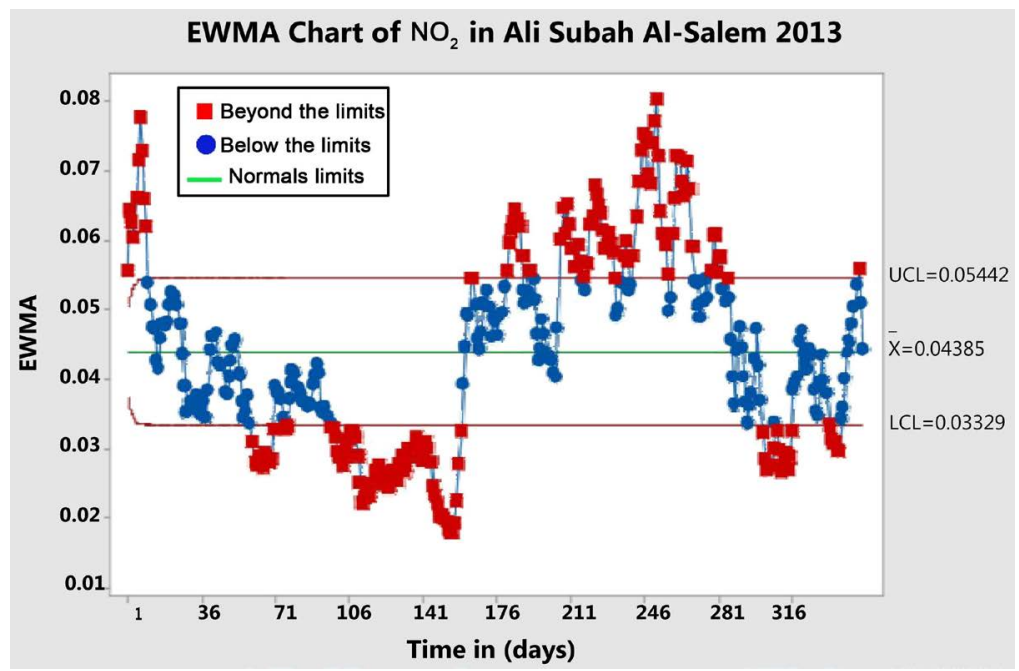

Figure 15. EWMA chart of $\mathrm{NO}_{2}$ in Ali Subah Al-Salem 2013.

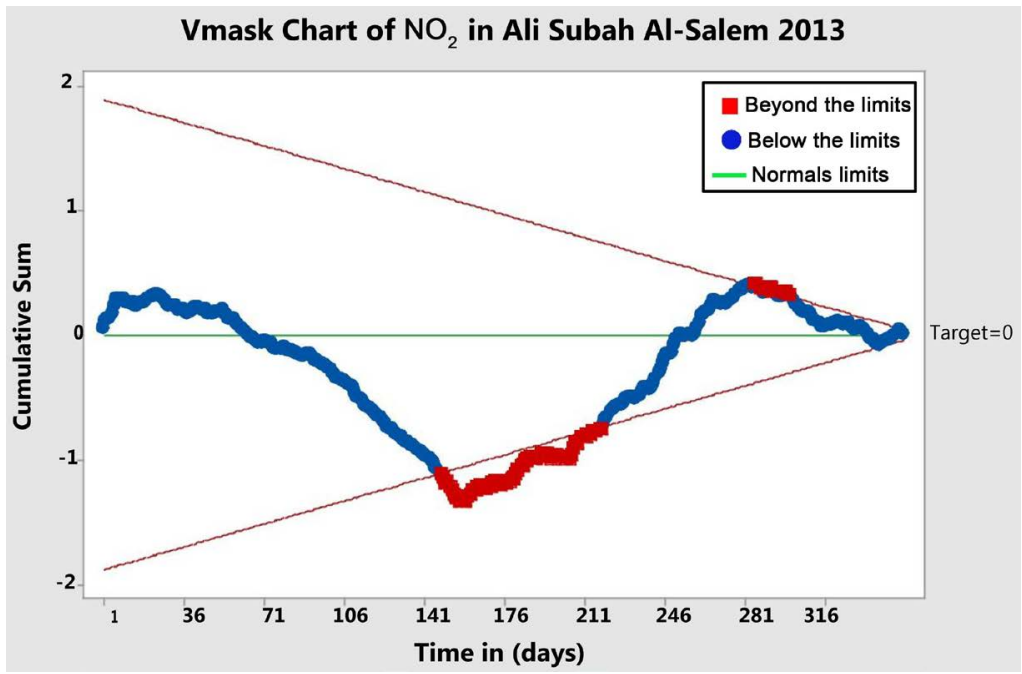

Figure 16. CUSUM chart of $\mathrm{NO}_{2}$ in Ali Subah Al-Salem 2013.

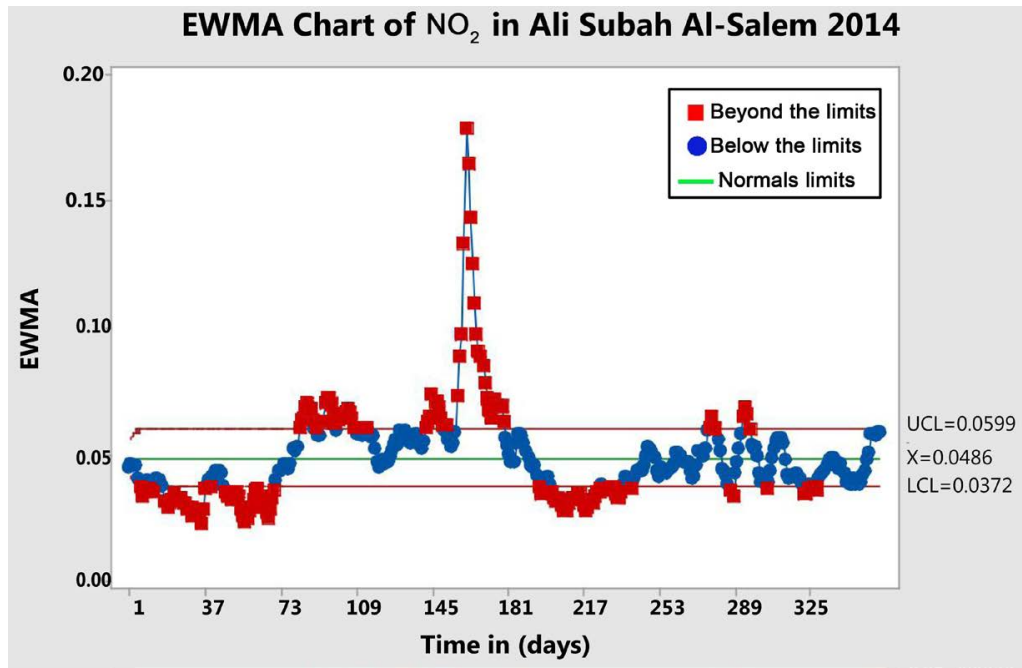

Figure 17. EWMA chart of $\mathrm{NO}_{2}$ in Ali Subah Al-Salem 2014. 


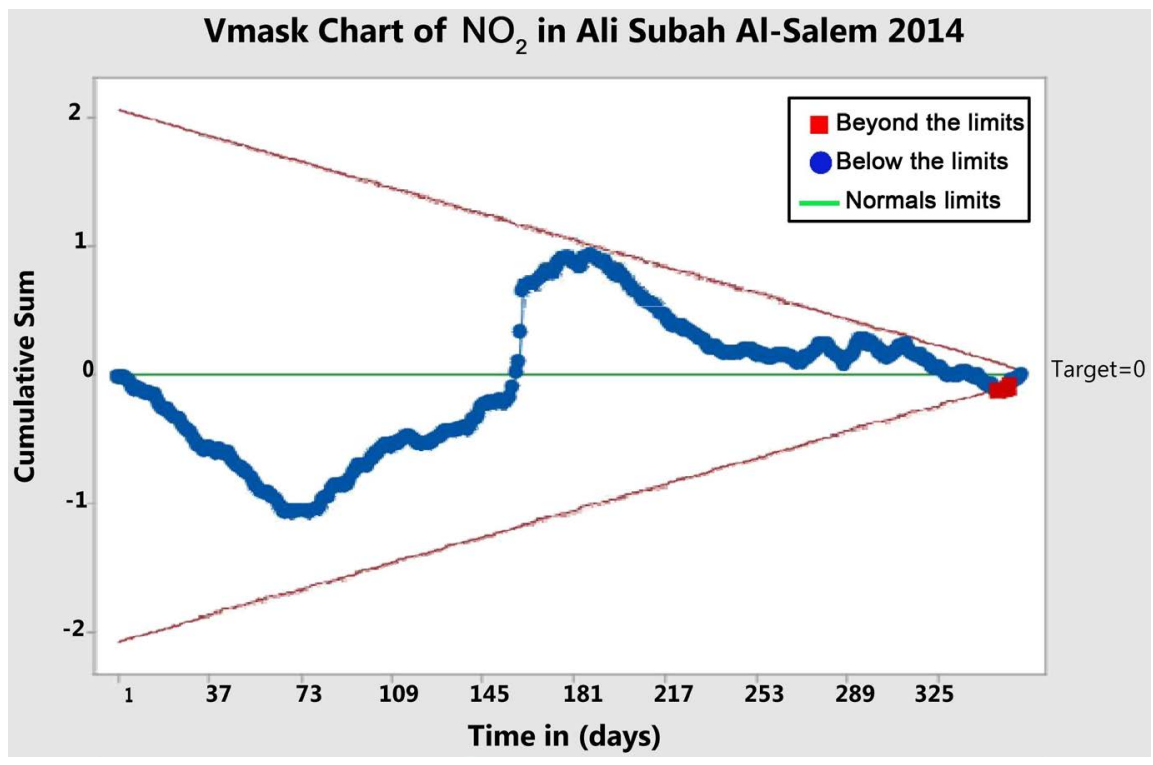

Figure 18. CUSUM chart of $\mathrm{NO}_{2}$ in Ali Subah Al-Salem 2014.

Jun 2014. However, CUSUM chart showed within average distribution for the gas concentration during this year.

From Figure 19 and Figure 20, it can be concluded that two periods 11 Oct. 2015 to 14 Nov. 2015 and 4 Dec. 2015 to 31 Dec. 2015 showed increasing concentration upon the normal average, while the CUSUM showed normal distribution within the year average.

From Figure 21 and Figure 22, EMWA showed 4 alarming periods 5 Jan. 2016 to 21 Feb. 2016, 18 Apr. 2016 to 24 Apr. 2016, 11 May 2016 to 19 May 2016, 9 Jun. 2016, 29 Jun. 2016 to 30 Jun. 2016, 28 Jul. 2016, and 31 Oct. 2016. CUSUM showed the increasing distribution of CO concentration above the average level from point 21 Jul. 2016 to 29 Dec. 2016.

From Figure 23 and Figure 24, it can be concluded that EMWA viewed the alarming days 3 Apr. 2017, 13 Apr. 2017 to 19 Apr. 2017, 29 Sep. 2017 to 12 Nov. 2017 (study time). The CUSUM draw had no out-of-control region.

From Figure 25 and Figure 26, EMWA showed many intervals that exceed the standard level of $\mathrm{NO} 2$ during the 5 years. These intervals are the points 1 Jan. 2013 to 11 Jan. 2013, 25 Jun. 2013 to 24 Oct. 2013, 28 Dec. 2013 to 30 Dec. 2013, 3 Apr. 2014 to 7 Jul. 2014, 15 Oct 2014 to 15 Nov. 2014, 27 Dec. 2014 to 2 Jan. 2015, 12 Oct. 2015 to 20 Feb. 2016, 17 Apr. 2016 to 31 Oct. 2016, and 30 Sep. 2017 to 8 Nov. 2017. CUSUM showed only one period of out-of-control distribution from points 14 Jul. 2016 to $21 \mathrm{Feb} .2017$.

From Figure 27 and Figure 28, it can be observed that EWMA showed alarms at the points from 15 Jan. 2013 to 18 Jan. 2013, 1 Apr. 2013 to 13 Apr. 2013, 9 Jul. 2013 to 10 Jul. 2013, 8 Aug. 2013 to 16 Aug. 2013, 16 Sep. 2013 to 22 Sep. 2013, 30 Sep. 2013 to 14 Oct. 2013, and 13 Dec. 2013 to 28 Dec. 2013. CUSUM displayed no upper limit period and all points were within average distribution.

From Figure 29 and Figure 30, EMWA displayed alarms at the time period 


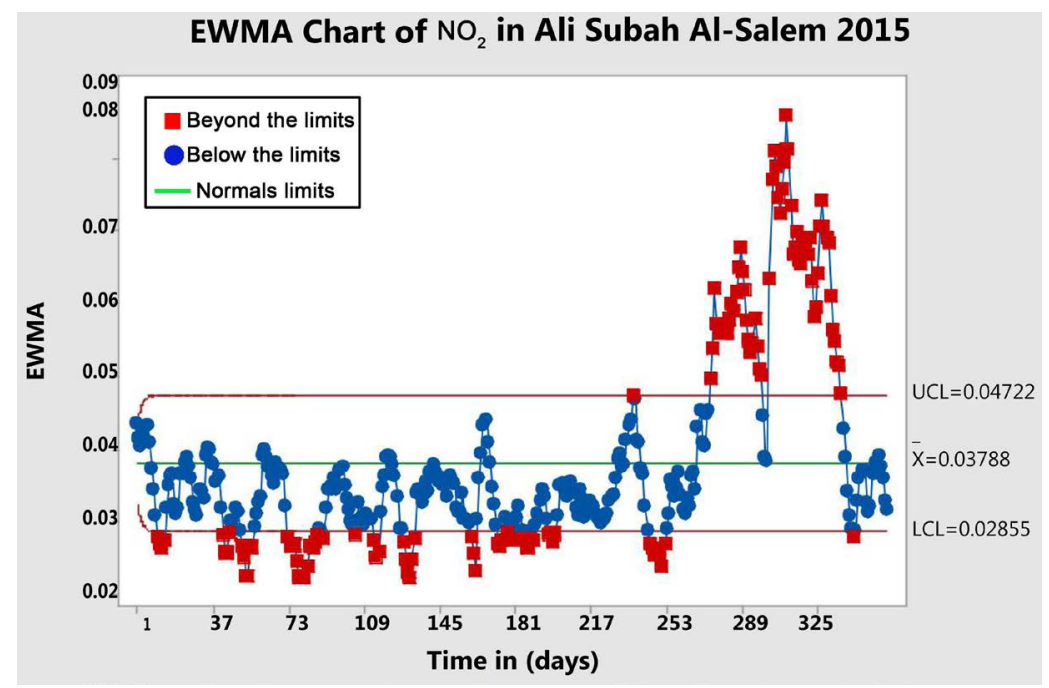

Figure 19. EWMA chart of $\mathrm{NO}_{2}$ in Ali Subah Al-Salem 2015.

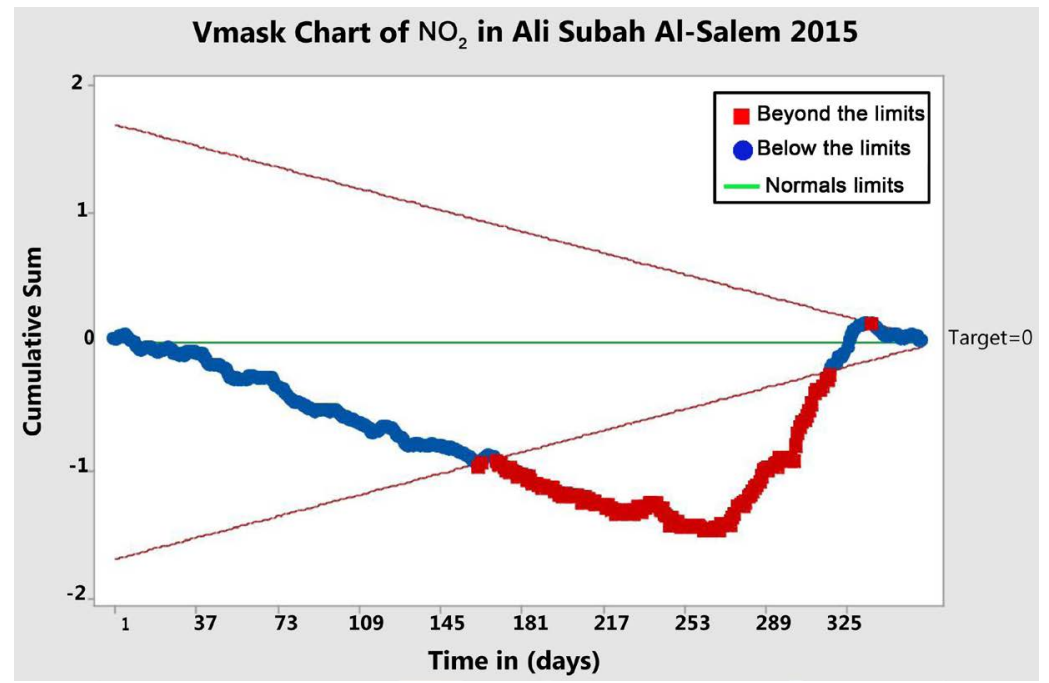

Figure 20. CUSUM chart of $\mathrm{NO}_{2}$ in Ali Subah Al-Salem 2015.

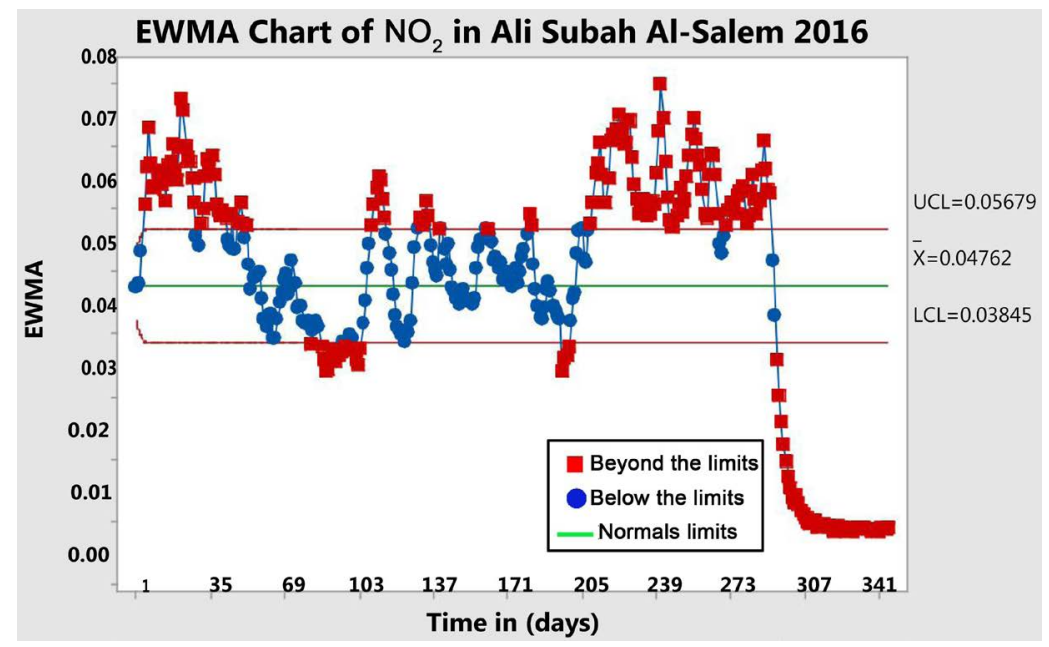

Figure 21. EWMA chart of $\mathrm{NO}_{2}$ in Ali Subah Al-Salem 2016. 


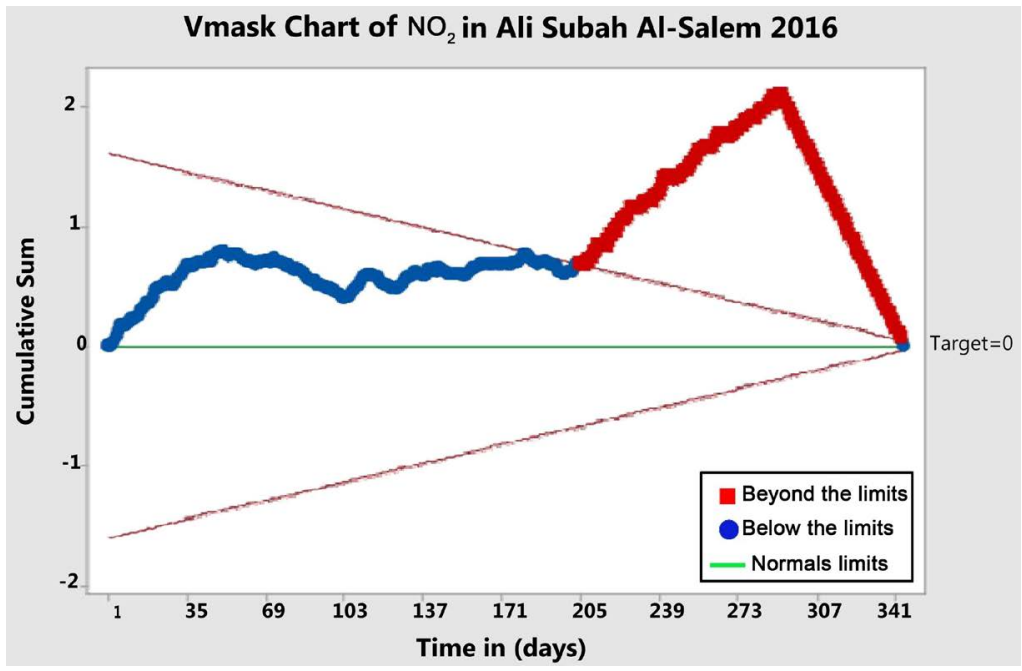

Figure 22. CUSUM chart of $\mathrm{NO}_{2}$ in Ali Subah Al-Salem 2016.

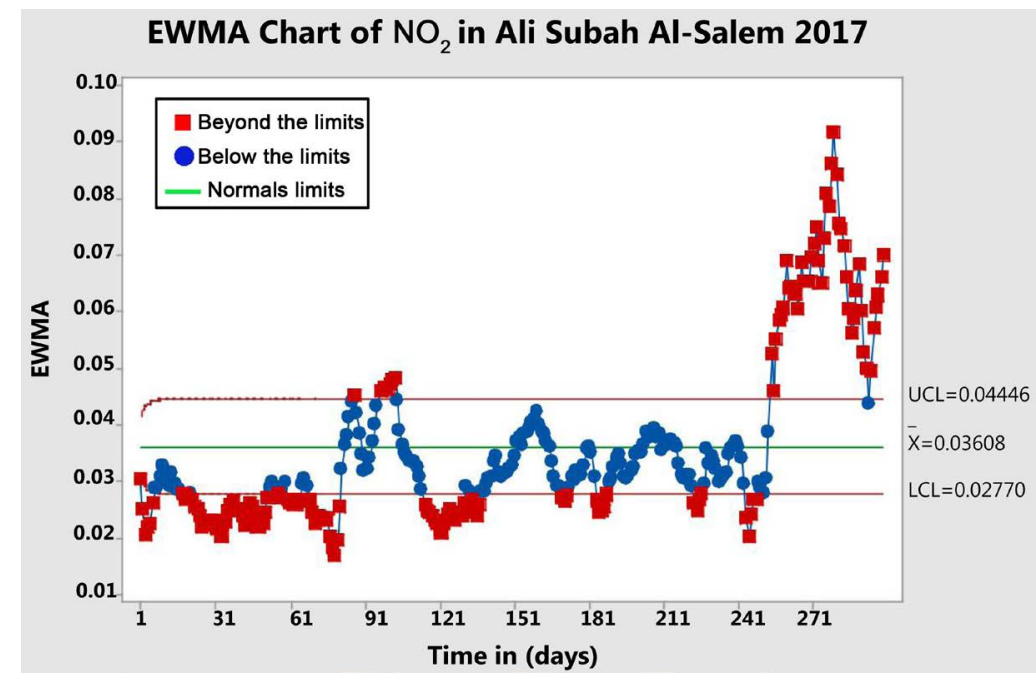

Figure 23. EWMA chart of $\mathrm{NO}_{2}$ in Ali Subah Al-Salem 2017.

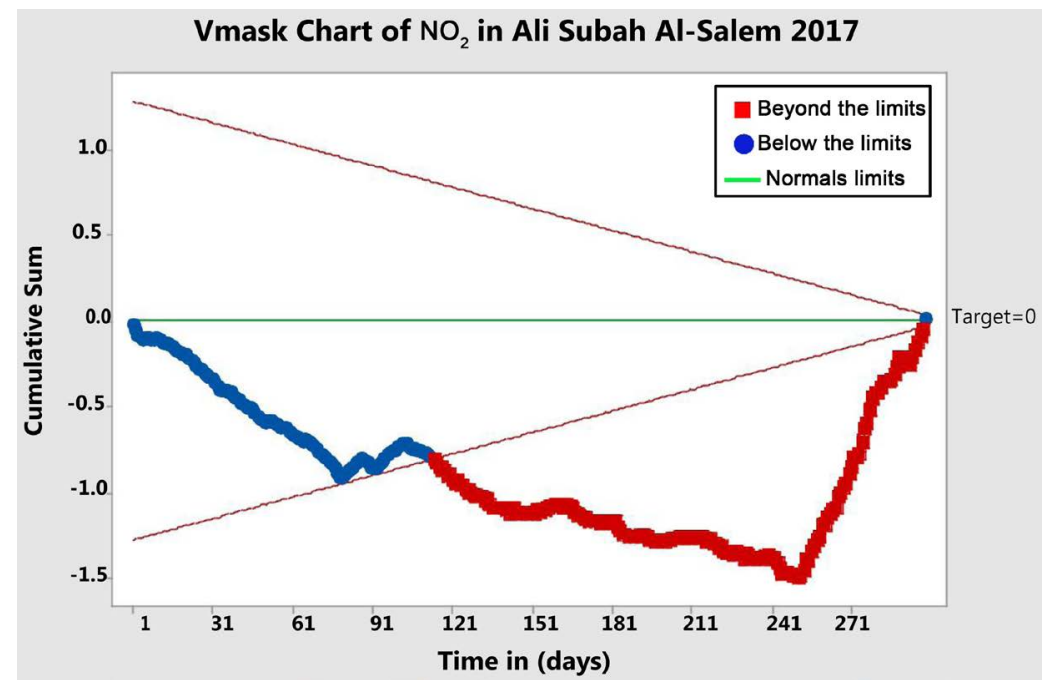

Figure 24. CUSUM chart of $\mathrm{NO}_{2}$ in Ali Subah Al-Salem 2017. 
EWMA Chart of $\mathrm{NO}_{2}$ in Ali Subah Al-Salem 2013-2017

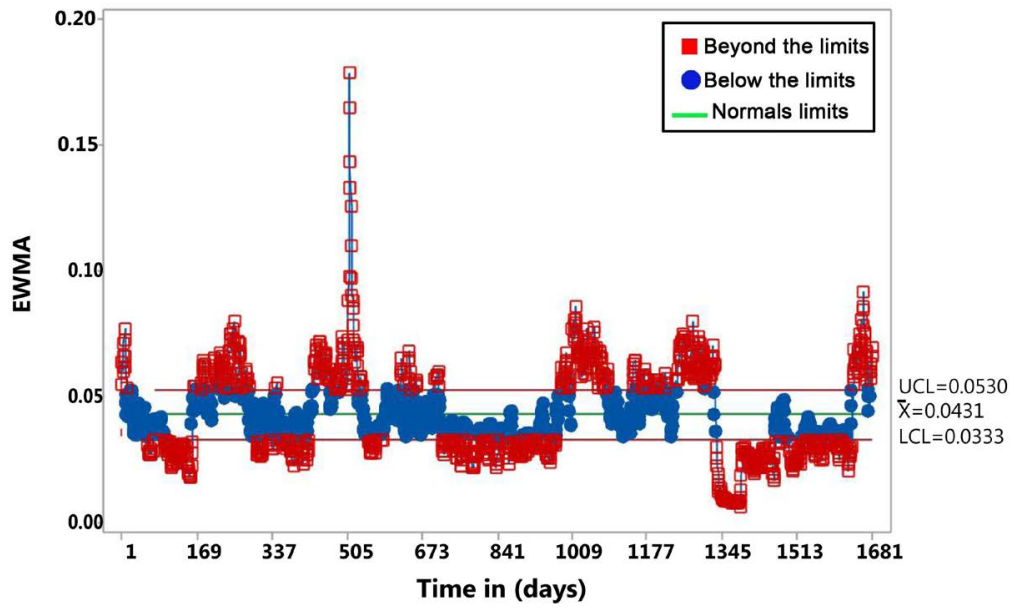

Figure 25. EWMA chart of $\mathrm{NO}_{2}$ in Ali Subah Al-Salem 2013-2017.

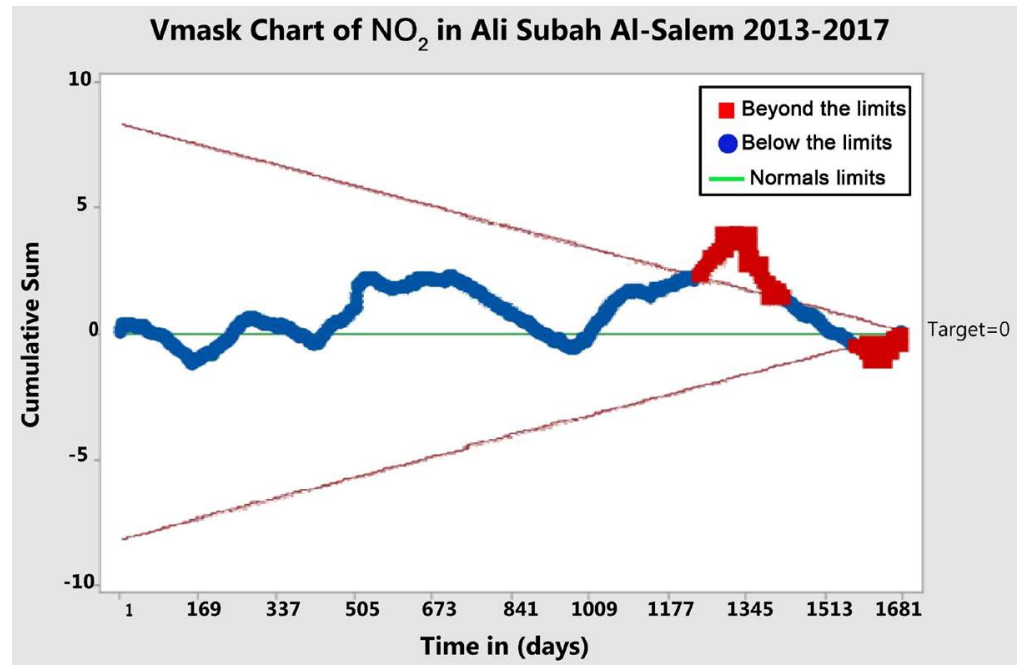

Figure 26. CUSUM chart of $\mathrm{NO}_{2}$ in Ali Subah Al-Salem 2013-2017.

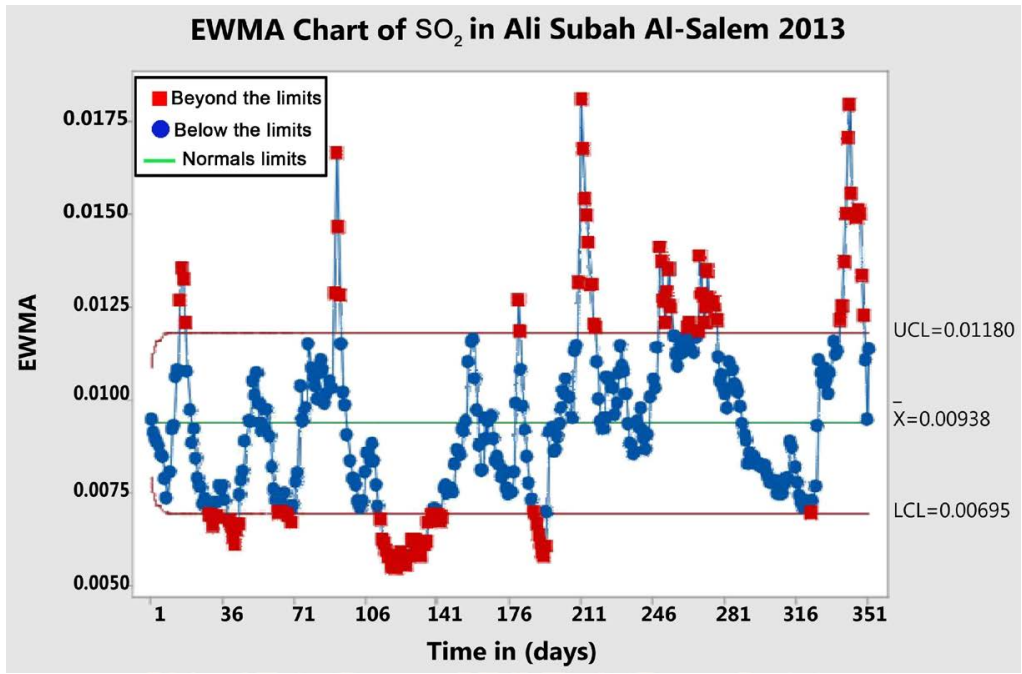

Figure 27. EWMA chart of $\mathrm{SO}_{2}$ in Ali Subah Al-Salem 2013. 


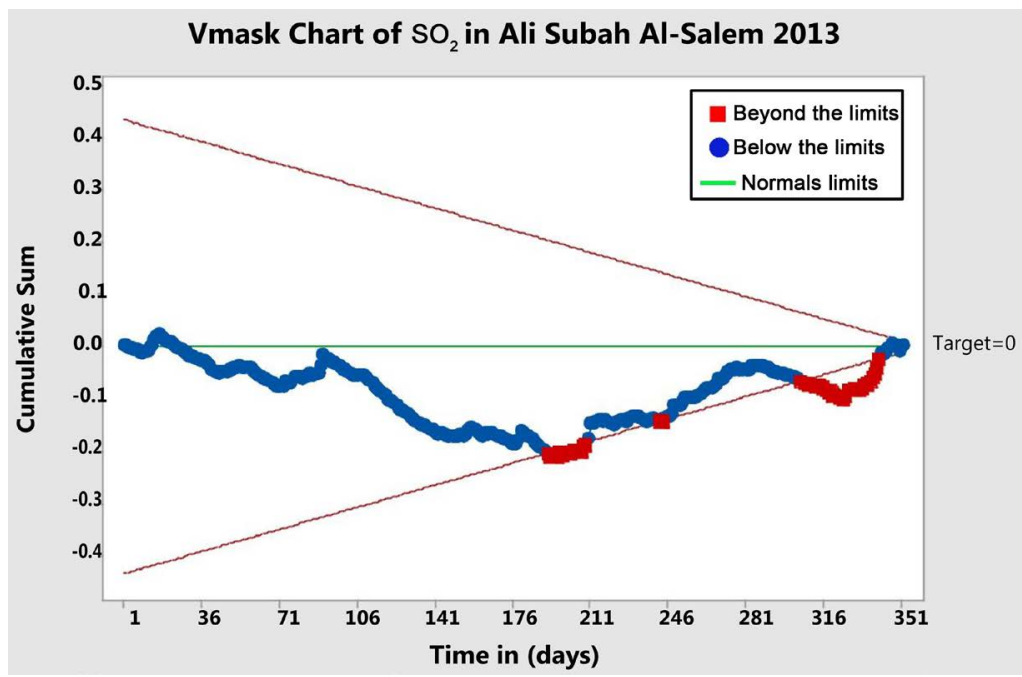

Figure 28. CUSUM chart of $\mathrm{SO}_{2}$ in Ali Subah Al-Salem 2013.

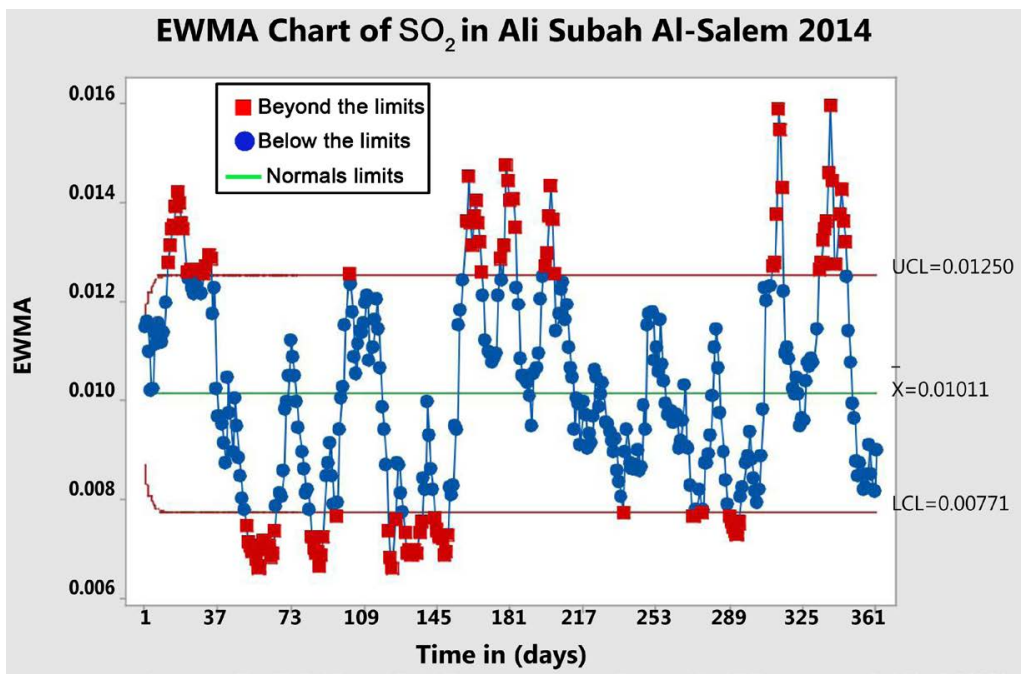

Figure 29. EWMA chart of $\mathrm{SO}_{2}$ in Ali Subah Al-Salem 2014.

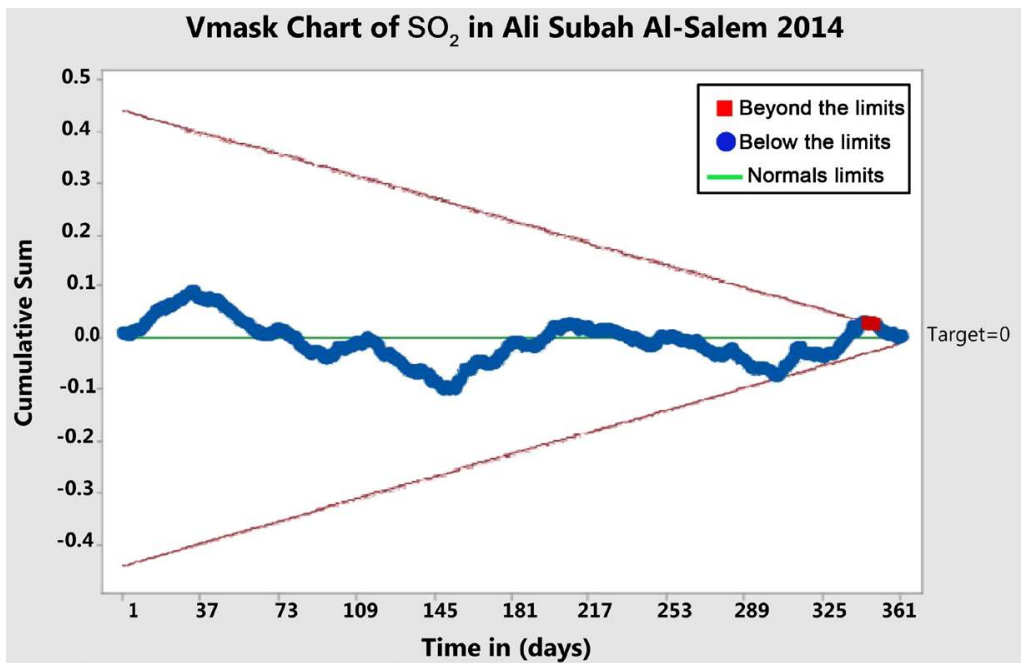

Figure 30. CUSUM chart of $\mathrm{SO}_{2}$ in Ali Subah Al-Salem 2014. 
from 12 Jan. 2014 to 2 Feb. 2014, 12 Apr. 2014, 10 Jun. 2014 to 18 Jun. 2014, 27 Jun 2014 to 4 Jul. 2014, 19 Jul. 2014 to 24 Jul. 2014, 9 Nov. 2014 to 14 Nov. 2014, and 2 Dec. 2014 to 15 Dec. 2014. EMWA gives clear view that the last two periods recognized a very high jump in gas concentration level especially in days 12 Nov. 2014 and 8 Dec. 2014. However, CUSUM chart showed within average distribution for the gas concentration during this year except the period from points 14 Dec. 2014 to 19 Dec. 2014.

From Figure 31 and Figure 32, EMWA viewed the alarming points 16 Jan. 2015 to 23 Jan. 2016, 17 Feb. 2015, 11 Mar. 2015 to 12 Mar. 2015, 31 Mar. 2015, 6 Apr. 2015 to 10 Apr. 2015, 20 Apr. 2015 to 23 Apr. 2015, 15 Jun. 2015 to 15 Jul. 2015, and 11 Dec. 2015 to 31 Dec. 2015. However, the CUSUM showed normal distribution within the year average.

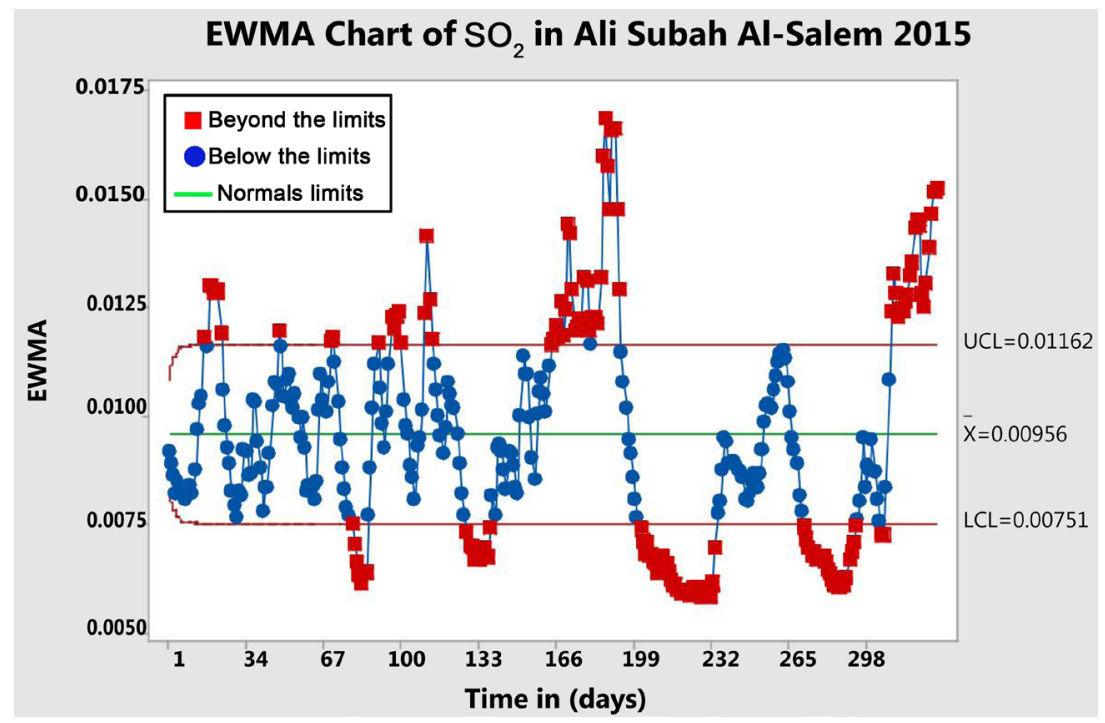

Figure 31. EWMA chart of $\mathrm{SO}_{2}$ in Ali Subah Al-Salem 2015.

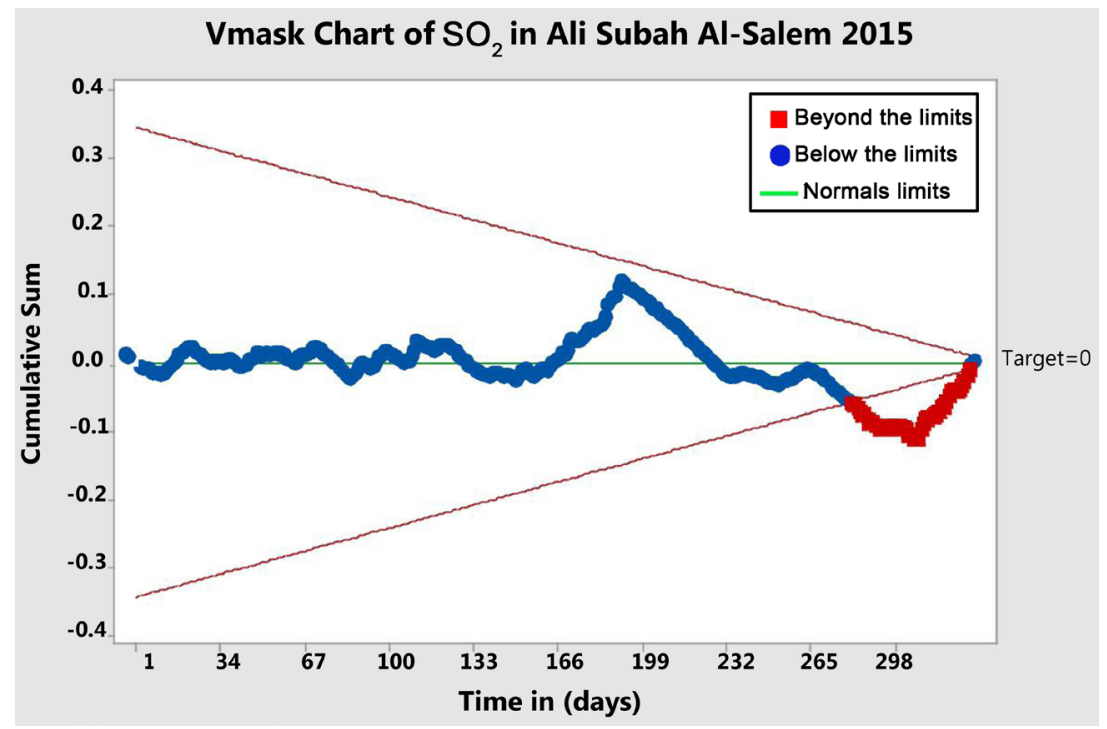

Figure 32. CUSUM chart of $\mathrm{SO}_{2}$ in Ali Subah Al-Salem 2015. 
From Figure 33 and Figure 34, it can be observed that EMWA showed alarming periods 13 Jan. 2016 to 19 Feb. 2016, 6 Jun. 2016 to 23 Jun. 2016, 29 Jun. 2016 to 25 Jul. 2016, 17 Aug. 2016 to 23 Aug. 2016, 6 Oct. 2016 to 7 Oct. 2016, and 21 Dec. 2016 to 26 Dec. 2016.EWMA showed a maximum out of control value in day $14 \mathrm{Jul}$. 2016. CUSUM showed the increasing distribution of $\mathrm{SO}_{2}$ concentration above the average level from point 9 Oct. 2016 to 2 Nov. 2016.

From Figure 35 and Figure 36, EMWA viewed the alarming points 1 Jan. 2017 to 2 Jan. 2017, 10 Jan. 2017 to 7 Feb. 2017, 9 Mar. 2017 to 10 Mar. 2017, 23 Apr. 2017 to 5 May 2017, 29 May 2017 to 30 Jun. 2017, and 26 Oct. 2017 to 12 Nov. 2017. The CUSUM draw one out-of-control region which is period from 28 May 2017 to 29 Aug. 2017.

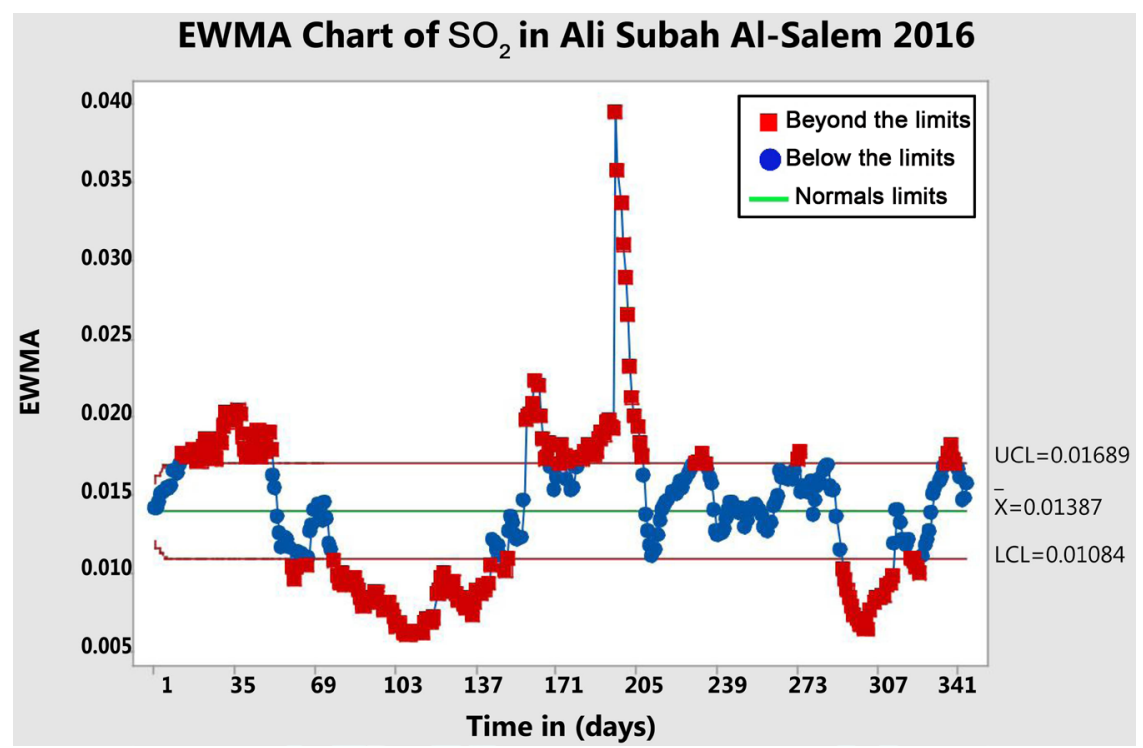

Figure 33. EWMA chart of $\mathrm{SO}_{2}$ in Ali Subah Al-Salem 2016.

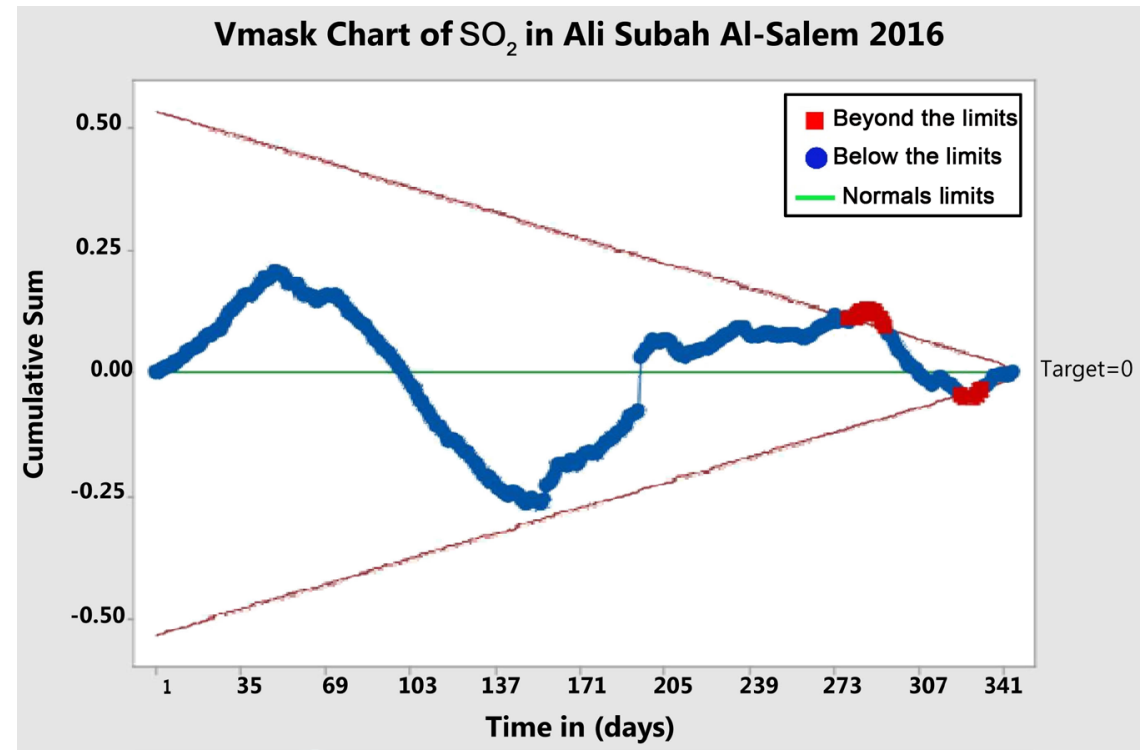

Figure 34. CUSUM chart of $\mathrm{SO}_{2}$ in Ali Subah Al-Salem 2016. 


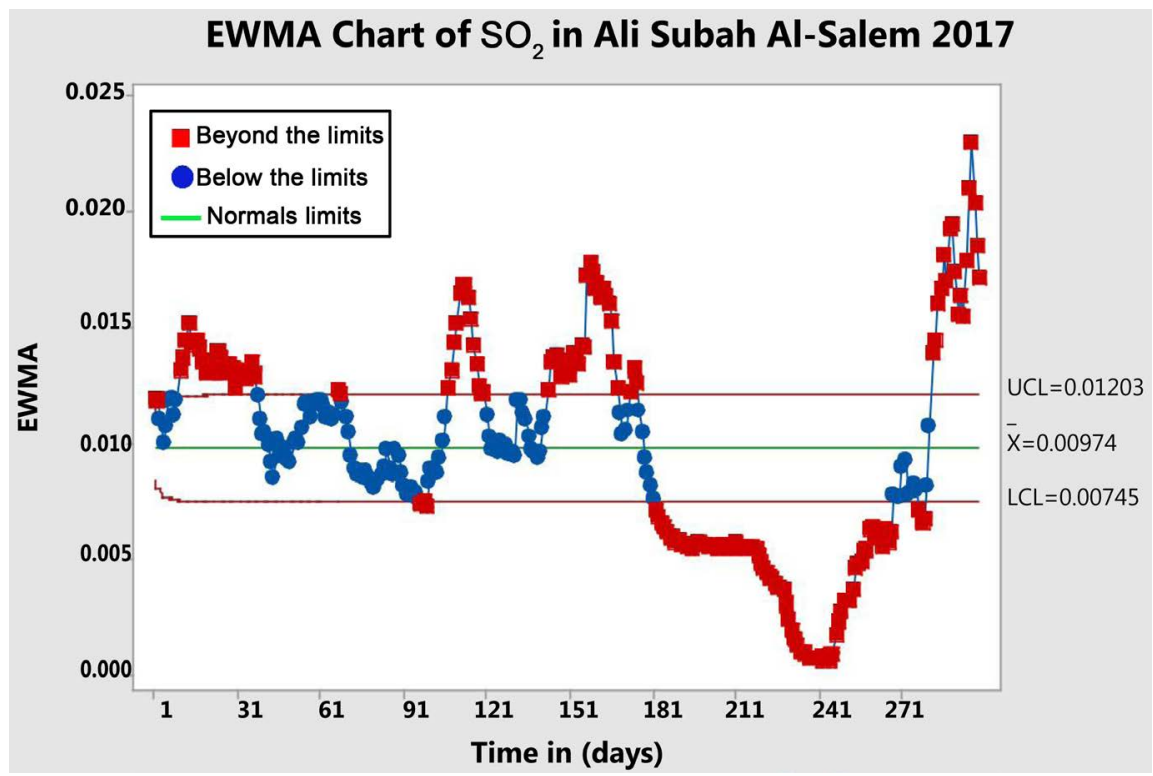

Figure 35. EWMA chart of $\mathrm{SO}_{2}$ in Ali Subah Al-Salem 2017.

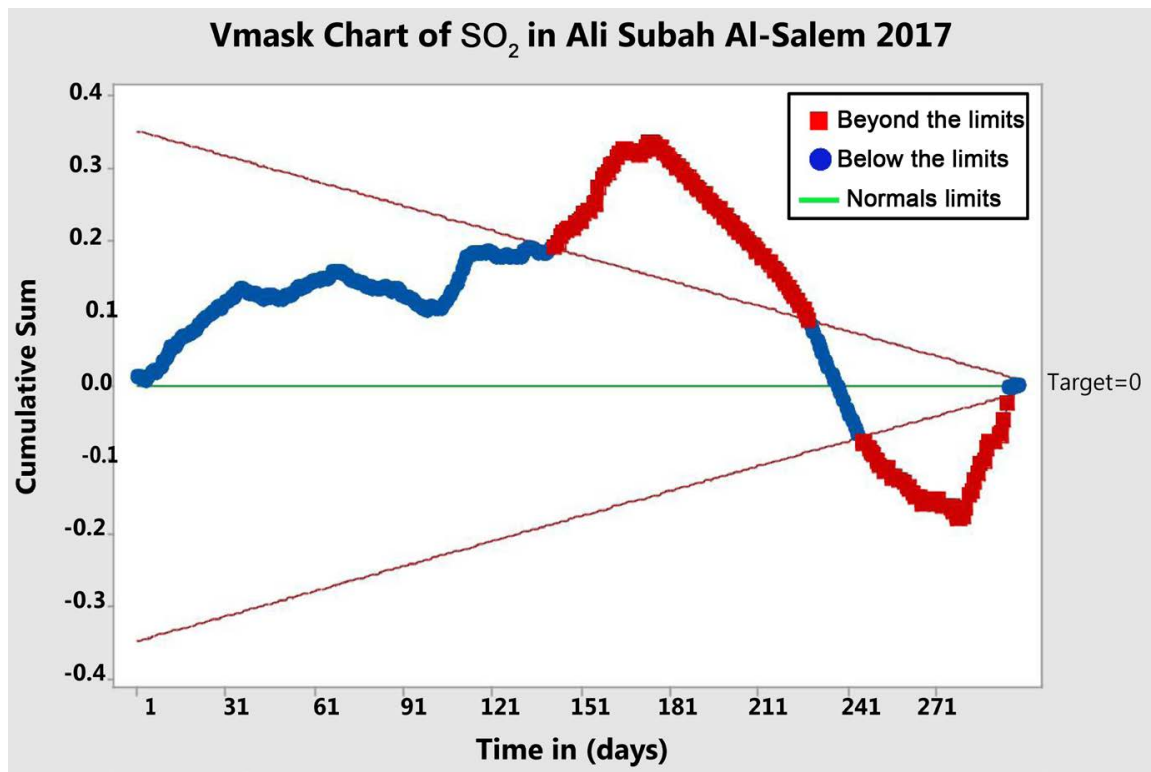

Figure 36. CUSUM chart of $\mathrm{SO}_{2}$ in Ali Subah Al-Salem 2017.

From Figure 37 and Figure 38, it can be observed that EMWA showed many intervals that exceed the standard level of $\mathrm{SO} 2$ during the 5 years. The highest concentration point is shown in point 14 Jul. 2016. CUSUM showed only one period of out-of-control distribution from points 6 Feb. 2017 to 9 Sep. 2017.

From Figure 39 and Figure 40, it can be observed that EWMA showed alarms at the points from 8 Jan. 2013 to 13 Jan. 2013, 7 Mar. 2013, 19 Mar. 2013, 21 May 2013 to 24 May 2013, 5 Jun. 2013 to 28 Jun. 2013, 5 July 2013 to 27 Jul. 2013, 5 Aug. 2013, and 18 Aug. 2013. CUSUM showed only the upper limit period from points 7 Jul. 2013 to 24 Dec. 2013 while the other locate within average distribution. 


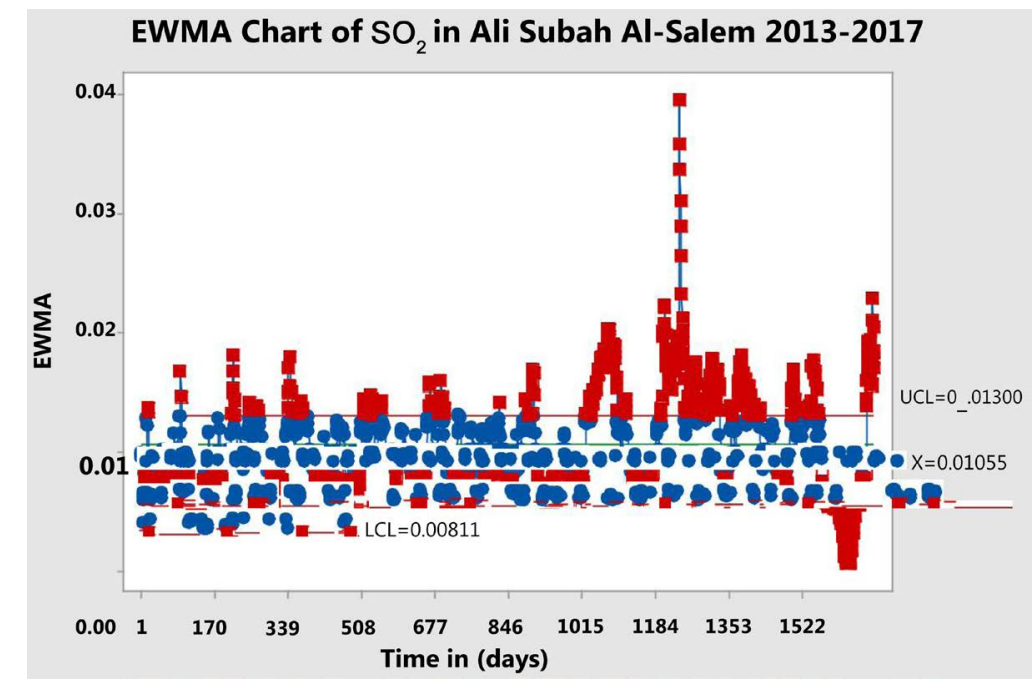

Figure 37. EWMA chart of $\mathrm{SO}_{2}$ in Ali Subah Al-Salem 2013-2017.

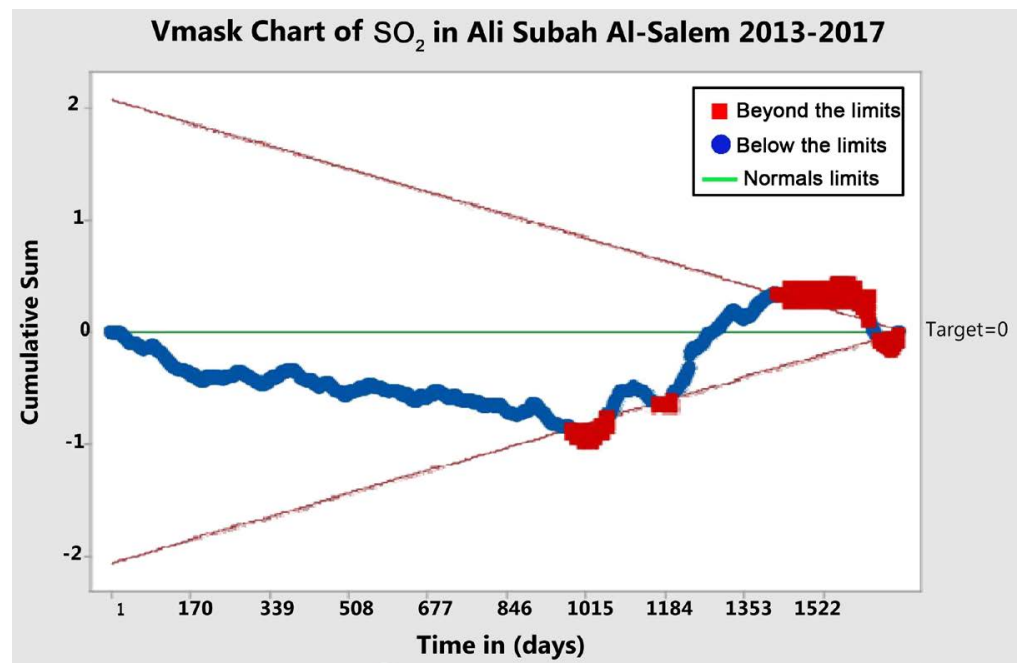

Figure 38. CUSUM chart of $\mathrm{SO}_{2}$ in Ali Subah Al-Salem 2013-2017.

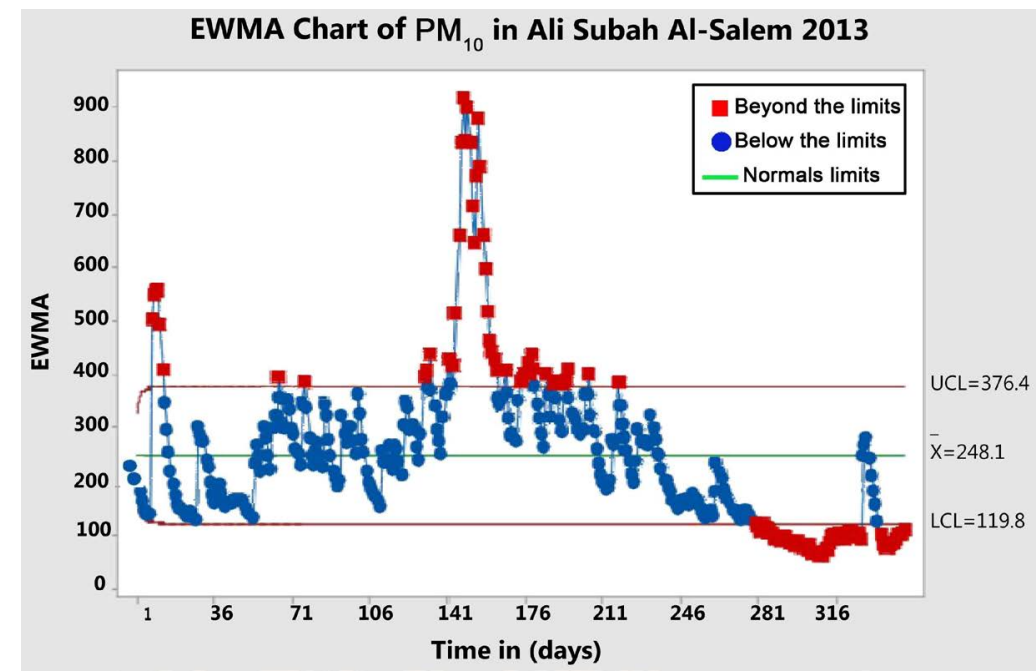

Figure 39. EWMA chart of $\mathrm{PM}_{10}$ in Ali Subah Al-Salem 2013. 


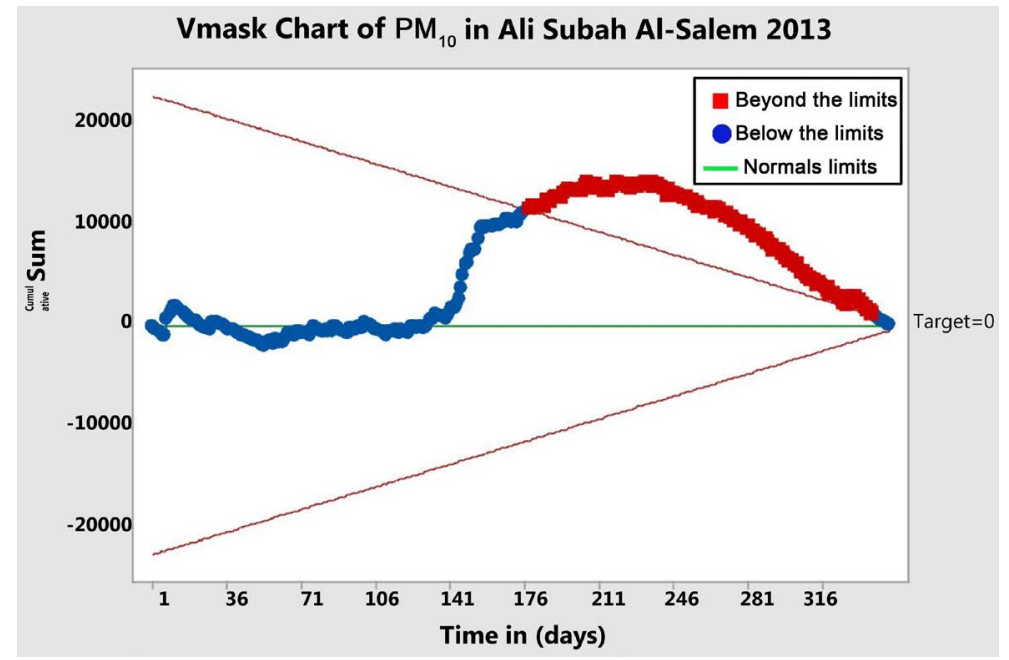

Figure 40. CUSUM chart of $\mathrm{PM}_{10}$ in Ali Subah Al-Salem 2013.

From Figure 41 and Figure 42, it can be observed that EMWA displayed alarms at the time period from 30 Mar. 2014 to 3 Apr. 2014, 30 Apr. 2014 to 13 May 2014, 12 Jun. 2014 to 26 Jun. 2014, 14 Jul. 2014 to 20 Jul. 2014, 28 Jul. 2014 to 29 Jul. 2014, 18 Aug. 2014 to 27 Aug. 2014, 29 Aug. 2014 to 6 Sep. 2014, 13 Oct. 2014 to 14 Oct. 2014, and 20 Oct. 2014 to 23 Oct. 2014. EMWA gives clear view that the period from 30 Apr. 2014 until 13 May 2014 had recognized a very high jump in gas concentration level specially in day 1 May 2014. However, CUSUM chart showed the only out of control period 13 Oct. 2014 to 23 Dec. 2014 while all other points were within average distribution for the gas concentration during this year.

From Figure 43 and Figure 44, it can be observed that periods 12 Feb. 2015 to 15 Feb. 2015, 17 Apr. 2015 to 27 Apr. 2015, 9 May 2015 to 10 May 2015, 23 May 2015 to 24 May 2015, 31 May 2015, 8 Jul. 2015 to 25 Jul. 2015, 1 Oct. 2015 to 12 Oct 2015, 22 Oct. 2015 to 25 Oct. 2015, and 2 Dec. 2015 showed increasing concentration upon the normal average, while the CUSUM showed one abnormal period points 18 Oct. 2015 to 24 Dec. 2015 that exceed the average distribution within the year.

From Figure 45 and Figure 46, it can be observed that EMWA showed 4 alarming periods 5 May 2016 to 16 May 2016, 15 Jun. 2016 to 6 Jul. 2016, 10 Jul. 2016 to 29 Jul. 2016, and 1 Oct. 2016 to 4 Oct. 2016. CUSUM showed the increasing distribution of $\mathrm{CO}$ concentration above the average level from point 30 Sep. 2016 to 17 Oct. 2016.

From Figure 47 and Figure 48, it can be concluded that EMWA viewed the alarming points 27 Jan. 2017, 18 Feb. 2017, 13 Mar. 2017 to 17 Mar. 2017, 31 May 2017 to 2 Jun. 2017, 21 Jun. 2017 to 27 Jun. 2017, 1 Jul. 2017, 8 Jul. 2017 to 10 Jul. 2017, 16 Aug. 2017 to 21 Aug. 2017, 11 Oct. 2017, 17 Oct. 2017, 20 Oct. 2017, 23 Oct. 2017, 27 Oct. 2017, and 31 Oct. 2017 to 12 Nov. 2017. EMWA showed the highest out of control point at 31 Oct. 2017. The CUSUM draw had no out-of-control region. 


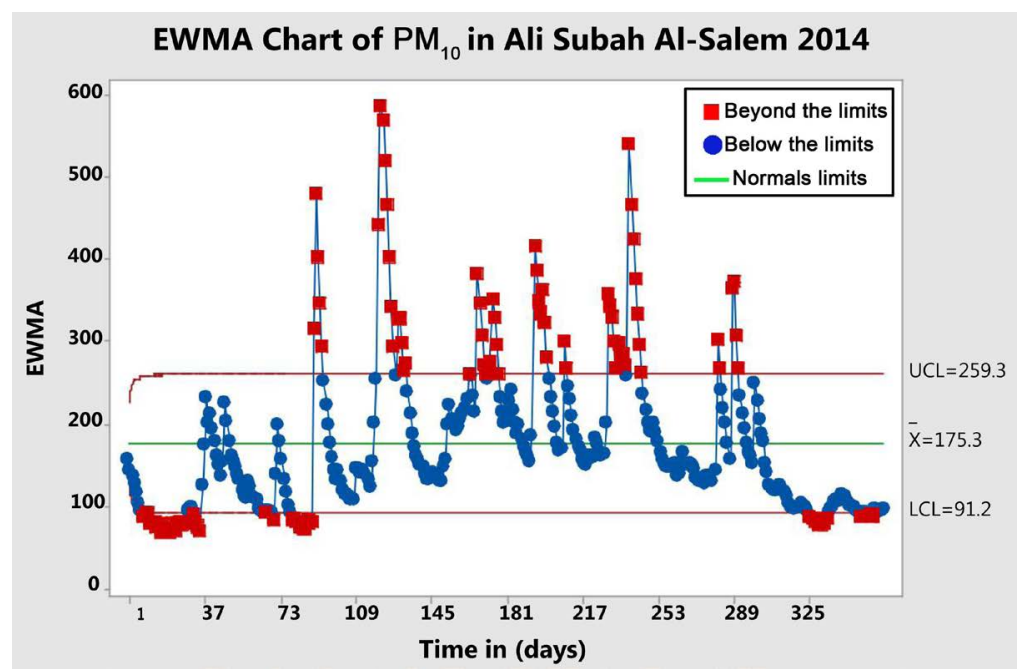

Figure 41. EWMA chart of $\mathrm{PM}_{10}$ in Ali Subah Al-Salem 2014.

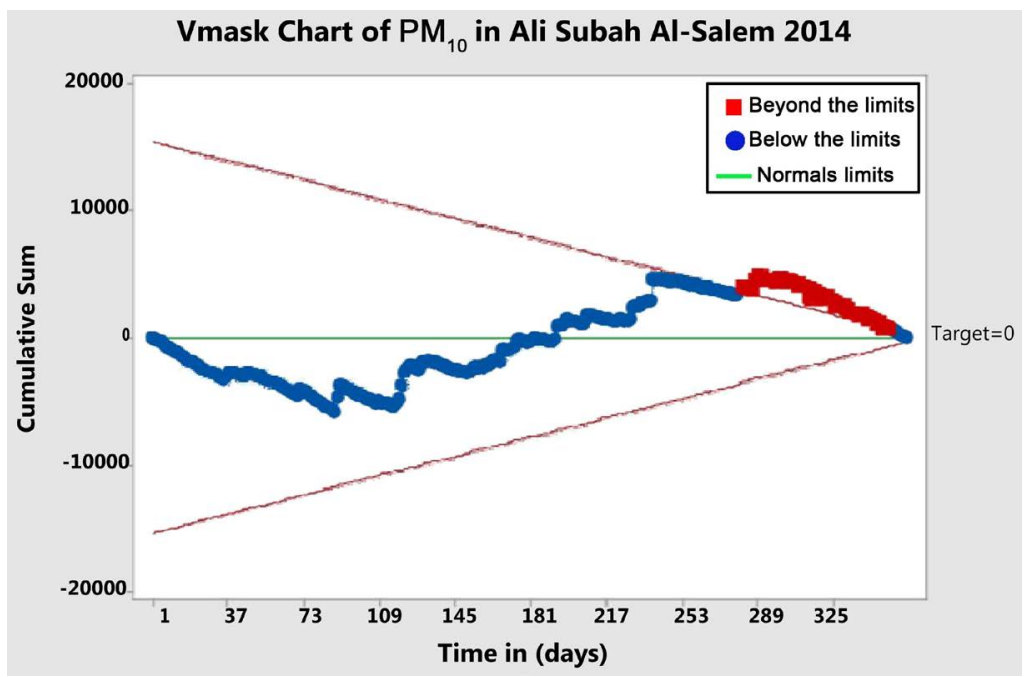

Figure 42. CUSUM chart of $\mathrm{PM}_{10}$ in Ali Subah Al-Salem 2014.

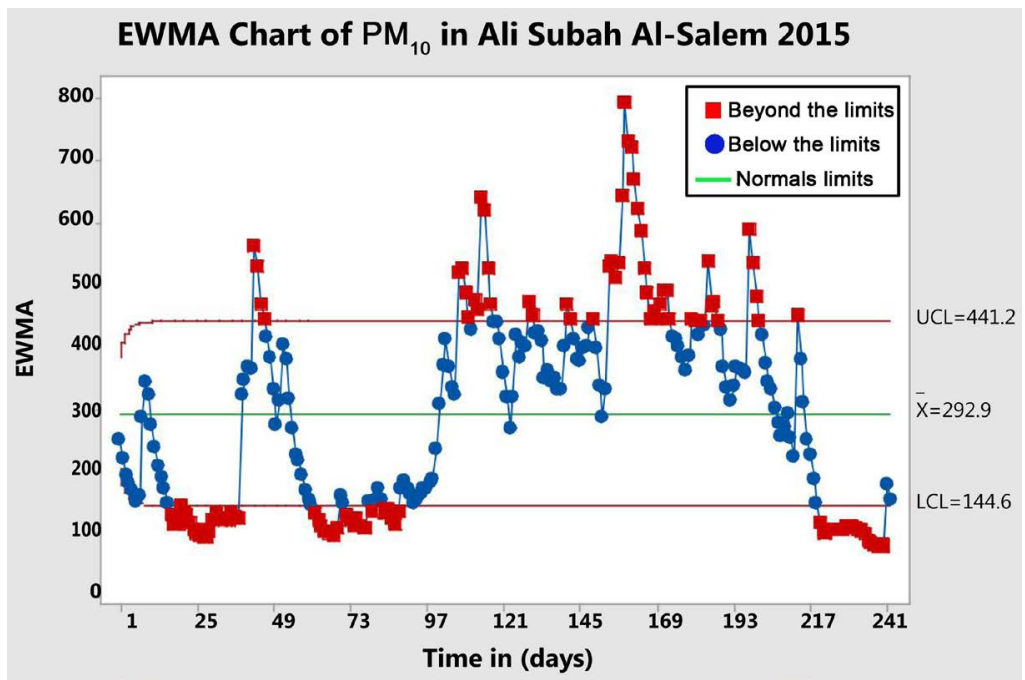

Figure 43. EWMA chart of $\mathrm{PM}_{10}$ in Ali Subah Al-Salem 2015. 


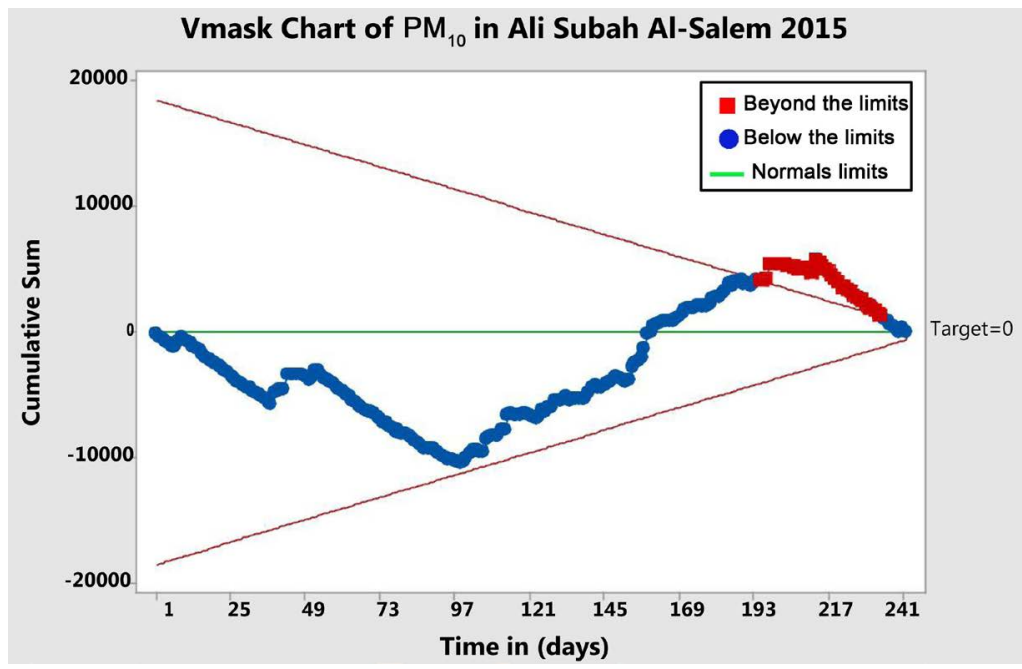

Figure 44. CUSUM chart of $\mathrm{PM}_{10}$ in Ali Subah Al-Salem 2015.

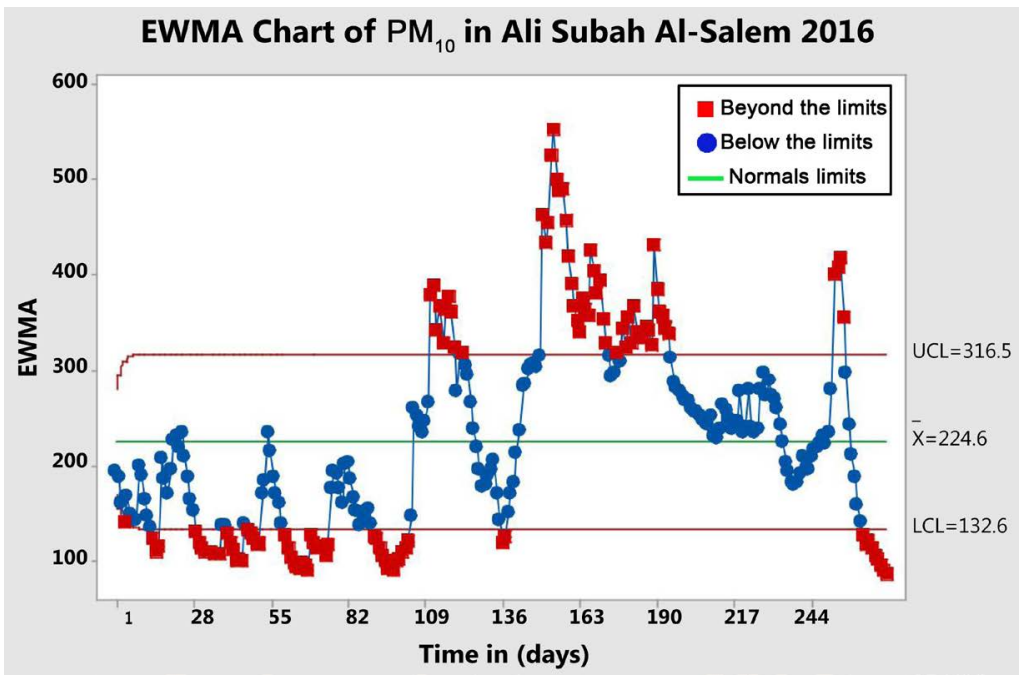

Figure 45. EWMA chart of $\mathrm{PM}_{10}$ in Ali Subah Al-Salem 2016.

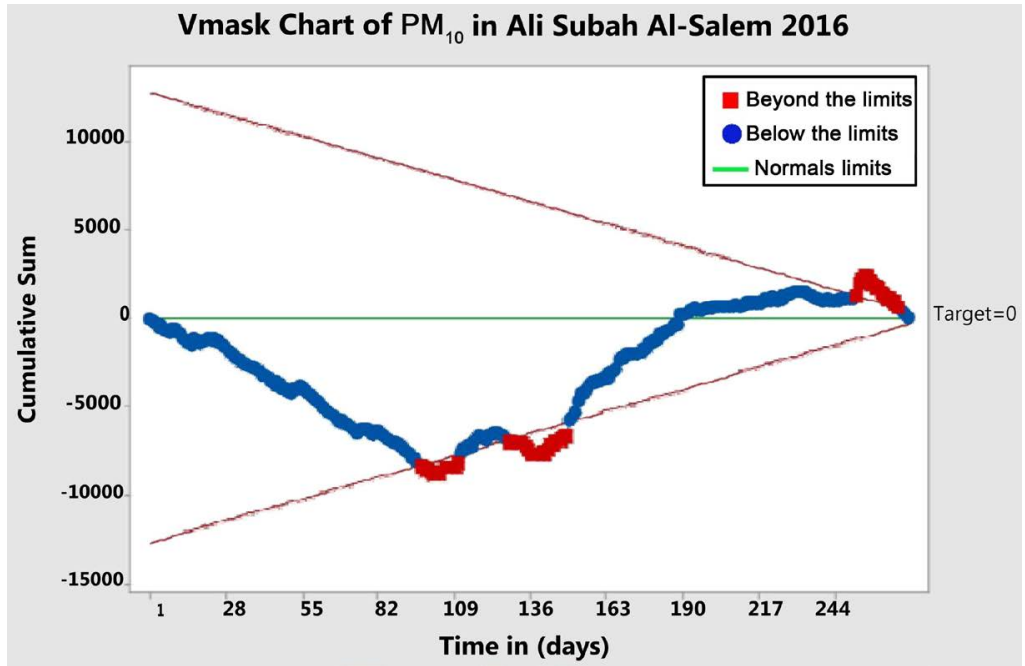

Figure 46. CUSUM chart of $\mathrm{PM}_{10}$ in Ali Subah Al-Salem 2016. 


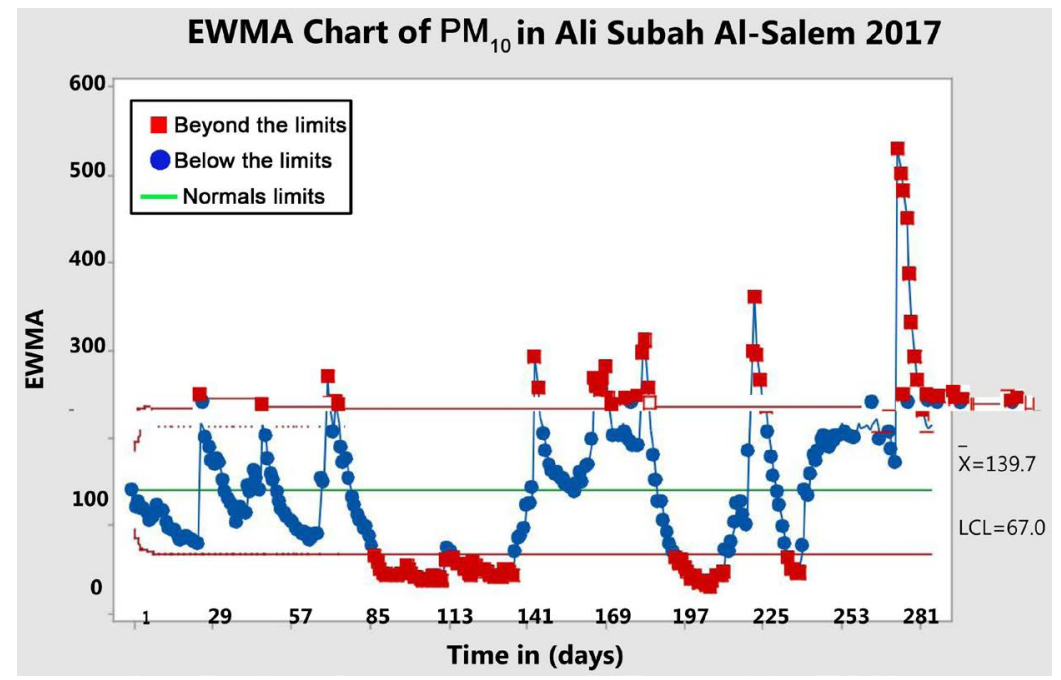

Figure 47. EWMA chart of $\mathrm{PM}_{10}$ in Ali Subah Al-Salem 2017.

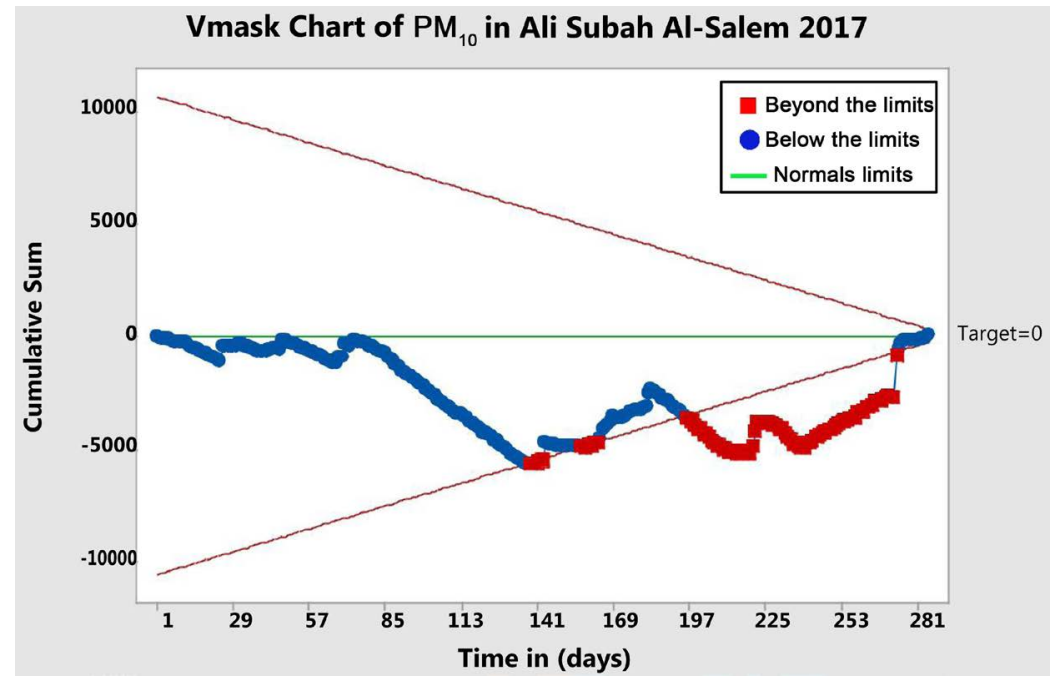

Figure 48. CUSUM chart of $\mathrm{PM}_{10}$ in Ali Subah Al-Salem 2017.

From Figure 49 and Figure 50, it can be observed that EMWA showed many intervals that exceed the standard level of $\mathrm{CO}$ during the 5 years. The highest concentration points occur in days 9 Jun. 2013 and 11 Jul. 2015. CUSUM showed only one period of out-of-control distribution from period 9 Jul. 2016 to 1 May 2017.

From Figure 51 and Figure 52, it can be observed that EWMA showed alarms at the points from 7 Aug. 2013 to 26 Nov. 2013 and 30 Nov. 2013 to 30 Dec. 2013. CUSUM showed no upper limit period and all the points act within average distribution.

From Figure 53 and Figure 54, it can be observed that EMWA displayed alarms at the time period from 12 Jan. 2014 to 3 Feb. 2014, 15 Mar. 2014 to 16 Mar. 2014, 9 Jun. 2014, 22 Jul. 2014, 9 Nov. 2014, 11 Nov. 2014 to 15 Nov. 2014, 20 Nov. 2014 to 11 Dec. 2014, 12 Dec 2014 to 21 Dec. 2014, and 24 Dec. 2014 to 31 Dec. 2014. EMWA gives clear view that the period from 20 Nov. 2014 until 11 
EWMA Chart of $\mathrm{PM}_{10}$ in Ali Subah Al-Salem 2013-2017

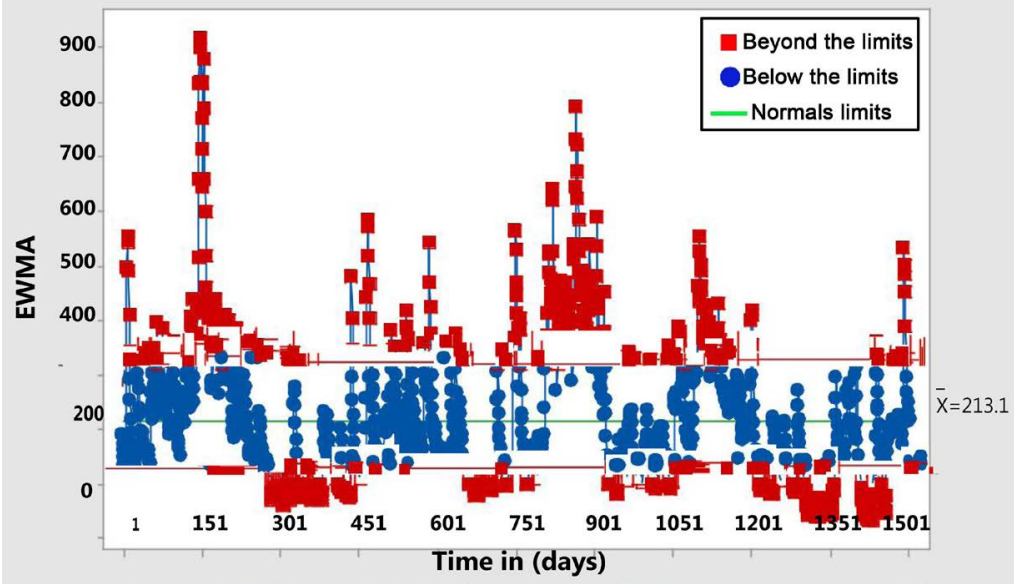

Figure 49. CUSUM chart of $\mathrm{PM}_{10}$ in Ali Subah Al-Salem 2013-2017.

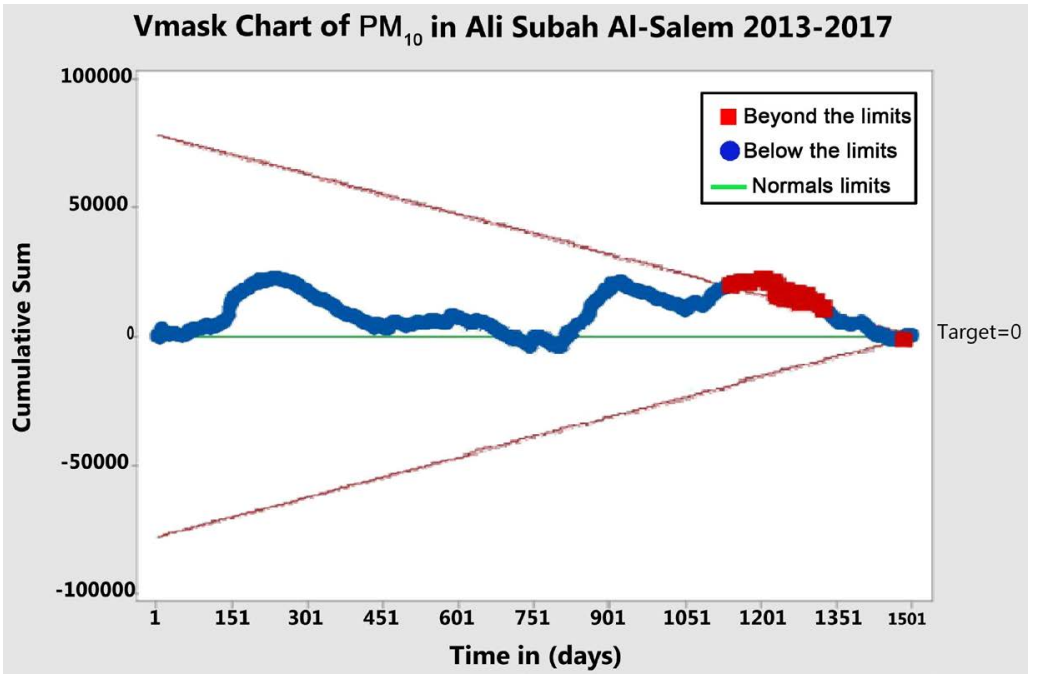

Figure 50. CUSUM chart of $\mathrm{PM}_{10}$ in Ali Subah Al-Salem 2013-2017.

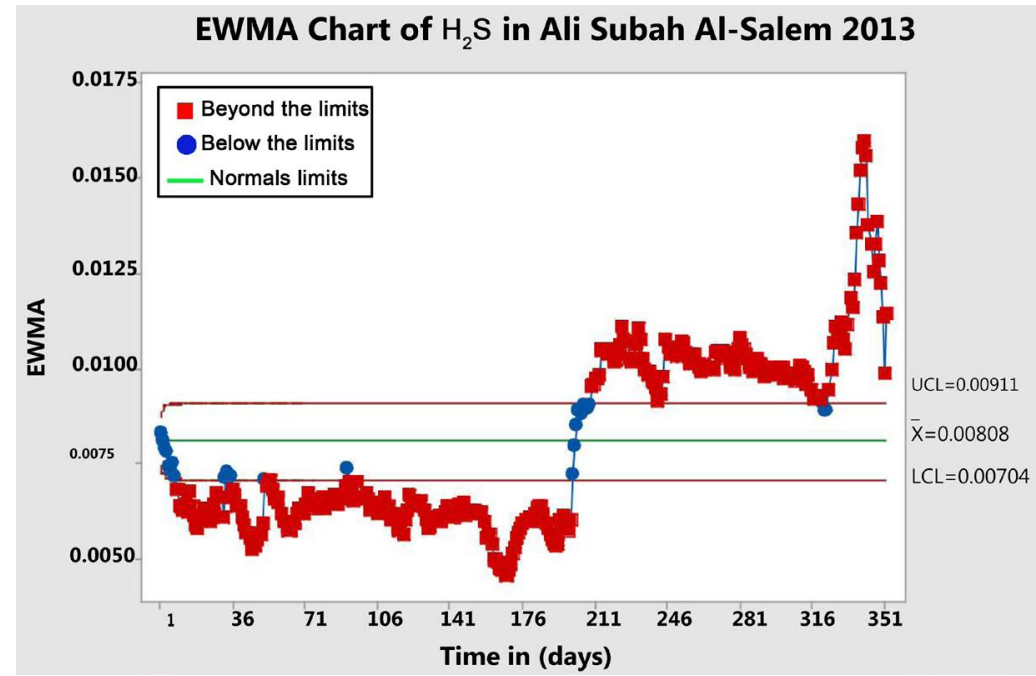

Figure 51. EWMA chart of $\mathrm{H}_{2} \mathrm{~S}$ in Ali Subah Al-Salem 2013. 


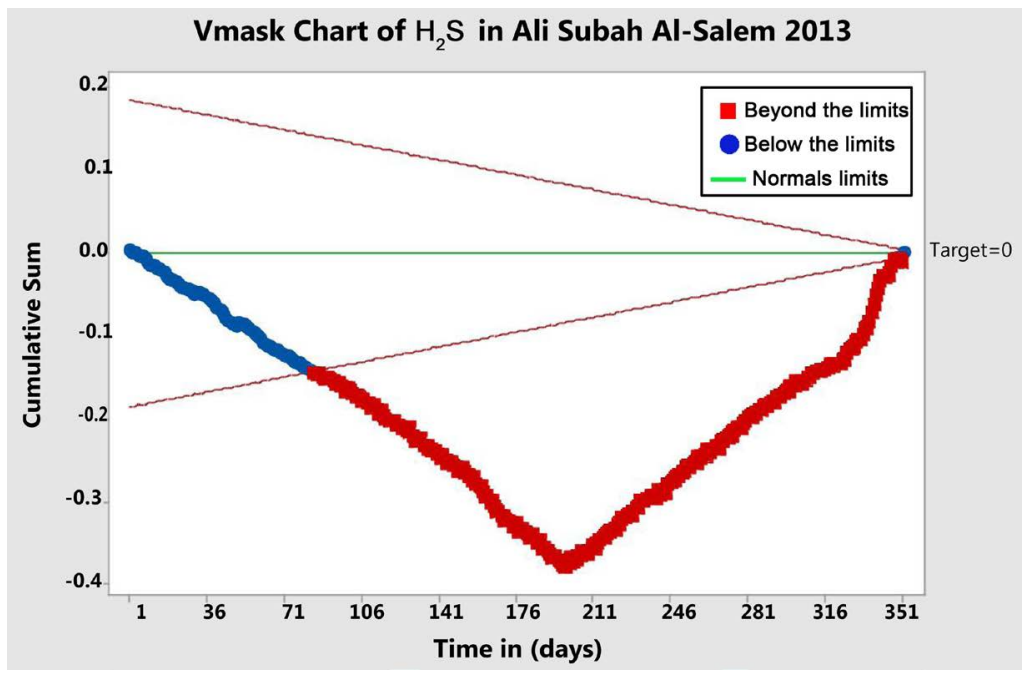

Figure 52. CUSUM chart of $\mathrm{H}_{2} \mathrm{~S}$ in Ali Subah Al-Salem 2013.

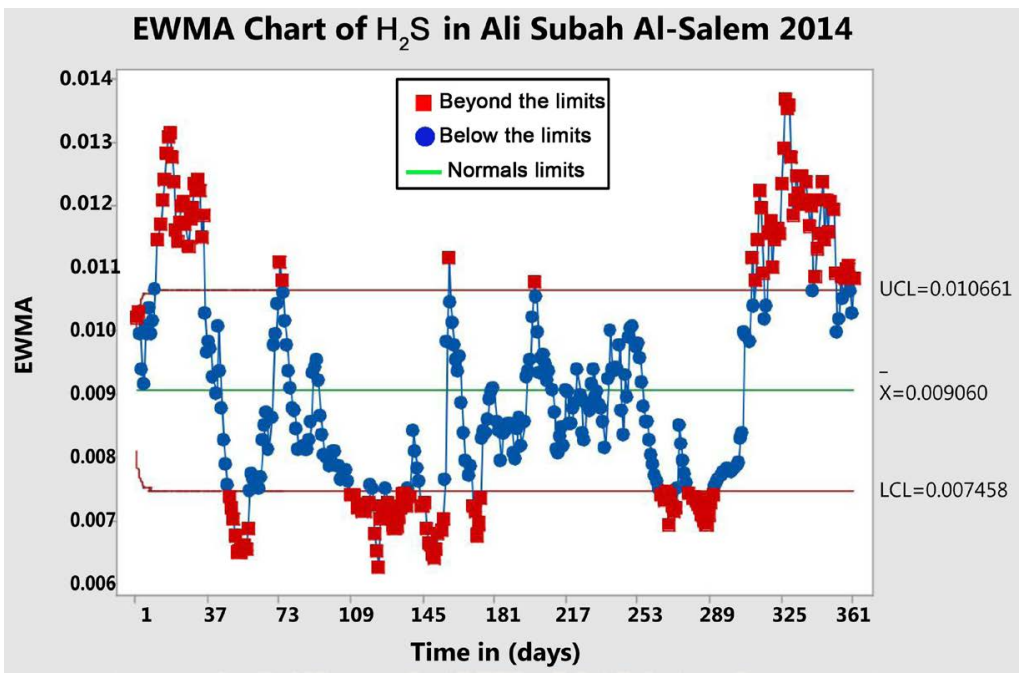

Figure 53. EWMA chart of $\mathrm{H}_{2} \mathrm{~S}$ in Ali Subah Al-Salem 2014.

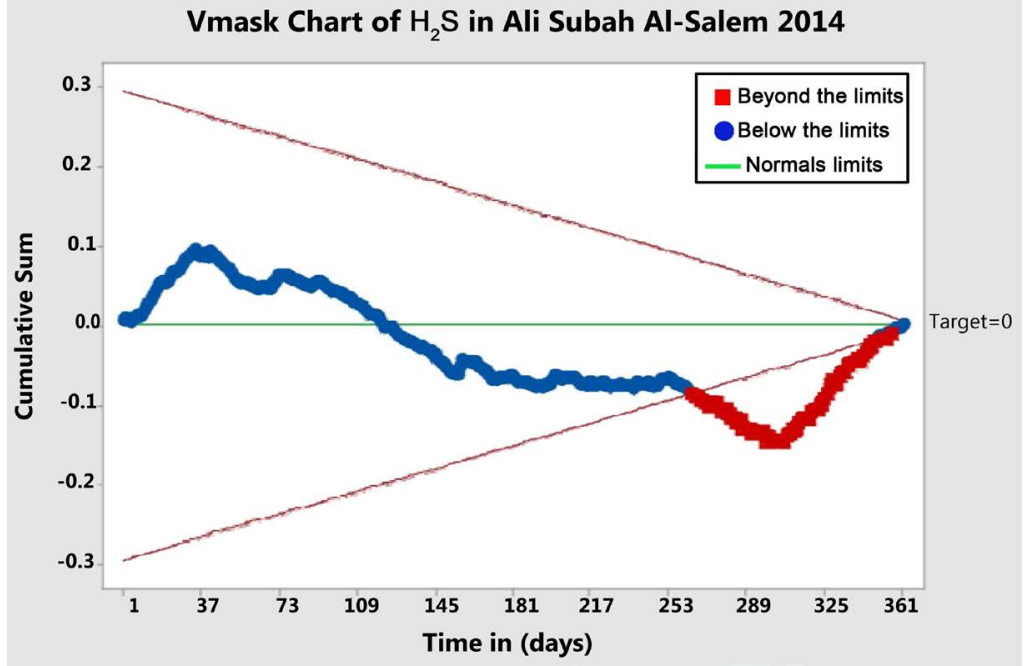

Figure 54. CUSUM chart of $\mathrm{H}_{2} \mathrm{~S}$ in Ali Subah Al-Salem 2014. 
Dec. 2014 had recognized a very high jump in gas concentration level specially in point 26 Nov. 2014. However, CUSUM chart showed within average distribution for the gas concentration during this year.

From Figure 55 and Figure 56, it can be observed that periods 19 Jan. 2015 to 22 Jan. 2015, 1 Apr. 2015, 14 Jul. 2015 to 23 Jul. 2015, 5 Sep. 2015 to 23 Sep. 2015, and 16 Dec. 2015 to 31 Dec. 2015 showed increasing concentration upon the normal average, while the CUSUM showed normal distribution within the year average.

From Figure 57 and Figure 58, it can be observed that EMWA showed alarming periods 7 Jan. 2016 to 16 Jan. 2016, 21 Jan 2016 to 27 Jan 2016, 14 Jul. 2016 to 28 Jul. 2016, 6 Aug. 2016 to 25 Aug. 2016, 18 Sep. 2016 to 7 Oct. 2016, 11 Oct. 2016 to 20 Oct. 2016, and 20 Dec. 2016 to 30 Dec. 2016. CUSUM showed no increasing distribution of $\mathrm{CO}$ concentration above the average level.

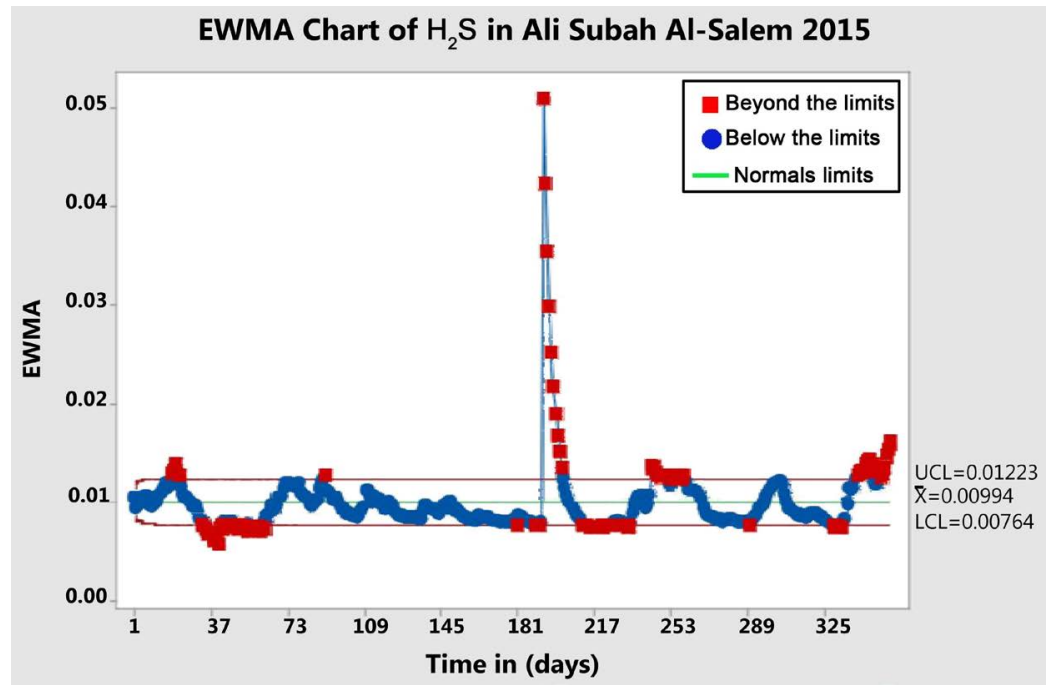

Figure 55. EWMA chart of $\mathrm{H}_{2} \mathrm{~S}$ in Ali Subah Al-Salem 2015.

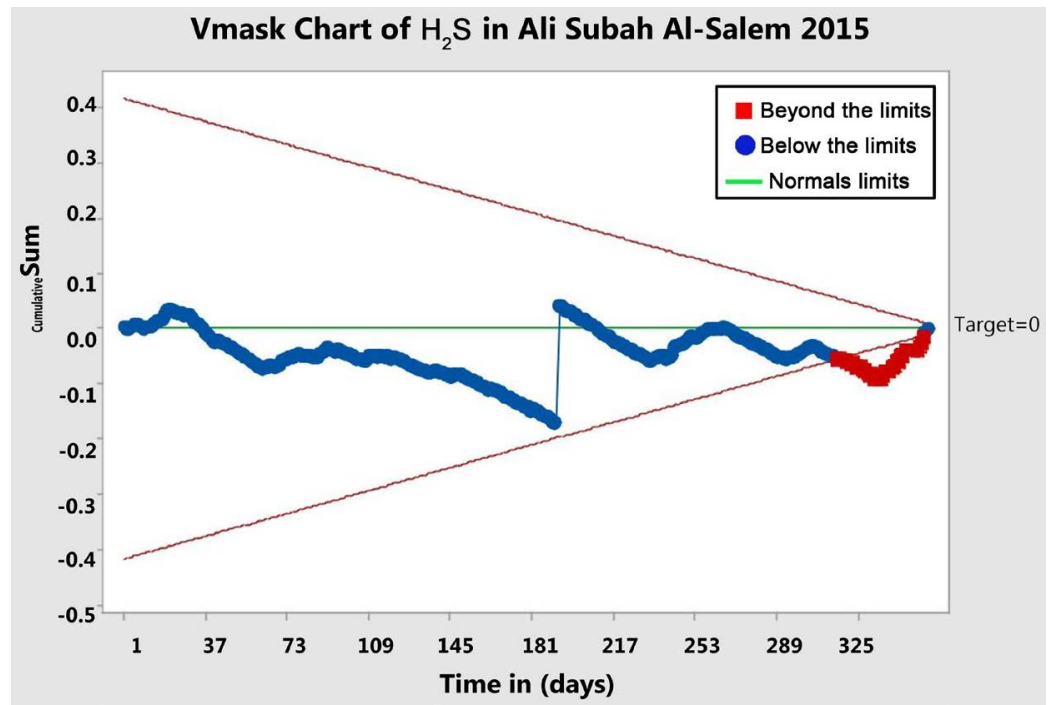

Figure 56. CUSUM chart of $\mathrm{H}_{2} \mathrm{~S}$ in Ali Subah Al-Salem 2015. 


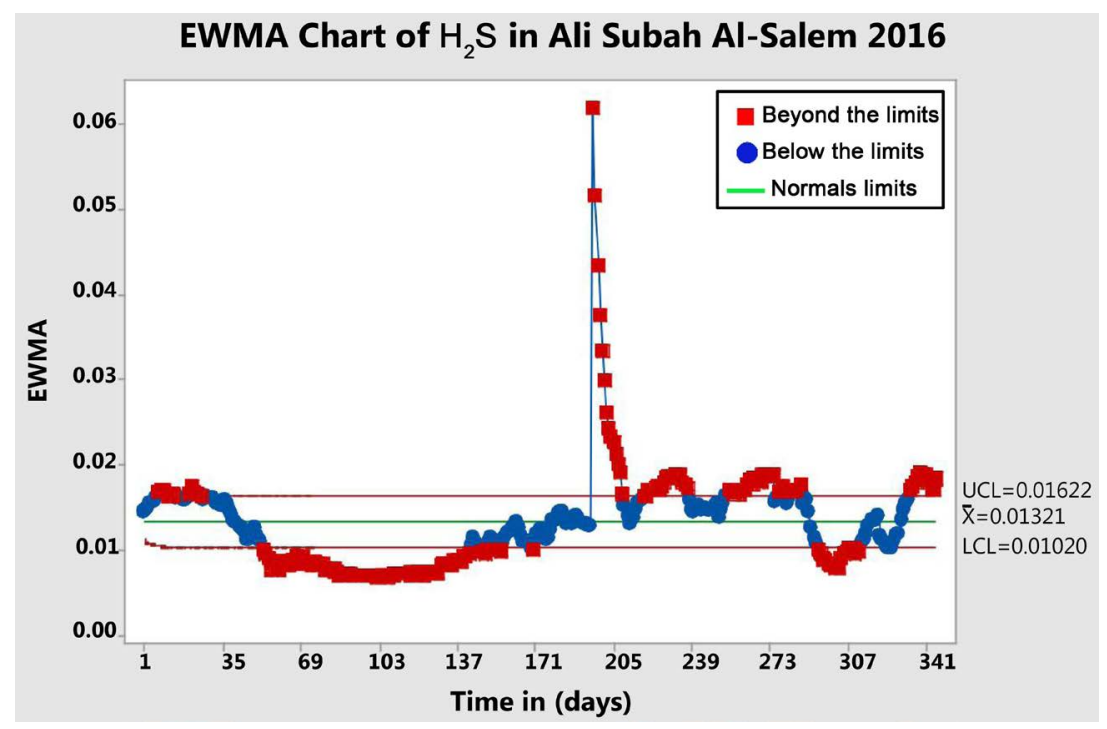

Figure 57. EWMA chart of $\mathrm{H}_{2} \mathrm{~S}$ in Ali Subah Al-Salem 2016.

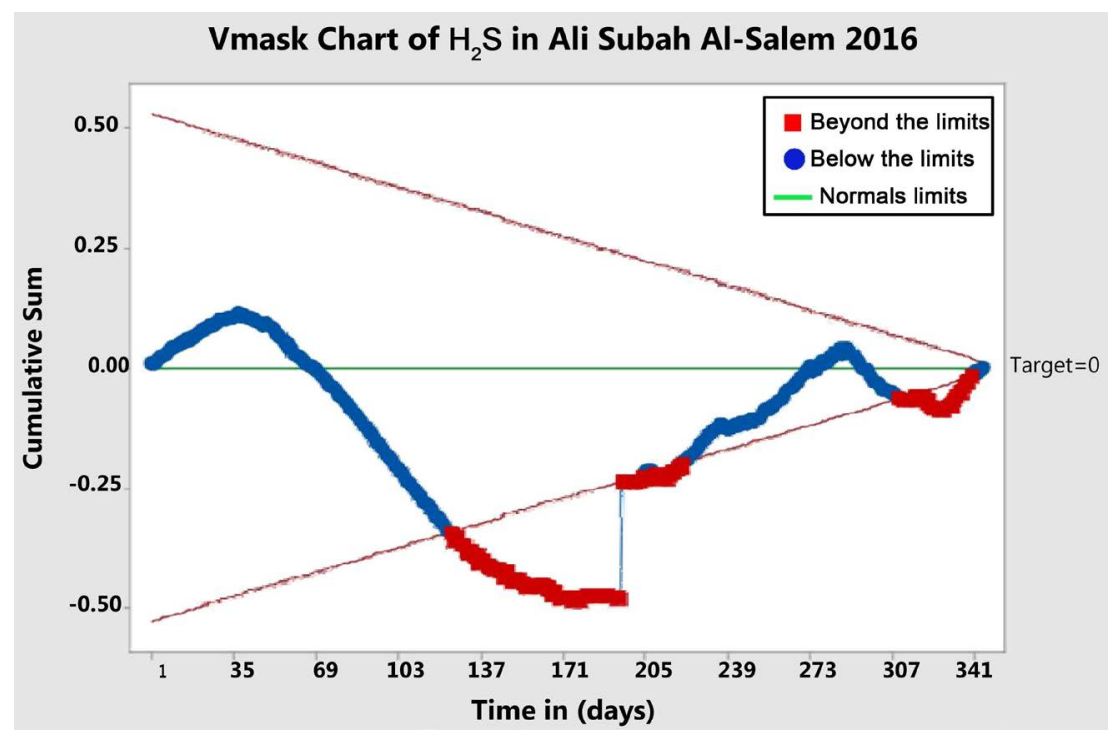

Figure 58. CUSUM chart of $\mathrm{H}_{2} \mathrm{~S}$ in Ali Subah Al-Salem 2016.

From Figure 59 and Figure 60, it can be conluded that EMWA viewed one alarming period from 20 Apr. 2017 to from 18 May 2017. The CUSUM draw out-of-control region from 28 Apr. 2017 to 28 Jul. 2017.

From Figure 61 and Figure 62, it can be observed that EMWA showed many intervals that exceed the standard level of $\mathrm{CO}$ during the 5 years. These intervals are the points 12 Dec. 2013 to 2 Feb. 2014, 14 Nov. 2014 to 17 Dec. 2014, 19 Jan. 2015 to 22 Jan. 2015, 1 Apr. 2015, 14 Jul. 2015 to 24 Jul. 2015, 5 Sep. 2015 to 23 Sep. 2015, 10 Nov. 2015, 15 Dec. 2015 to 18 Feb. 2016, 8 Jun. 2016 to -1361 , and 1386-1447. EMWA recognized that the period from 1230 until 31 Oct. 2016 had a very high jump in gas concentration level specially in day 14 Jul. 2016. CUSUM showed only one period of out-of-control distribution from 31 Dec. 2016 to 26 Jul. 2017. 


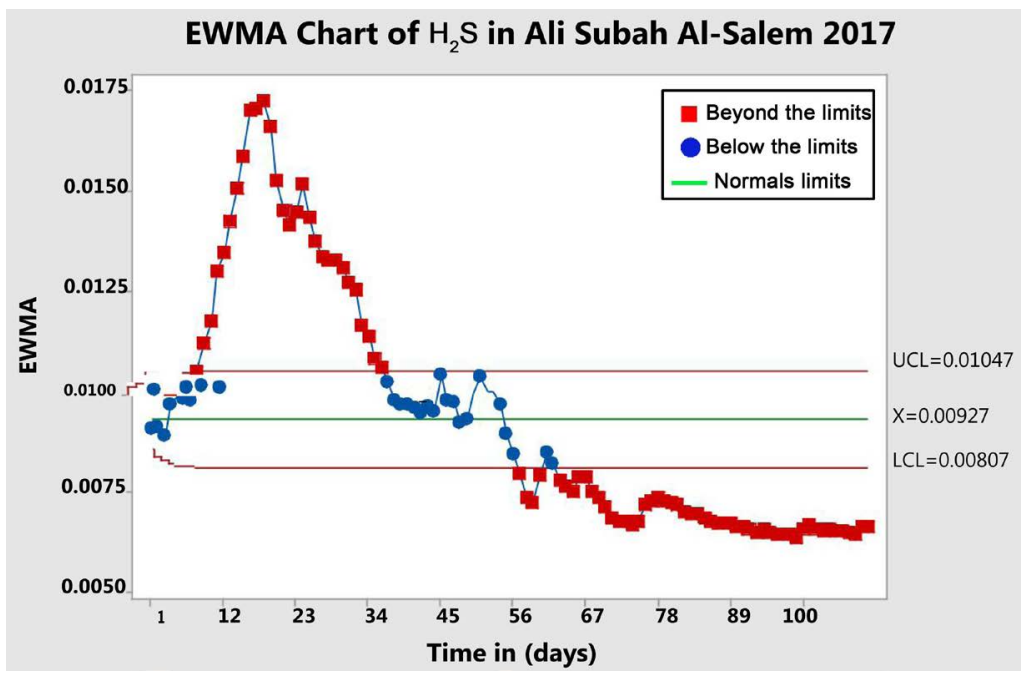

Figure 59. EWMA chart of $\mathrm{H}_{2} \mathrm{~S}$ in Ali Subah Al-Salem 2017.

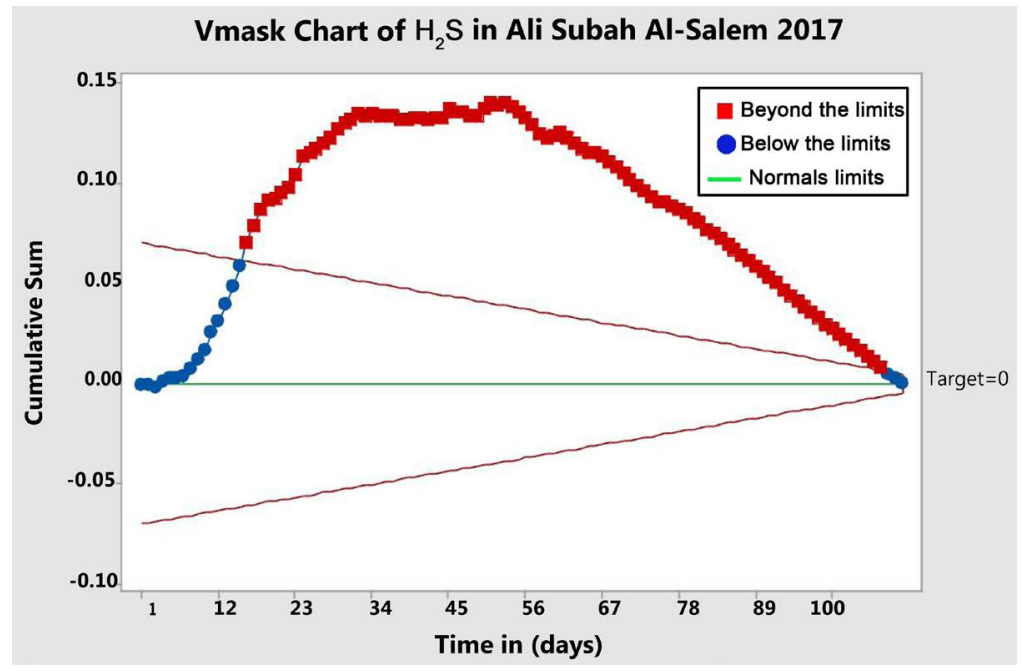

Figure 60. CUSUM chart of $\mathrm{H}_{2} \mathrm{~S}$ in Ali Subah Al-Salem 2017.

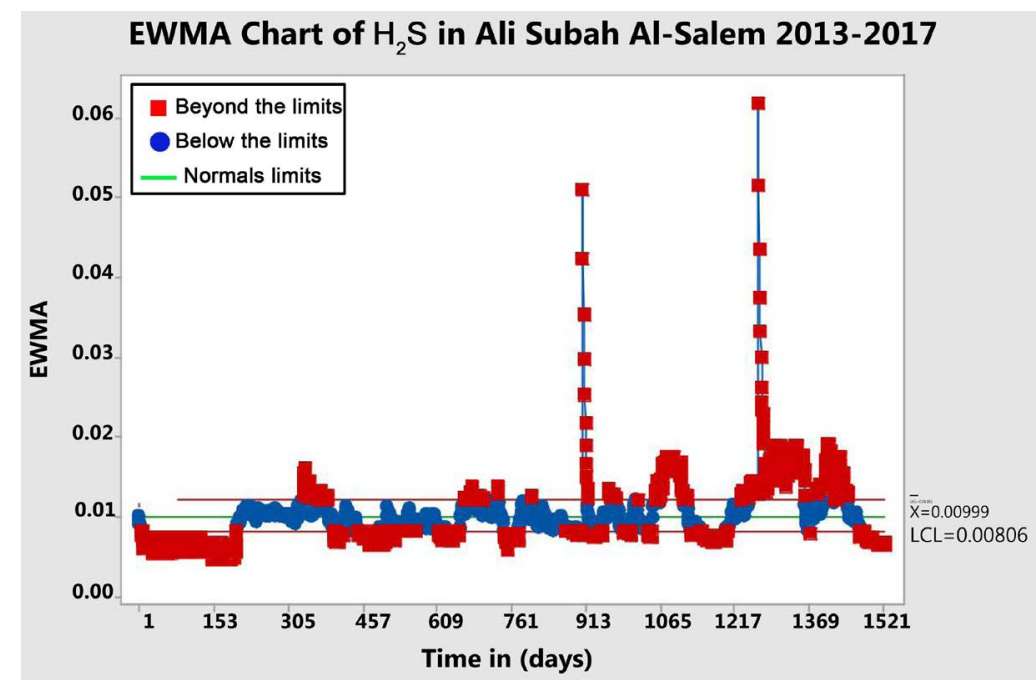

Figure 61. EWMA chart of $\mathrm{H}_{2} \mathrm{~S}$ in Ali Subah Al-Salem 2013-2017. 


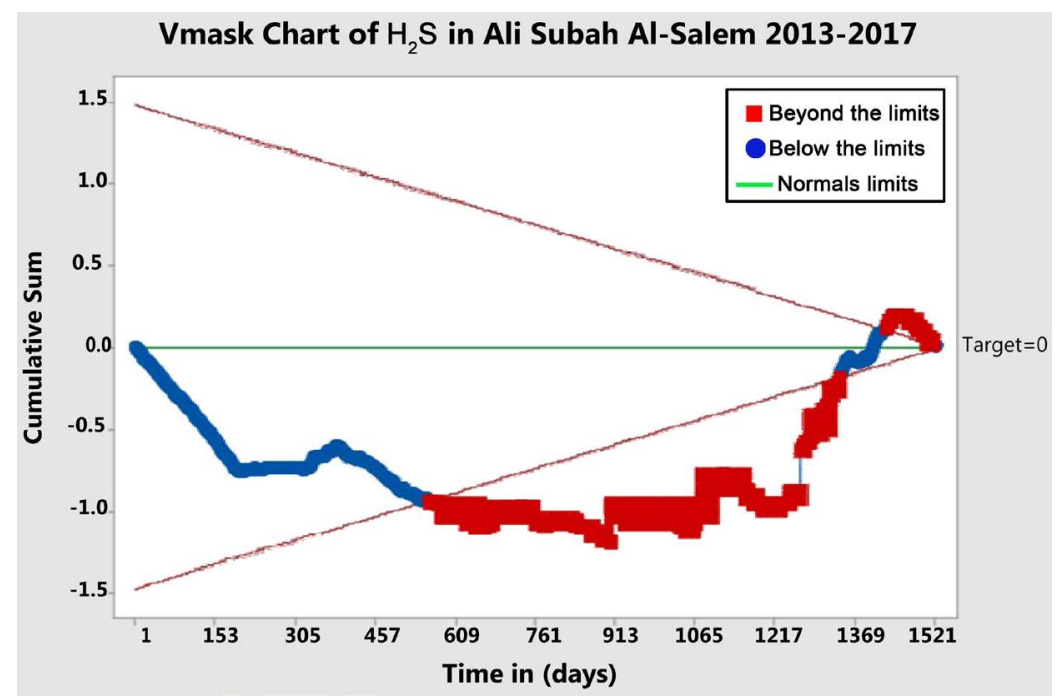

Figure 62. CUSUM chart of $\mathrm{H}_{2} \mathrm{~S}$ in Ali Subah Al-Salem 2013-2017.

From Figure 63 and Figure 64, it can be observed that EWMA showed alarms at the days 2 Jan. 2013, 7 Jan. 2013 to 8 Jan. 2013, 11 Aug. 2013 to 24 Sep. 2013, 2 Oct. 2013 to 8 Oct. 2013, 28 Oct. 2013 to 17 Nov. 2013, 9 Dec. 2013, and 27 Dec. 2013 to 31 Dec. 2013. CUSUM showed no upper limit period and the point locate within average distribution.

From Figure 65 and Figure 66, it can be concluded that EMWA displayed alarms at the time period from 3 Jan. 2014 to 4 Jan. 2014, 9 Jan. 2014 to 11 Jan. 2014, 15 Jan. 2014 to 16 Jan. 2014, 17 Aug. 2014 to 12 Sep. 2014, 26 Sep. 2014 to 8 Oct. 2014, 10 Oct. 2014 to 17 Oct. 2014, 24 Oct. 2014 to 3 Nov. 2014, 12 Nov. 2014 to 14 Nov. 2014, 7 Dec. 2014 to 13 Dec. 2014, and 27 Dec. 2014. However, CUSUM chart showed no exceed concentration values and all points were within average distribution for the gas concentration during this year.

From Figure 67 and Figure 68, it can be observed that periods 31 Mar. 2015 to 2 Apr. 2015, 4 Apr. 2015 to 10 May 2015, 12 May 2015 to 13 May 2015, 17 May 2015 to 1 Jun. 2015, 25 Jul. 2015 to 1 Aug. 2015, 30 Aug. 2015, 5 Nov. 2015, and 6 Dec. 2015 to 7 Dec. 2015 showed increasing concentration upon the normal average, while the CUSUM showed only one out of control region from 30 Oct. 2015 to 30 Dec. 2015. Otherwise, points were within the year average.

From Figure 69 and Figure 70, it can be observed that EMWA showed alarming periods 6 Mar. 2016 to 24 Mar. 2016, 31 Mar. 2016, and 3 Apr. 2016. However, CUSUM showed no abnormal increasing in distribution of CO concentration above the average level.

From Figure 71 and Figure 72, it can be observed that EMWA viewed the alarming points 14 Apr. 2017 to 28 Apr. 2017. The CUSUM chart had no out-of-control region.

From Figure 73 and Figure 74, it can be observed that EMWA showed many intervals that exceed the standard level of $\mathrm{CO}$ during the 5 years. It gives clear vision that there is a big jump in the concentration of NMHC in points 20 Aug. 
EWMA Chart of NMHC in Ali Subah AI-Salem 2013

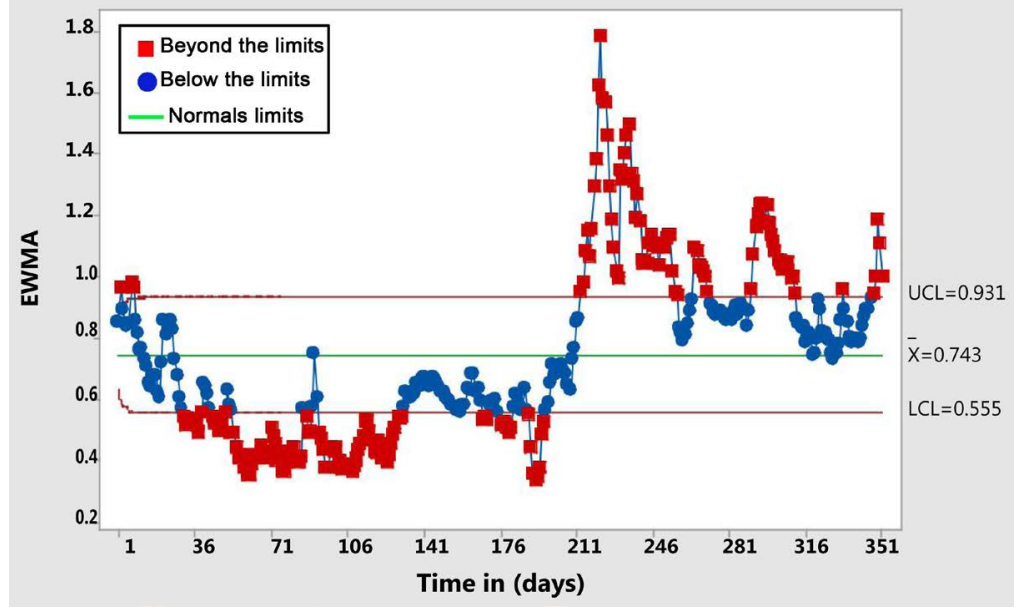

Figure 63. EWMA chart of NMHC in Ali Subah Al-Salem 2013.

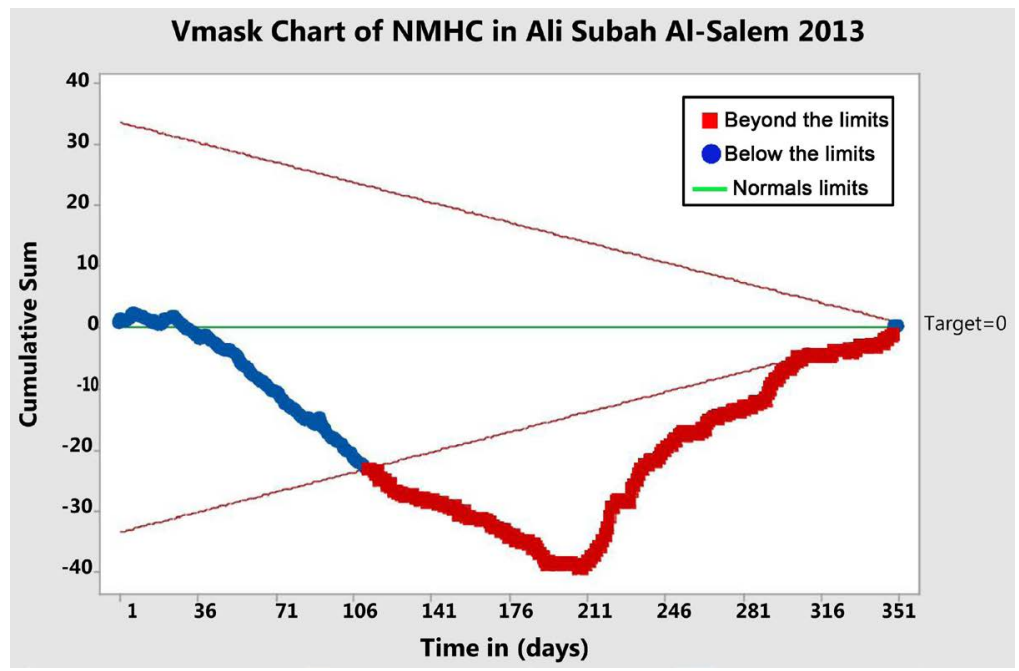

Figure 64. CUSUM chart of NMHC in Ali Subah Al-Salem 2013.

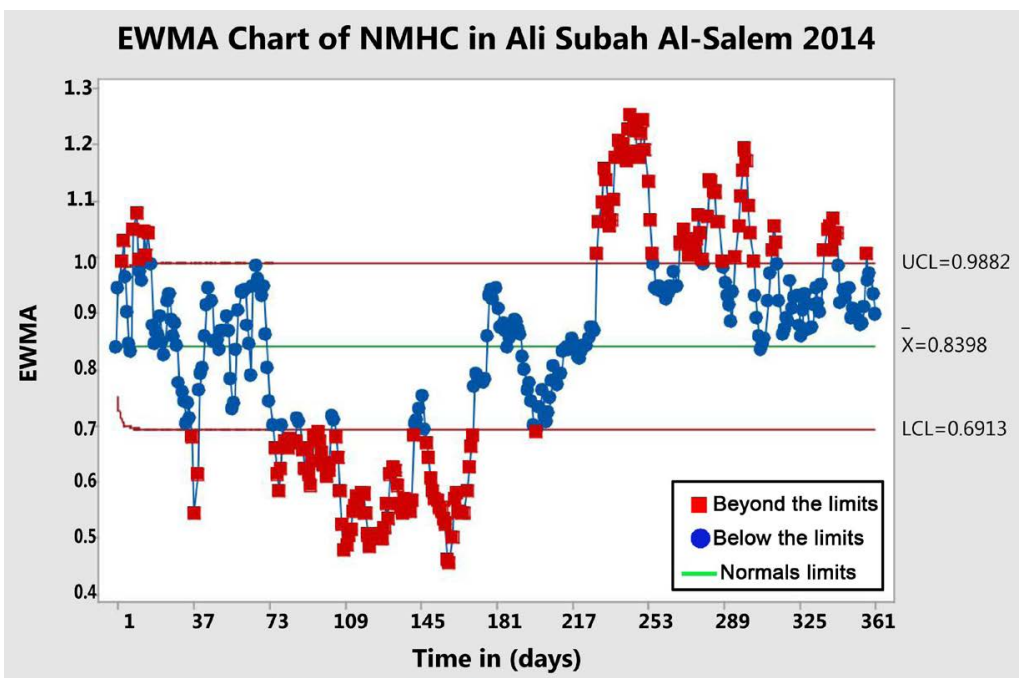

Figure 65. EWMA chart of NMHC in Ali Subah Al-Salem 2014. 


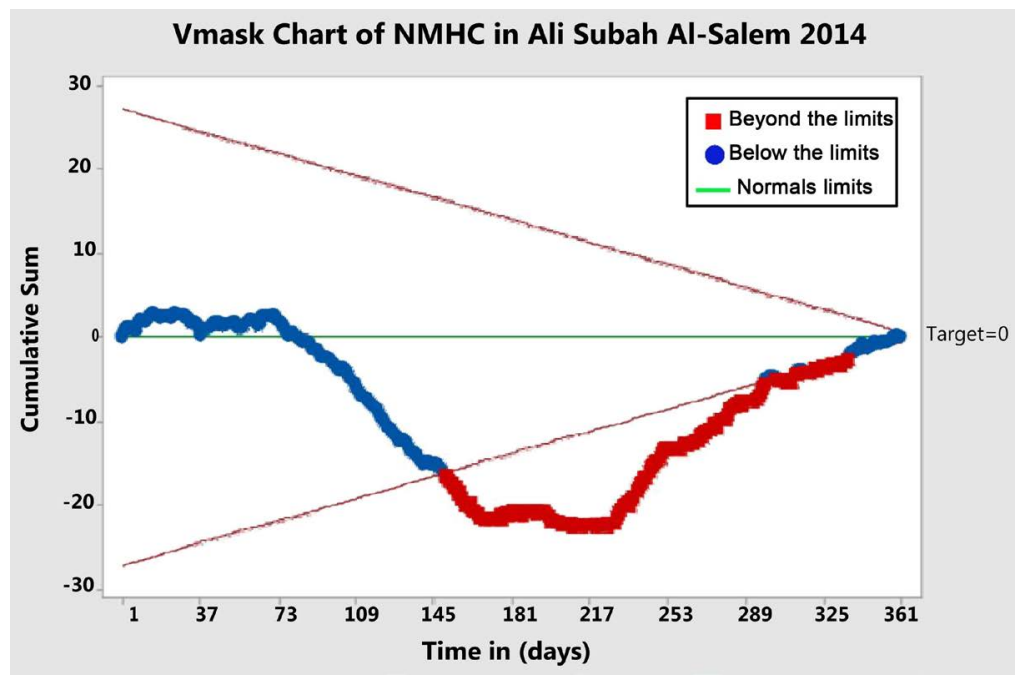

Figure 66. CUSUM chart of NMHC in Ali Subah Al-Salem 2014.

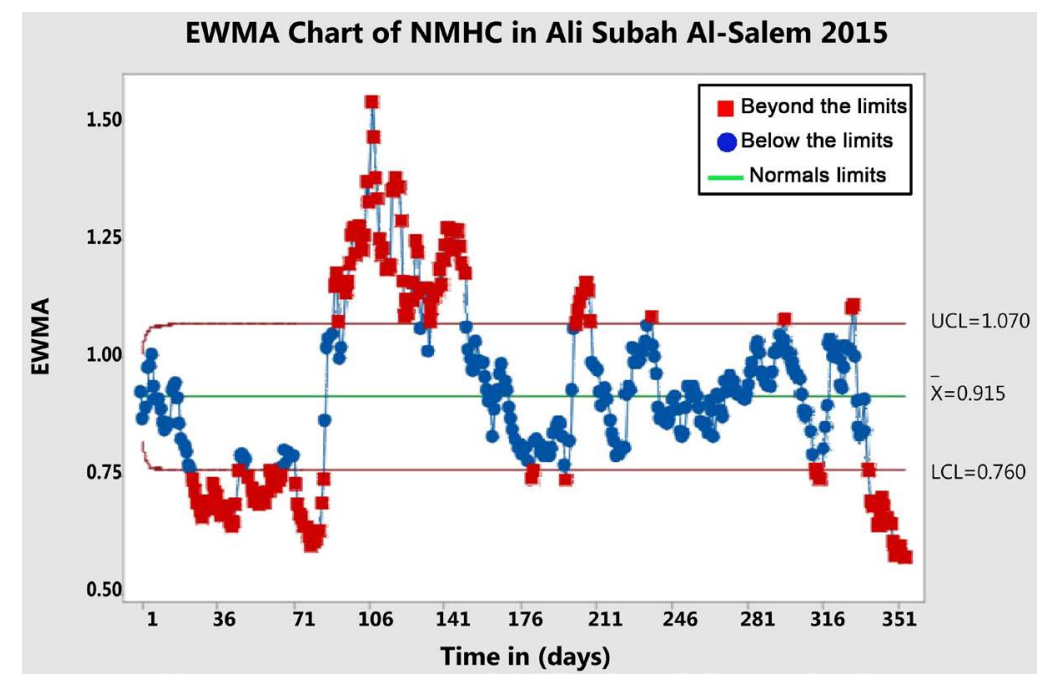

Figure 67. EWMA chart of NMHC in Ali Subah Al-Salem 2015.

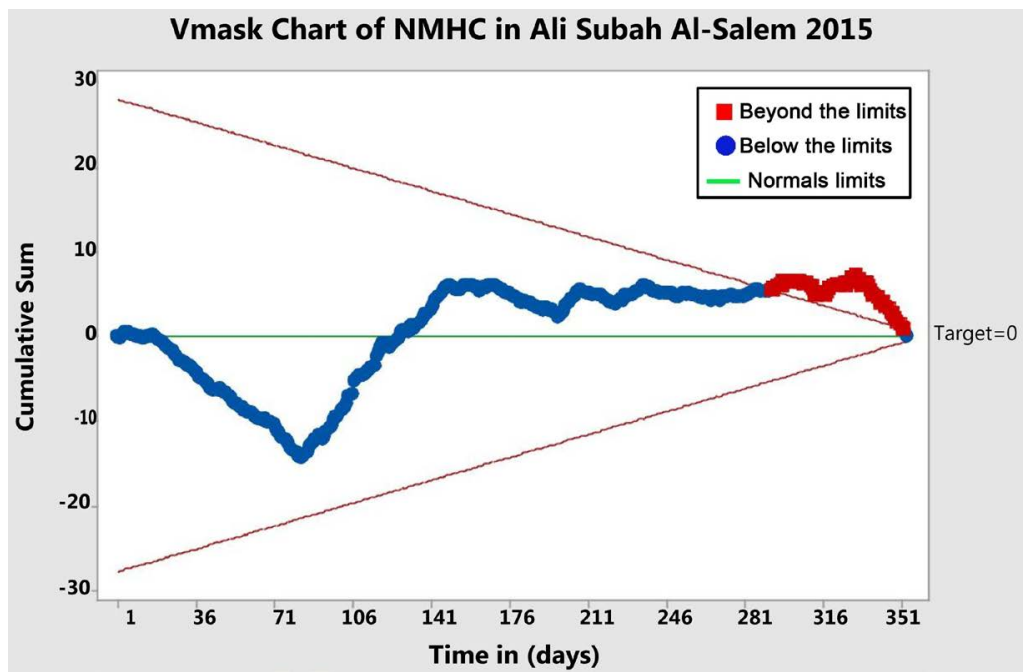

Figure 68. CUSUM chart of NMHC in Ali Subah Al-Salem 2015. 
EWMA Chart of NMHC in Ali Subah Al-Salem 2016

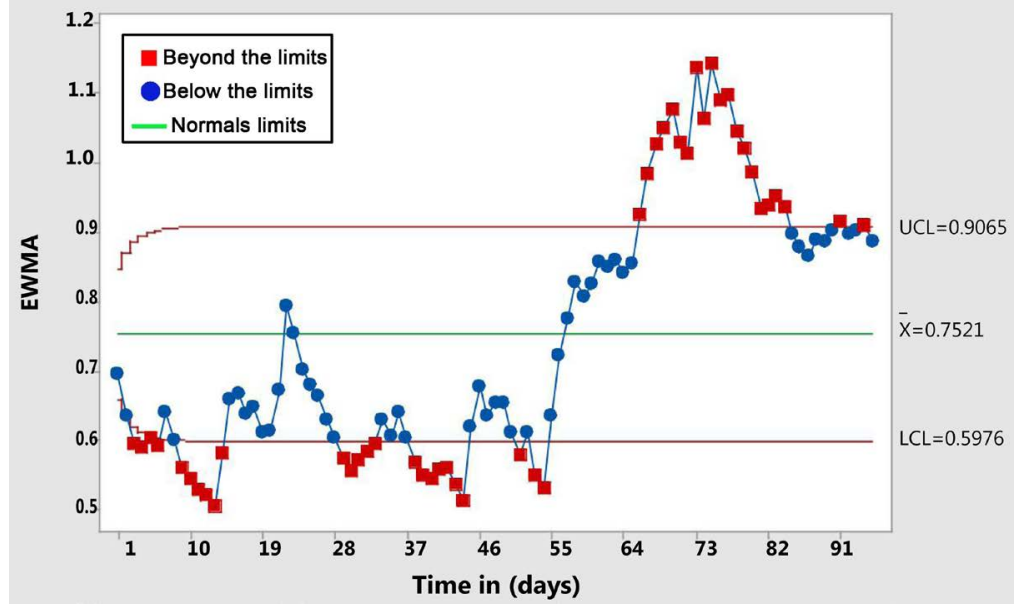

Figure 69. EWMA chart of NMHC in Ali Subah Al-Salem 2016.

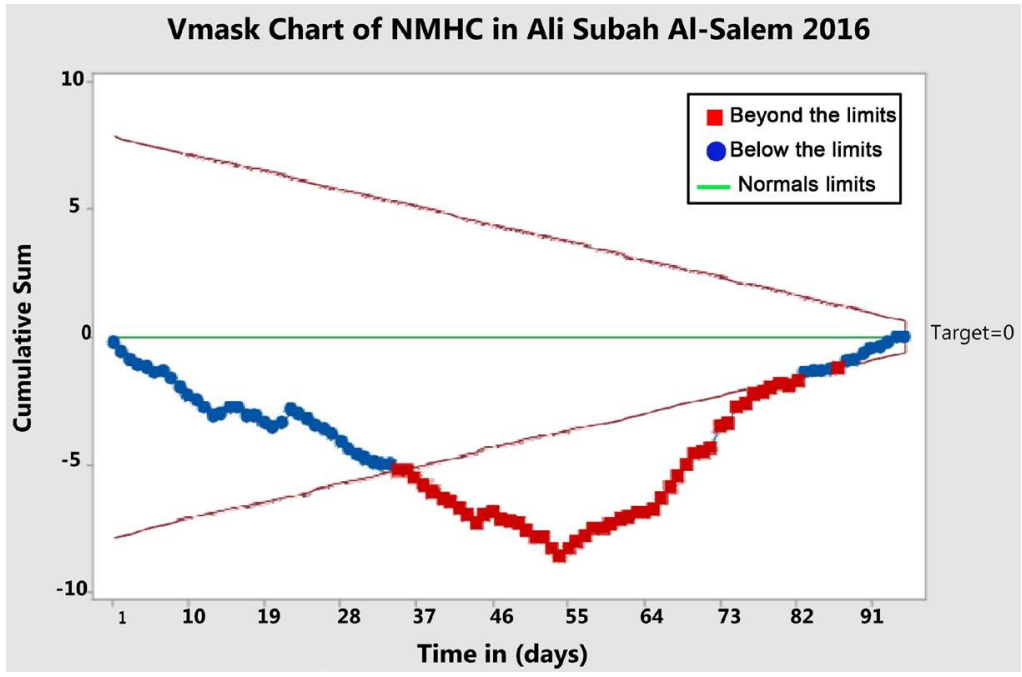

Figure 70. CUSUM chart of NMHC in Ali Subah Al-Salem 2016.

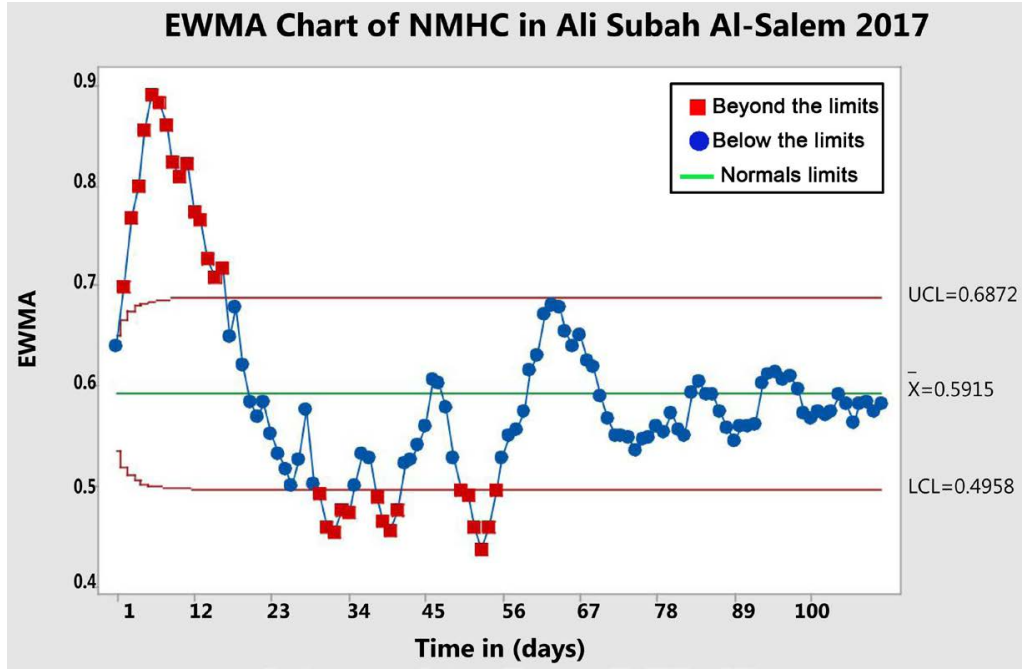

Figure 71. EWMA chart of NMHC in Ali Subah Al-Salem 2017. 


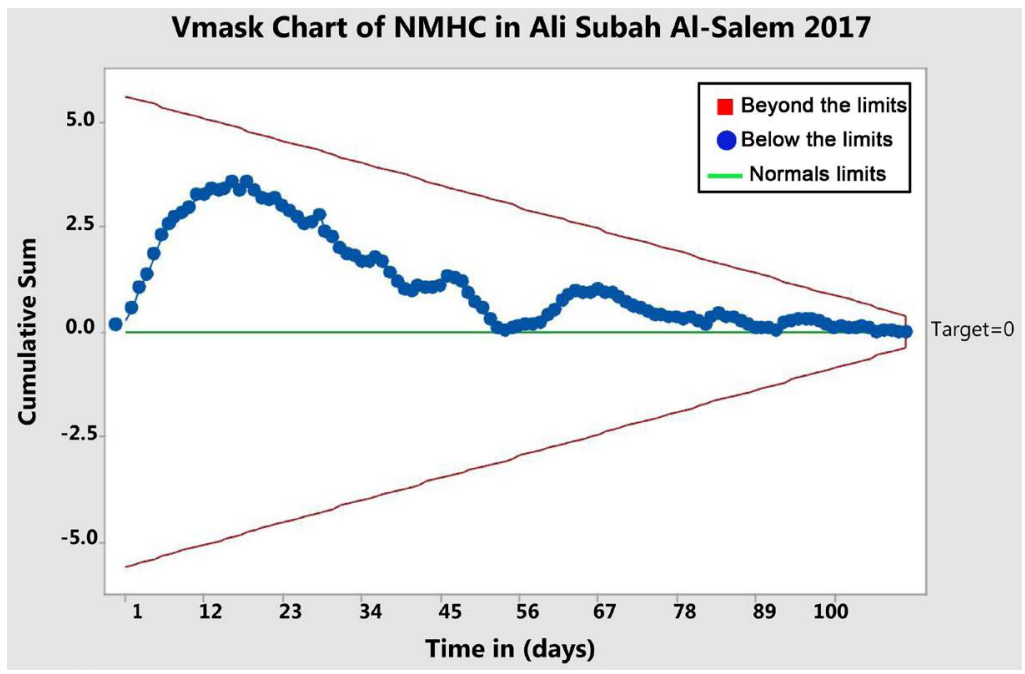

Figure 72. CUSUM chart of NMHC in Ali Subah Al-Salem 2017.

EWMA Chart of NMHC in Ali Subah Al-Salem 2013-2017

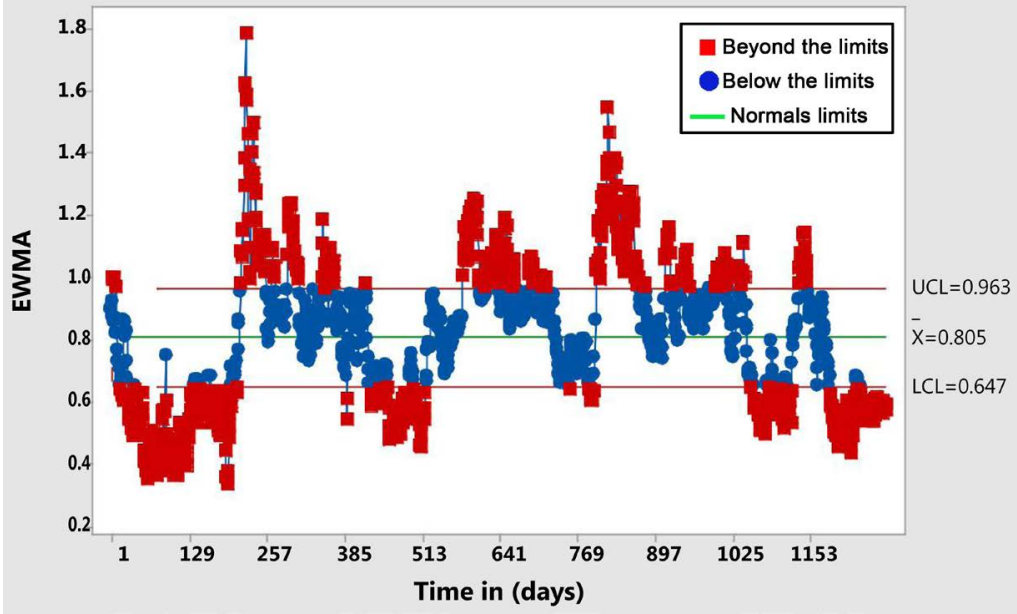

Figure 73. EWMA chart of NMHC in Ali Subah Al-Salem 2013-2017.

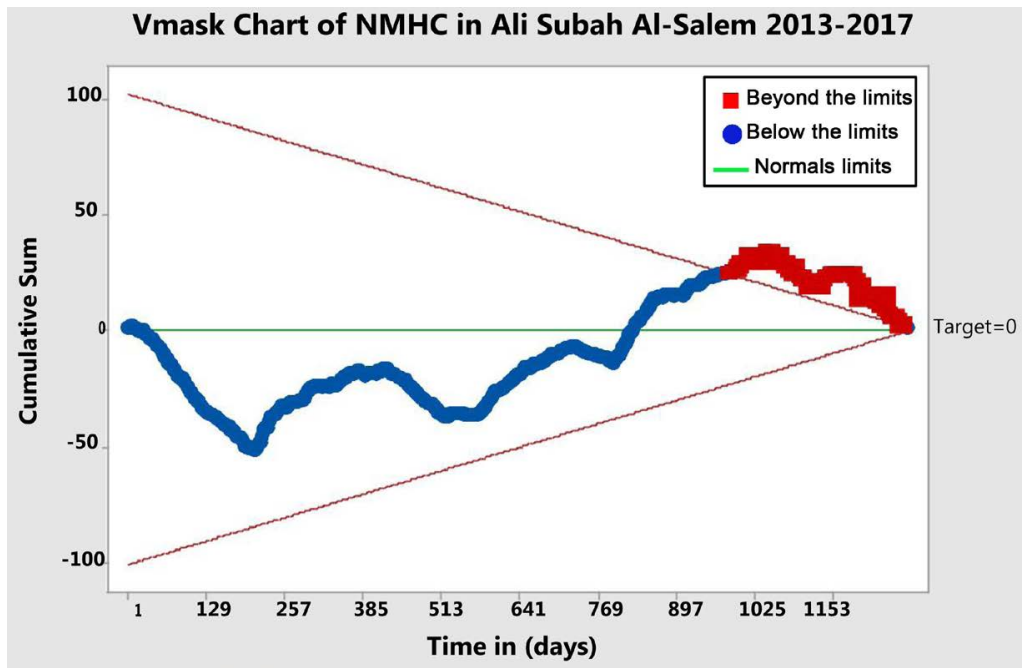

Figure 74. CUSUM chart of NMHC in Ali Subah Al-Salem 2013-2017. 
2013 and 17 Apr. 2015. CUSUM showed only one period of out-of-control distribution from points 24 Sep. 2015 to 26 Jul. 2017.

\section{Trend analysis Results}

The Minitab results for each pollutants trends are presented in this chapter. The results will be investigated for each pollutant exceeding the average for each area in the study by calculating the percentage difference either percentage increase or percentage decrease. In addition, the major change in concentration levels are described in the tables.

The CUSUM results can be summarized in the following Tables 1-6 for each pollutants.

\section{Conclusions}

The EWMA method provides first alarm for uncontrolled behavior of pollutants level. The results showed a trend average for CO and NMHC in the three study areas which exceed the standard concentration level in Kuwait and WHO (CO = 1.208 , $\mathrm{NMHC}=0.580)$. However, remaining pollutants $\left(\mathrm{NO}_{2}, \mathrm{SO}_{2}, \mathrm{PM}_{10}, \mathrm{H}_{2} \mathrm{~S}\right)$ displayed within average concentration according to KEPA standard levels.

Table 1. CUSUM for CO, Ali Subah Al-Salem, Al-Mutla and Al-Mansouriaya.

\begin{tabular}{|c|c|c|c|c|}
\hline $\mathrm{CO}$ & & & Seasons & \\
\hline Location & Years & $\begin{array}{c}\text { Winter } \\
\text { (6Dec.-15 Feb.) }\end{array}$ & $\begin{array}{c}\text { Spring } \\
\text { (16 Feb.-20 May) }\end{array}$ & $\begin{array}{c}\text { Summer } \\
\text { (21 May-5 Dec.) }\end{array}$ \\
\hline \multirow[t]{6}{*}{ Ali Subah Al-Salem } & 2013 & $+81.43 \%$ & $+64.01 \%$ & $-88.79 \%$ \\
\hline & 2014 & - & - & - \\
\hline & 2015 & $+95.84 \%$ & $+27.83 \%$ & $-93.44 \%$ \\
\hline & 2016 & $+56 \%$ & - & $-78.77 \%$ \\
\hline & 2017 & $+96.63 \%$ & +67.25 & -96.9 \\
\hline & 2013-2017 & $+97.54 \%$ & - & -99.26 \\
\hline \multirow[t]{6}{*}{ Al-Mutla } & 2013 & +13.63 & - & - \\
\hline & 2014 & +46.55 & $+89.36 \%$ & -89.75 \\
\hline & 2015 & -94.69 & - & +98.88 \\
\hline & 2016 & -57.44 & +73.25 & -37.85 \\
\hline & 2017 & - & - & - \\
\hline & 2013-2017 & +89.1 & -70.27 & -47.12 \\
\hline \multirow[t]{6}{*}{ Al-Mansouriya } & 2013 & -60.61 & -35 & +94.74 \\
\hline & 2014 & +98.72 & -76.46 & - \\
\hline & 2015 & - & - & - \\
\hline & 2016 & - & - & - \\
\hline & 2017 & +84.75 & +67.30 & -97.29 \\
\hline & 2013-2017 & +93.1 & -94.97 & -95 \\
\hline
\end{tabular}


Table 2. CUSUM for $\mathrm{NO}_{2}$, Ali Subah Al-Salem, Al-Mutla and Al-Mansouriaya.

\begin{tabular}{|c|c|c|c|c|}
\hline $\mathrm{NO}_{2}$ & & & Seasons & \\
\hline Location & Years & $\begin{array}{c}\text { Winter } \\
\text { (6Dec.-15 Feb.) }\end{array}$ & $\begin{array}{c}\text { Spring } \\
\text { (16 Feb.-20 May) }\end{array}$ & $\begin{array}{c}\text { Summer } \\
\text { (21 May-5Dec.) }\end{array}$ \\
\hline \multirow[t]{6}{*}{ Ali Subah Al-Salem } & 2013 & $+91.52 \%$ & - & $+85.3 \%$ \\
\hline & 2014 & - & - & -95.67 \\
\hline & 2015 & +54.45 & - & - \\
\hline & 2016 & +99.86 & -35.4 & $-2 \%$ \\
\hline & 2017 & - & - & - \\
\hline & 2013-2017 & -26.46 & -95.73 & 99.5 \\
\hline \multirow[t]{6}{*}{ Al-Mutla } & 2013 & - & 31.6 & - \\
\hline & 2014 & 95.45 & 96.86 & -96.46 \\
\hline & 2015 & 97.5 & 37.8 & -99.2 \\
\hline & 2016 & 94.5 & 61.33 & -97.28 \\
\hline & 2017 & - & - & - \\
\hline & 2013-2017 & - & - & - \\
\hline \multirow[t]{5}{*}{ Al-Mansouriya } & 2013 & 49.45 & 72.19 & -85.6 \\
\hline & 2014 & - & - & - \\
\hline & 2015 & 68.37 & 52.81 & -77.04 \\
\hline & 2016 & - & 15.5 & -82.61 \\
\hline & $2013-2016$ & 97.43 & 68.96 & -40.98 \\
\hline
\end{tabular}

Table 3. CUSUM for $\mathrm{SO}_{2}$, Ali Subah Al-Salem, Al-Mutla and Al-Mansouriaya.

\begin{tabular}{|c|c|c|c|c|}
\hline $\mathrm{SO}_{2}$ & & & Seasons & \\
\hline Location & Years & $\begin{array}{c}\text { Winter } \\
\text { (6Dec.-15 Feb.) }\end{array}$ & $\begin{array}{c}\text { Spring } \\
\text { (16 Feb.-20 May) }\end{array}$ & $\begin{array}{c}\text { Summer } \\
\text { (21 May-5 Dec.) }\end{array}$ \\
\hline \multirow[t]{6}{*}{ Ali Subah Al Salem } & 2013 & - & - & - \\
\hline & 2014 & 90.14 & -98.43 & -76.47 \\
\hline & 2015 & 57.21 & -71.88 & -97.54 \\
\hline & 2016 & 99.5 & -99.02 & -18.9 \\
\hline & 2017 & 91.34 & 30.5 & -96.81 \\
\hline & 2013-2017 & 59.5 & - & -88.63 \\
\hline \multirow[t]{6}{*}{ Al-Mutla } & 2013 & - & - & - \\
\hline & 2014 & - & - & - \\
\hline & 2015 & - & - & -20 \\
\hline & 2016 & 76.41 & 27.75 & -78.89 \\
\hline & 2017 & 97.94 & 55.61 & -99.87 \\
\hline & 2013-2017 & 89.6 & 72.57 & -36.96 \\
\hline \multirow[t]{5}{*}{ Al-Mansouriya } & 2013 & 96.52 & -76.6 & -94.94 \\
\hline & 2014 & 67.15 & -5.99 & -68.89 \\
\hline & 2015 & - & 90.87 & -94.86 \\
\hline & 2016 & 99.36 & -56.12 & -97.31 \\
\hline & $2013-2016$ & 97.22 & -34.54 & -69.2 \\
\hline
\end{tabular}


Table 4. CUSUM for PM10, Ali Subah Al-Salem, Al-Mutla and Al-Mansouriaya.

\begin{tabular}{|c|c|c|c|c|}
\hline PM10 & & & Seasons & \\
\hline Location & Years & $\begin{array}{c}\text { Winter } \\
\text { (6Dec.-15 Feb.) }\end{array}$ & $\begin{array}{c}\text { Spring } \\
\text { (16 Feb.-20 May) }\end{array}$ & $\begin{array}{c}\text { Summer } \\
\text { (21 May-5 Dec.) }\end{array}$ \\
\hline \multirow[t]{6}{*}{ Ali Subah Al-Salem } & 2013 & -96.03 & - & -71.36 \\
\hline & 2014 & -85.71 & - & 62.03 \\
\hline & 2015 & -93.79 & - & 99.47 \\
\hline & 2016 & - & - & 68.35 \\
\hline & 2017 & - & - & - \\
\hline & 2013-2017 & -31.48 & -17.4 & 87.06 \\
\hline \multirow[t]{6}{*}{ Al-Mutla } & 2013 & - & - & -48.79 \\
\hline & 2014 & -73.16 & - & -67.7 \\
\hline & 2015 & - & - & -87.13 \\
\hline & 2016 & - & - & - \\
\hline & 2017 & - & - & -92.86 \\
\hline & 2013-2017 & -15.17 & -31.91 & -88.73 \\
\hline \multirow[t]{6}{*}{ Al-Mansouriya } & 2013 & -90.76 & - & -85.4 \\
\hline & 2014 & -99.07 & - & - \\
\hline & 2015 & -30.21 & 78.82 & -55.09 \\
\hline & 2016 & - & - & - \\
\hline & 2017 & -84.57 & - & -71.14 \\
\hline & 2013-2017 & -94.01 & - & -65.37 \\
\hline
\end{tabular}

Table 5. CUSUM for $\mathrm{H}_{2} \mathrm{~S}$, Ali Subah Al-Salem, Al-Mutla and Al-Mansouriaya.

\begin{tabular}{|c|c|c|c|c|}
\hline $\mathrm{H}_{2} \mathrm{~S}$ & & & Seasons & \\
\hline Location & Years & $\begin{array}{c}\text { Winter } \\
\text { (6 Dec.-15 Feb.) }\end{array}$ & $\begin{array}{c}\text { Spring } \\
\text { (16 Feb.-20 May) }\end{array}$ & $\begin{array}{c}\text { Summer } \\
\text { (21 May-5 Dec.) }\end{array}$ \\
\hline \multirow[t]{6}{*}{ Ali Subah Al-Salem } & 2013 & - & - & - \\
\hline & 2014 & 93.04 & -87.03 & - \\
\hline & 2015 & -93.07 & - & -74.25 \\
\hline & 2016 & 94.5 & -92.04 & - \\
\hline & 2017 & - & 99.17 & -98.03 \\
\hline & $2013-2017$ & 64.63 & 58.42 & -76.96 \\
\hline \multirow[t]{6}{*}{ Al-Mutla } & 2013 & - & - & - \\
\hline & 2014 & - & 91.45 & -97.997 \\
\hline & 2015 & - & - & - \\
\hline & 2016 & 85.39 & 24.05 & -87.65 \\
\hline & 2017 & 95.47 & -13.7 & -93.96 \\
\hline & $2013-2017$ & 68.71 & 9.39 & 66.5 \\
\hline \multirow[t]{5}{*}{ Al-Mansouriya } & 2013 & -8.35 & 71.72 & -68.09 \\
\hline & 2014 & -60.2 & -19.23 & - \\
\hline & 2015 & - & - & 75.68 \\
\hline & 2016 & 98.3 & -62.17 & -95.83 \\
\hline & $2013-2016$ & 98.73 & -60.27 & -25.41 \\
\hline
\end{tabular}


Table 6. CUSUM for NMHC, Ali Subah Al-Salem, Al-Mutla and Al-Mansouriaya.

\begin{tabular}{|c|c|c|c|c|}
\hline NMHC & & & Seasons & \\
\hline Location & Years & $\begin{array}{c}\text { Winter } \\
\text { (6 Dec.-15 Feb.) }\end{array}$ & $\begin{array}{c}\text { Spring } \\
\text { (16 Feb.-20 May) }\end{array}$ & $\begin{array}{c}\text { Summer } \\
\text { (21 May-5 Dec.) }\end{array}$ \\
\hline \multirow[t]{6}{*}{ Ali Subah Al-Salem } & 2013 & - & - & - \\
\hline & 2014 & 70.93 & -59.65 & - \\
\hline & 2015 & - & - & 93.75 \\
\hline & 2016 & - & - & - \\
\hline & 2017 & - & 82.98 & -84.87 \\
\hline & $2013-2017$ & -40.3 & 86.05 & -86.67 \\
\hline \multirow[t]{5}{*}{ Al-Mutla } & 2013 & - & - & - \\
\hline & 2014 & 91.73 & -86.09 & - \\
\hline & 2015 & - & - & - \\
\hline & 2016 & 97.5 & 62.7 & -96.94 \\
\hline & $2013-2016$ & - & 97.5 & -97.5 \\
\hline \multirow[t]{5}{*}{ Al-Mansouriya } & 2013 & - & - & -21.43 \\
\hline & 2014 & - & - & - \\
\hline & 2015 & -41.12 & & 75.86 \\
\hline & 2016 & 89.24 & 54.5 & -98.00 \\
\hline & $2013-2016$ & 32.32 & 35.71 & -16.52 \\
\hline
\end{tabular}

The CUSUM method is essential to identify the shifts from the mean of any process. CUSUM method is applied to detect the changes in air pollutant concentrations observed during 2013-2017 at three selective areas in Kuwait. The effect of oil refinery and industrial plants is investigated in Ali Subah Al-Salem area from which the pollutants $\mathrm{CO}, \mathrm{NO}_{2}, \mathrm{H}_{2} \mathrm{~S}$, and NMHC are high while other pollutant acted within average concentration levels. In Al-Mutla, in spite of no external exposure, it faced increase percentage in $\mathrm{CO}, \mathrm{NMHC}$, and $\mathrm{H}_{2} \mathrm{~S}$ concentration and decrease in $\mathrm{NO}_{2}$ and $\mathrm{PM}_{10}$ concentration levels is observed using CUSUM method. Also, $\mathrm{SO}_{2}$ acted normally and no series trends were observed in Al-Mutla. As expected, increase in CO concentration in Al-Mansouriya from the heavy traffic surrounded the area. However, increasing in $\mathrm{NO}_{2}, \mathrm{NMHC}$, and $\mathrm{H}_{2} \mathrm{~S}$ concentration levels is observed using CUSUM method. $\mathrm{SO}_{2}$ and $\mathrm{PM}_{10}$ concentration does not have serious effect in Al-Mansouriya area. The study is useful for policy makers to examine the effect of policy instruments and make further action plans. Since CUSUM and EWMA showed the ability to detect changes in any data distribution, it is recommended to use CUSUM method for decision maker to examine the effect of any parameters and make further control plans. Although the above methods may provide early alarms and detection of changes in underlying demand as proved in this study, it would not analyze the cause of the change. Further studies may add the cause as a new parameter 
with the time to compare the trends between pollutants.

\section{Conflicts of Interest}

The authors declare no conflicts of interest regarding the publication of this paper.

\section{References}

[1] Regenstein, L. (1982) America the Poisoned. Acropolis Books Ltd., Washington DC.

[2] Al-Bassam, E. and Khan, A. (2004) Air pollution and Road Traffic in Kuwait. WIT Transactions on the Built Environment, 75, 10.

[3] Al-Rashed, A. (2015) Mineralogical, Micromorphologlcal and Elemental Composition of Particles at Atmospheric Kuwait Dust. Egyptian Journal of Geology, 59, 113-131.

[4] Al-Rukaibi, F., Al-Mutairi, N. and Al-Rashed, A. (2018) Concentration of Air Pollutants in an Urban Parking Garage in Kuwait. World Review of Science, Technology and Sustainable Development, 14.

[5] Al-Kandari, M.H.M. (1994) Evaluation of the Effect of Air Pollution on Human Health in Kuwait. Doctoral Dissertation, London School of Hygiene \& Tropical Medicine, London.

[6] Schoon, N. (1990) Pollution Is Blamed for the Warmest Year on Record. Guardian, II/01/90

[7] Santos, S. (1987) Risk Assessment. Environmental Science and Technology, 21, 239-240. https://doi.org/10.1021/es00157a602

[8] Wetherington, L. (2010) Evaluation of CUSUM and EWMA Control Charts to Detect Changes in Underlying Demand Trends of Naval Aviation Spares. Thesis, School of Monterey, California.

[9] Page, E.S. (1954) Continuous Inspection Schemes. Biometrika, 41, 100-115. https://doi.org/10.1093/biomet/41.1-2.100

[10] Lucas, J.M. (1982) Combined Shewhart-CUSUM Quality Control Schemes. Journal of Quality Control, 14, 51-59. https://doi.org/10.1080/00224065.1982.11978790

[11] Carslaw, D.C., Ropkins, K. and Bell, M.C. (2006) Change-Point Detection of Gaseous and Particulate Traffic-Related Pollutants at a Roadside Location. Environmental Science Technology, 40, 6912-6918. https://doi.org/10.1021/es060543u

[12] Biswas, R.K., Masud, M.S. and Kabir, E. (2016) Shewhart Control Chart for Individual Measurement: An Application in a Weaving Mil. Australasian Journal of Business, Social Science and Information Technology, 2, 89-100.

[13] Barratt, B., Atkinson, R., Anderson, H.R., Beevers, S., Kelly, F., Mudway, I. and Wilkinson, P. (2007) Investigation into the Use of the CUSUM Technique in Identifying Changes in Mean Air Pollution Levels Following Introduction of a Traffic Management Scheme. Atmospheric Environment, 41, 1784-1791.

https://doi.org/10.1016/j.atmosenv.2006.09.052 